\title{
THERMALLY INDUCED DEFORMATIONS IN NUCLEAR FUEL ELEMENTS
}

\author{
by \\ Haihui (Stella) Yang \\ B. Eng., Xiangtan University, China, 1994
}

\begin{abstract}
A Thesis
presented to Ryerson University

in partial fulfillment of the requirements for the degree of

Master of Applied Science

in the Program of Mechanical Engineering
\end{abstract}

Toronto, Ontario, Canada, 2004 


\section{UMI Number: EC52992}

\section{All rights reserved \\ INFORMATION TO USERS}

The quality of this reproduction is dependent upon the quality of the copy submitted. Broken or indistinct print, colored or poor quality illustrations and photographs, print bleed-through, substandard margins, and improper alignment can adversely affect reproduction.

In the unlikely event that the author did not send a complete manuscript and there are missing pages, these will be noted. Also, if unauthorized copyright material had to be removed, a note will indicate the deletion.

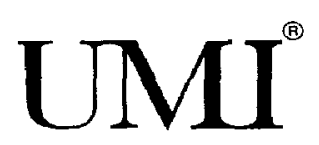

UMI Microform EC52992

Copyright 2008 by ProQuest LLC

All rights reserved. This microform edition is protected against unauthorized copying under Title 17, United States Code.

ProQuest LLC

789 East Eisenhower Parkway

P.O. Box 1346

Ann Arbor, MI 48106-1346 


\section{Author's Declaration Page}

I hereby declare that I am the sole author of this thesis.

I authorize Ryerson University to lend this thesis to other institutions or individuals for the purpose of scholarly research.

Signature

I further authorize Ryerson University to reproduce this thesis by photocopying or by other means, in total or in part, at the request of other institutions or individuals for the purpose of scholarly research.

Signature 


\section{*. Borrower's Page}

Ryerson University requires the signatures of all persons using or photocopying this thesis. Please sign below, and give address and date.

1. Name:

Date:

Address:

2. Name:

Date:

Address: 


\begin{abstract}
THERMALLY INDUCED DEFORMATIONS IN NUCLEAR FUEL ELEMENTS

By: Haihui (Stella) Yang

Master of Applied Science

in the Program of Mechanical Engineering, Ryerson University, 2004

Nonlinear three-dimensional multibody surface-surface contacts, thermally induced deformations, and the curvature transfer factor in CANDU fuel elements are investigated using the finite
\end{abstract} element method in this thesis.

ANSYS is selected to obtain numerical solutions for CANDU fuel elements under several operating conditions. In the ANSYS models, the 20-node structural elements (SOLID186) are employed to mesh individual solids; the surface-to-surface contact pairs (TARGE170 and CONTA174) are used to handle contacts between solids. Sensitivity studies on the curvature transfer factor are conducted for several key operational parameters.

If there is full radial contact between the pellets and the sheath, a CANDU fuel element may be considered as a composite beam because of the large length-to-diameter ratio. The Timoshenko beam theory is used in conjunction with a three-node beam element to explore the thermal deformation behaviors of a fuel element. A program written in MATLAB is much more efficient compared with the ANSYS solutions. 


\section{ACKNOWLEDGEMENT}

The author would especially like to thank Professor S. D. Yu for his advice, patience and assistance throughout the thesis work. Technical advice from staff engineers at AECL during the preparation of this thesis is also acknowledged.

In addition, heartfelt thanks go to my family members for their understanding and support.

Finally, thanks are due to the Natural Sciences and Engineering Research Council of Canada (NSERC) and AECL for their financial support. 
TABLE OF CONTENTS

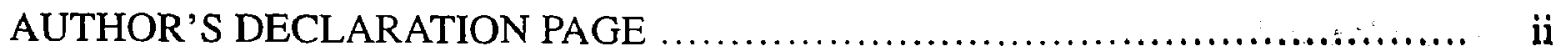

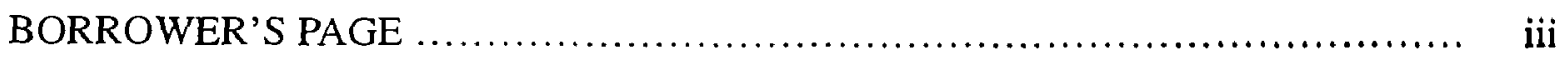

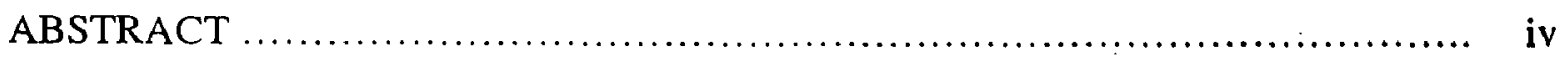

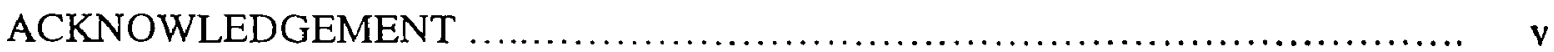

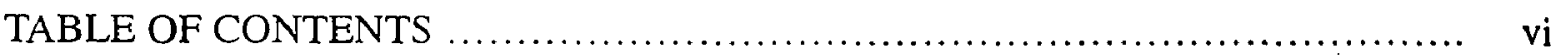

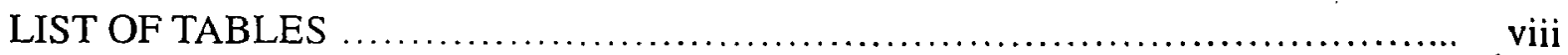

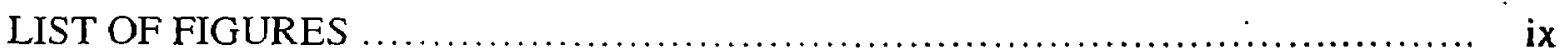



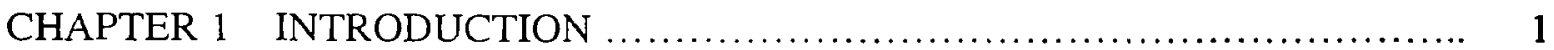

CHAPTER 2 FINITE ELEMENT MODELING …............................ 7

2.1 Simplification of a Fuel Element .................................. 7

2.2 Cylindrical Coordinate System ................................. 7

2.3 Solid Model Development ......................................... 8

2.4 Mesh Generation ................................................ 10

2.5 Solution Techniques ........................................... 11

CHAPTER 3 MULTIBODY CONTACTS IN A CANDU FUEL ELEMENT ......... 13

3.1 Analysis Procedure ......................................... 13

3.2 Validation of FE Models .......................................... 16

3.2.1 Test of Radial Contact ......................................... 16

3.2.2 Test of Axial Contact .......................................... 18

3.2.3 Test of Contact Pair between Two Pellets .......................... 21

CHAPTER 4 THERMAL EXPANSIONS AND BENDING IN FUEL ELEMENT ... 23

4.1 Uniform Temperature ......................................... 23

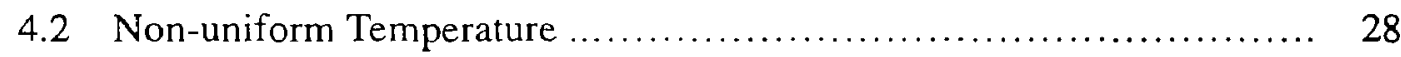

4.3 Bending of a Composite Beam .................................... 31

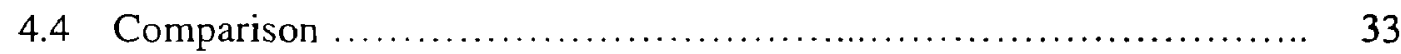

CHAPTER 5 CURVATURE TRANSFER FACTOR CORRELATION .............. 35

5.1 Parameters Affecting CTF ..................................... 35

5.2 Sensitivity Studies .............................................. 36

5.2.1 Initial Pellet-Pellet Axial Gap .................................. 36

5.2.2 Initial Sheath-Pellet Radial Gap ................................. 42

5.2.3 Average Pellet Volume Temperature ............................ 45

5.2.4 Temperature Gradient Across Pellet Diameter ....................... 51

5.3 Curvature Transfer Factor Curve ............................. 57

CHAPTER 6 THERMAL BENDING ANALYSIS OF A FUEL ELEMENT USING THE TIMOSHENKO BEAM THEORY ............................. 61

6.1 Theoretical Development ..................................... 61

6.2 Numerical Results ........................................... 66

CHAPTER 7 CONCLUSIONS AND FUTURE WORK ….................... 69

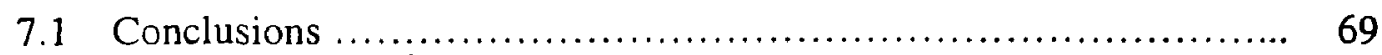

7.2 Future Work ..................................................... 71

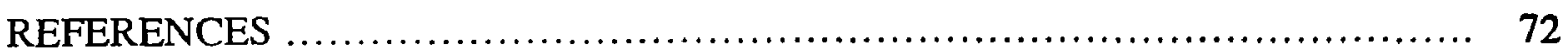




\section{TABLE OF CONTENTS}

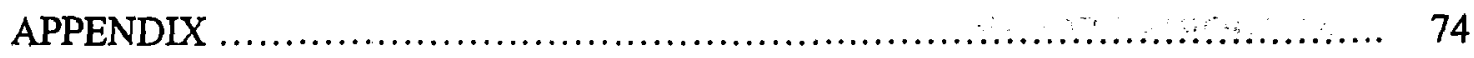

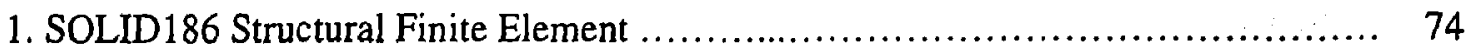

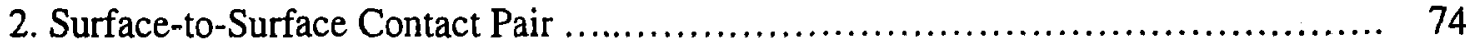




\section{LIST OF TABLES}

Table Number and Caption

Pages

Table 2-1 Geometric Parameters $\ldots \ldots \ldots \ldots \ldots \ldots \ldots \ldots \ldots \ldots \ldots \ldots \ldots \ldots \ldots \ldots \ldots \ldots . . \ldots$

Table 2-2 Material Properties .................................................. 10

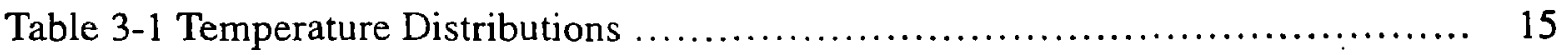

Table 3-2 Comparisons of Axial Contact Pressure and Stress ..................... 21

Table 3-3 Comparison of Pressure Between Two Pellets .......................... 22

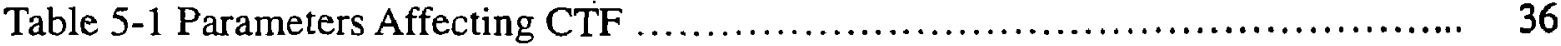




\section{LIST OF FIGURES}

Figure Number and Caption

Figure 1-1 Schematic of a CANDU6 fuel bundle .....................................

Figure 1-2 A typical CANDU6 fuel element ...................................... 2

Figure 1-3 Fuel element bending in a fuel bundle .................................. 2

Figure 2-1 Simplification of a fuel element ....................................... 7

Figure 2-2 Cylindrical coordinate system used in the fuel element ...................... 8

Figure 2-3 A portion of simplified solid components of fuel element …............... 8

Figure 2-4 Portion of meshed pellets and sheath .................................... $\quad 10$

Figure 2-5 Meshed end cap and a portion of meshed pellet and sheath ................. 10

Figure 3-1 Illustration of temperatures in fuel element …........................... 15

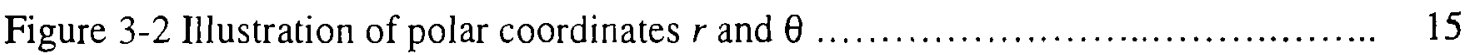

Figure 3-3 Test of radial contact between pellet and sheath .......................... 16

Figure 3-4 Comparison of radial contact pressure .................................. 17

Figure 3-5 Comparison of radial displacement ................................. 18

Figure 3-6 Test of axial contact between second pellet and end cap ................... 19

Figure 3-7 Test of contact pair between two pellets ............................... 21

Figure 4-1 Radial displacement in the sheath inner surface .......................... 24

Figure 4-2 Radial contact pressure between sheath inner surface and pellets ........... 24

Figure 4-3 Axial expansion of pellet centerline node at the midplane .................... 25

Figure 4-4 Axial contact pressure for axial contact pairs ............................. 26

Figure 4-5 Illustration of top and bottom inner surfaces of sheath .................... 26

Figure 4-6 Radial stress distribution in top inner surface of the sheath ................. 27

Figure 4-7 Axial stress distribution in top inner surface of the sheath ................... 27

Figure 4-8 Radial displacement in the sheath inner surface ......................... 28

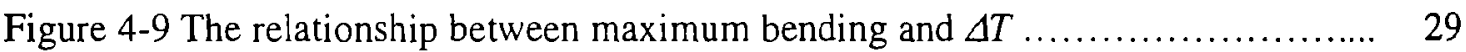

Figure 4-10 Radial stress distribution in top and bottom inside surfaces of sheath ...... 30

Figure 4-11 Axial stress distribution in top and bottom inside surfaces of sheath ........ 30

Figure 4-12 A simply supported composite beam .............................. 31

Figure 4-13 Beam cross-section and its axial strain due to bending ................... 32

Figure 4-14 Comparison of ANSYS and composite beam theory results .............. 34

Figure 5-1 Sheath nodes contacting with central nodes of each pellet ................. 37

Figure 5-2 Sheath nodes contacting with end side nodes of each pellet ................ 37

Figure 5-3 Radial displacement for non-axial gap model ............................ 38

Figure 5-4 Radial displacement for axial gap 0.05mm model ........................ 39

Figure 5-5 Radial displacement for axial gap $0.1 \mathrm{~mm}$ model .......................... 39

Figure 5-6 Radial stress distribution for non-axial gap model ........................ 40

Figure 5-7 Central node radial stress distribution for axial gap 0.05mm model .......... 40

Figure 5-8 End side node radial stress distribution for axial gap 0.05mm model ........ 41

Figure 5-9 Central node radial stress distribution for axial gap $0.1 \mathrm{~mm}$ model .......... 41

Figure 5-10 End side node radial stress distribution for axial gap $0.1 \mathrm{~mm}$ model ........ 42

Figure 5-11 Radial displacement for non-radial gap model ........................... 43 


\section{LIST OF FIGURES}

Figure Number and Caption

Pages

Figure 5-12 Radial displacement for radial gap 0.005mm model ..................... 44

Figure 5-13 Radial stress distribution for non-radial gap model ................... 44

Figure 5-14 Radial stress distribution for radial gap $0.005 \mathrm{~mm}$ model ................ 45

Figure 5-15 Radial Displacement for non-axial gap model $\left(T_{0}=343.15^{\circ} \mathrm{K}\right) \ldots \ldots \ldots \ldots . \quad 46$

Figure 5-16 Radial displacement for non axial gap model $\left(T_{0}=393.15^{\circ} \mathrm{K}\right) \ldots \ldots \ldots \ldots \ldots . \quad 47$

Figure 5-17 Radial stress distribution for non-axial gap model $\left(T_{0}=343.15^{\circ} \mathrm{K}\right) \ldots \ldots \ldots \ldots \quad 47$

Figure 5-18 Radial stress distribution for non-axial gap model $\left(T_{0}=393.15^{\circ} \mathrm{K}\right) \ldots \ldots \ldots . \quad 48$

Figure 5-19 Radial displacement for axial gap $0.1 \mathrm{~mm}$ model $\left(T_{0}=393.15^{\circ} \mathrm{K}\right) \ldots \ldots \ldots \ldots . \quad 48$

Figure 5-20 Radial displacement for axial gap $0.1 \mathrm{~mm}$ model $\left(T_{0}=493.15^{\circ} \mathrm{K}\right) \ldots \ldots \ldots \ldots . \quad 49$

Figure 5-21 Central node radial stress distribution for axial gap $0.1 \mathrm{~mm}$ model

$$
\left(T_{0}=393.15^{\circ} \mathrm{K}\right)
$$

Figure 5-22 End side node radial stress distribution for axial gap 0.1 mm model

$$
\left(T_{0}=393.15^{\circ} \mathrm{K}\right)
$$

Figure 5-23 Central node radial stress distribution for axial gap $0.1 \mathrm{~mm}$ model

$$
\left(T_{0}=493.15^{\circ} \mathrm{K}\right)
$$

Figure 5-24 End side node radial stress distribution for axial gap 0.1 mm model

$$
\left(T_{0}=493.15^{\circ} \mathrm{K}\right)
$$

Figure 5-25 Radial displacement for non-axial gap model $\left(\Delta T=50^{\circ} \mathrm{K}\right) \ldots \ldots \ldots \ldots \ldots . \quad 52$

Figure 5-26 Radial displacement for non-axial gap model $\left(\Delta T=100^{\circ} \mathrm{K}\right) \ldots \ldots \ldots \ldots \ldots . \quad 53$

Figure 5-27 Radial stress distribution for non-axial gap model $\left(\Delta T=50^{\circ} \mathrm{K}\right) \ldots \ldots \ldots \ldots . \quad 53$

Figure 5-28 Radial stress distribution for non-axial gap model $\left(\Delta T=100^{\circ} \mathrm{K}\right) \ldots \ldots \ldots . \quad 54$

Figure 5-29 Radial displacement for axial gap $0.1 \mathrm{~mm}$ model $\left(\Delta T=50^{\circ} \mathrm{K}\right) \ldots \ldots \ldots \ldots . \quad 54$

Figure 5-30 Radial displacement for axial gap $0.1 \mathrm{~mm}$ model $\left(\Delta T=200^{\circ} \mathrm{K}\right) \ldots \ldots \ldots \ldots . \quad 55$

Figure 5-31 Central node radial stress distribution for axial gap $0.1 \mathrm{~mm}$ model

$\left(\Delta T=50^{\circ} \mathrm{K}\right.$ )

Figure 5-32 End side node radial stress distribution for axial gap $0.1 \mathrm{~mm}$ model $\left(\Delta T=50^{\circ} \mathrm{K}\right)$

Figure 5-33 Central node radial stress distribution for axial gap $0.1 \mathrm{~mm}$ model

$$
\left(\Delta T=200^{\circ} \mathrm{K}\right)
$$




\section{LIST OF FIGURES}

Figure Number and Caption

Figure 5-34 End side node radial stress distribution for axial gap $0.1 \mathrm{~mm}$ model

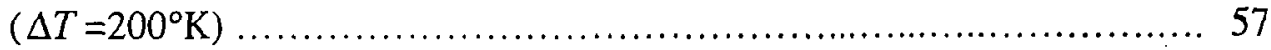

Figure 5-35 Single meshed pellet pure bending ............................... 58

Figure 5-36 CTF curve for FE model involving neither radial nor axial gap ........... 59

Figure 5-37 CTF values varying with $\Delta T$ for FE model involving neither radial nor axial gap ................................................. 59

Figure 5-38 CTF curve for FE model involving axial gap $0.1 \mathrm{~mm} \ldots \ldots \ldots \ldots \ldots \ldots \ldots . \ldots 0$

Figure 6-1 Definition of the Timoshenko beam ................................ 62

Figure 6-2 A fuel element having one pellet missing ............................. 62

Figure 6-3 A three-node beam element ..................................... 63

Figure $6-4$ Illustration of two adjacent substructures ............................ 65

Figure 6-5 Bending moment left when one pellet is missing ..................... 67

Figure 6-6 Comparison of deformation with pellet missing at various locations ........ 68

Appendix Figure 1 A SOLID1 86 structural finite element ........................ 74

Appendix Figure 2 CONTA174 surface-to-surface contact element .................... 75

Appendix Figure 3 Contact detection points located at Gauss integration points ........ 76 


\section{LIST OF SYMBOLS}

$[K]$

$\{u\}$

$\{F\}$

$\Delta T_{1}$

$T_{\text {ref }}$

$T_{0}$

$\Delta T$

$r$

$\theta$

$T_{p}$

$T_{s}$

$r_{s, i}$

$\sigma_{s}$

$\sigma_{p}$

$A_{s}$

$A_{p}$

$E_{s}$

$\varepsilon_{s}$

$\varepsilon_{s}^{t h}$

$E_{p}$

$\varepsilon_{p}$ global stiffness matrix

global displacement vector

global load vector

temperature difference between pellet and sheath

reference temperature

average pellet volume temperature

temperature gradient across pellet diameter

radial coordinate

angular coordinate

pellet temperature

sheath temperature

sheath inner surface radius

sheath axial stress

pellet axial stress

sheath cross-sectional area

pellet cross-sectional area

Young's modulus of sheath

sheath axial strain due to deformation

sheath axial strain due to thermal load

Young's modulus of pellet

pellet axial strain due to deformation 


\section{LIST OF SYMBOLS}

\begin{tabular}{ll}
$\varepsilon_{p}^{\text {th }}$ & pellet axial strain due to thermal load \\
$\alpha_{p}$ & pellet thermal expansion coefficient \\
$L_{p}$ & length of each pellet \\
$p_{z}$ & axial contact pressure \\
$M^{T}$ & thermal bending moment \\
$r_{p}$ & pellet radius \\
$I_{p}$ & second moment of area of pellet cross section \\
$I_{s}$ & second moment of area of sheath cross section \\
$r_{s, 0}$ & sheath outer surface radius \\
$u_{y}$ & three-node beam element lateral displacement \\
$\varphi_{y}$ & three-node beam element bending angle \\
$\xi$ & local coordinate \\
$T_{e}$ & shape function matrix \\
$k_{e}$ & element geometric matrix \\
$D_{e}$ & element displacement vector \\
$l_{e}$ & length of three-node beam element \\
\hline
\end{tabular}




\section{Chapter 1}

\section{INTRODUCTION}

A CANDU ${ }^{\circledR} 6$ fuel bundle, shown in Figure 1-1, consists of 37 fuel elements brazed to two plates at the ends. A typical CANDU6 fuel element, shown in Figure 1-2, consists of a thin hollow Zircaloy sheath, a fuel stack of thirty $\mathrm{UO}_{2}$ pellets stuffed inside the sheath, and two Zircaloy end caps welded to the sheath.

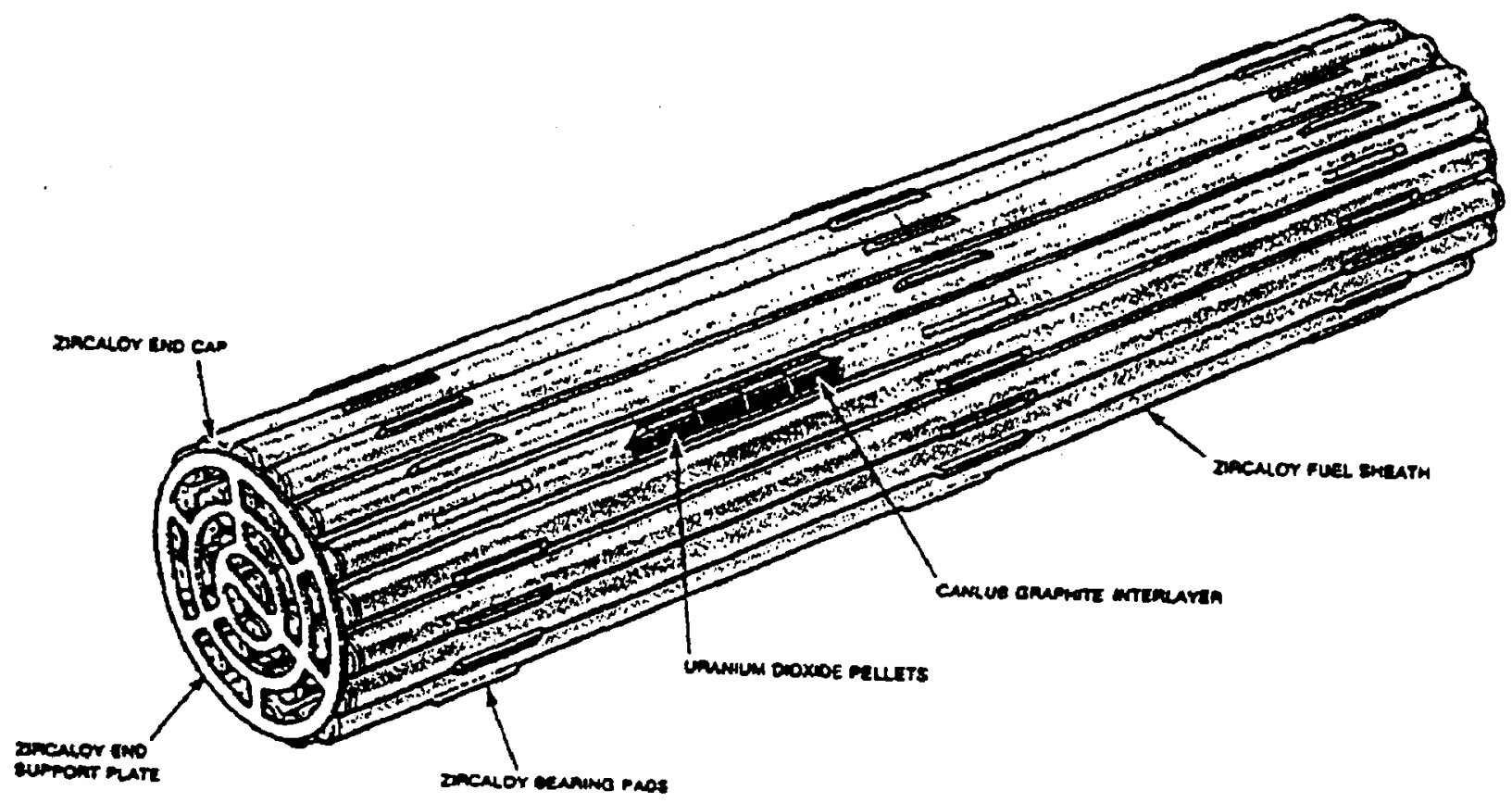

Figure 1-1 Schematic of a CANDU6 fuel bundle

${ }^{-}$CANDU: CANada Deuterium Uranium; registered trademark of Alomic Energy of Canada Limited (AECL). 


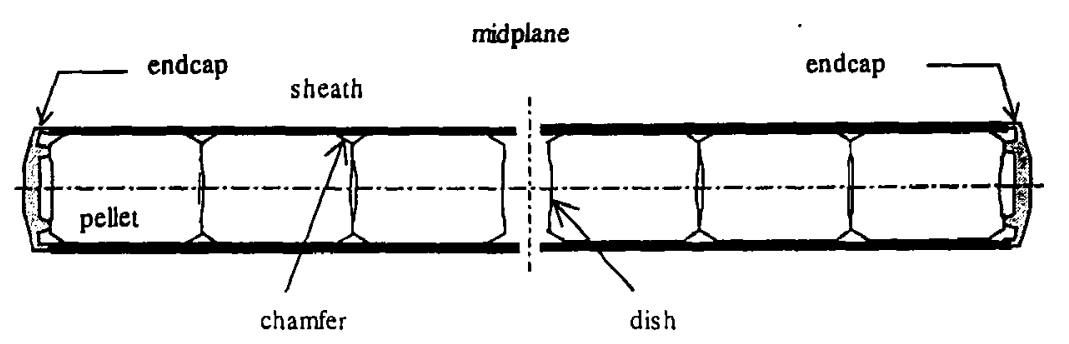

Figure 1-2. A typical CANDU6 fuel element

During operations, the temperature in the pellets may vary circumferentially because of the neutron flux depression and non-uniform heat transfer coefficient across the pellet-sheath gap. As a result, the pellets bend. Since the radial gap between the sheath and pellets is very small, the thermally induced bending in the pellets may be transferred to the sheath. Thus, the whole fuel element may bend. Figure 1-3 shows fuel element bending in a fuel bundle. The bending behavior in a fuel element should be explored to prevent the fuel element from contacting with the pressure tube enclosing the fuel bundle.



Figure 1-3 Fuel element bending in a fuel bundle 
To assess the amount of a fuel element bending caused by the pellet bending, a curvature transfer factor (CTF), defined as the ratio of sheath curvature to the pellet curvature, is used in the Canadian nuclear industry to assess the degree at which a pellet can impose its curvature on the sheath.

Contact problems are nonlinear as the actual contacting surface, and the stresses and displacements on the contacting surface are all unknown prior to the solution of the problem. Consequently, contact problems involve systems of inequalities or nonlinear equations. In general, it is difficult to obtain exact analytical solutions to the nonlinear equations. In the nuclear industry, bending and contact problems in CANDU fuel elements were investigated. Tayal (1989) developed the BOW code using the composite beam theory to calculate the bending of a fuel element due to temperature gradients, hydraulic drag force and gravity. Suk et al. (1995) investigated thermally induced bowing of CANDU fuel elements employing a generalized and explicit analytical method. Xu (2000) used an annulus type of three-dimensional finite element for solving thermomechanical and pellet-sheath contact problems in a nuclear fuel element. In this thesis, multibody contacts are analyzed while modeling radial contacts between the sheath and pellets, as well as axial contacts between the neighboring pellets and between the end pellets and the end caps.

Due to the complex geometry and loading conditions of the fuel element, ANSYS, a general-purpose finite element code, is used for modeling and simulations of thermomechanical 
and contact behaviors of CANDU fuel elements. Three-dimensional finite element models having various initial radial and axial gap sizes are created, for which symmetry conditions are considered as possible to simplify the modeling. The 20-node structural finite element (SOLID186) is employed to mesh all solid components of a CANDU fuel element - pellets, sheath and end cap. The SOLID186 element is a high order three-dimensional structural solid element supporting thermal stress analysis, and it is suitable for meshing irregular geometry. Temperature is the only driving force for fuel element expansion and bending. Non-uniform temperature loads are applied directly on the finite element nodes via input tables.

The potential contact areas are large in a CANDU fuel element. The entire sheath inner surface may be in contact with all pellet outer surfaces; end surfaces of each pellet may be in contact with its neighboring pellets. The surface-to-surface contact pairs consisting of TARGE170 and CONTA174 are built to model the interactions between the pellets and sheath, and between the neighboring pellets. CONTA174 is applicable to three-dimensional coupled thermal-structural contact analysis. Real constant FKN is used to define a normal contact stiffness factor. A smaller value provides easier convergence but with more penetration. The stiffness factor has to be adjusted to avoid convergence difficulties or too much penetration. Real constant FTOLN, defined as a tolerance factor, is applied in the normal direction of the surface. The value for this factor is based on the thickness of the element. Contact compatibility is satisfied if penetration is within a clearance of the value FTOLN multiplied by the depth of the underlying solid element. Initial contact conditions, such as closing the gap, reducing initial penetration, or either closing 
the gap or reducing initial penetration, have to be adjusted at the beginning of the analyses to ensure that the contact pairs are in contact in the initial geometry. For the contact algorithm, the direct penalty method is employed to formulate the contact conditions, and the most attractive reason is that additional iterations can be avoided.

Three simple test cases are conducted for simplified models involving only one or two pellets to validate the ANSYS models. Radial contact pressure, radial displacement, axial contact pressure, axial stress and pressure between two neighboring pellets are calculated based on the uniform temperature in pellets and sheath and a concentrated force applied on end cap. An analytical solution for bending of a composite beam is derived to further validate the finite element model.

When there is full radial contact between the pellets and the sheath, a CANDU fuel element may be considered as a composite beam for which a numerical solution may be obtained using the finite beam elements. In this case, a MATLAB code is developed to deal with the thermally induced deformations of a fuel element. A series of sensitivity studies is performed for situations involving a missing pellet at various locations. The Timoshenko beam theory is employed in combination with a three-node beam element to enhance the accuracy of computed values.

Assessment of bending of nuclear fuel elements can help demonstrate the integrity of fuel and of surrounding components under normal operating conditions. The sensitivity studies conducted on geometric and operational parameters show which parameters are the main factors affecting 
bending. The FE results obtained in this thesis provide some guidance to the Canadian nuclear industry concerning how much bending of pellets due to circumferential temperature gradients gets transferred to the sheath through contacts. 


\section{Chapter 2}

\section{FINITE ELEMENT MODELING}

\subsection{Simplification of a Fuel Element}

In modeling a fuel element, the following assumptions are made:

1) All materials are isotropic;

2) Initial radial and axial gaps are uniform everywhere in a fuel element;

3) Temperature distribution is symmetric with respect to both the fuel element midplane and the vertical plane, and the same for every pellet;

4) Friction between two contacting surfaces is negligible.

From the above assumptions, the deformations of all components in a fuel element are symmetric with respect to the fuel element midplane. Hence only a quarter of a fuel element is modeled as shown in Figure 2-1.

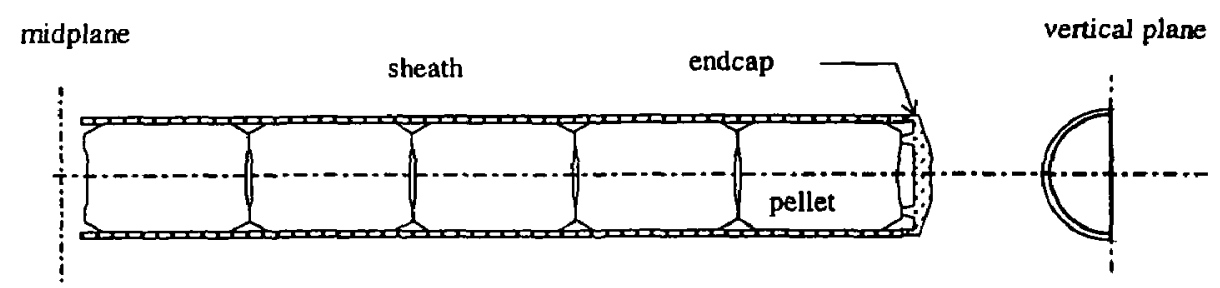

Figure 2-1 Simplification of a fuel element

\subsection{Cylindrical Coordinate System}


Due to the axisymmetry of the fuel element, the cylindrical coordinates shown in Figure 2-2 are used.

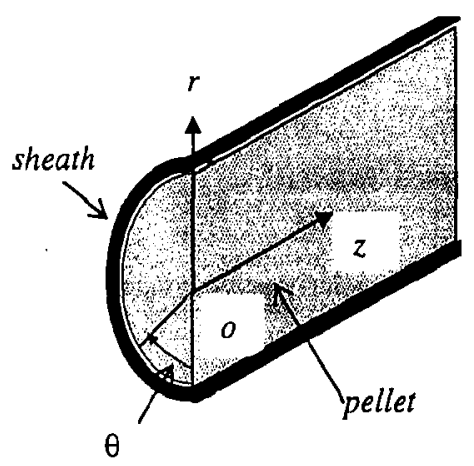

Figure 2-2 Cylindrical coordinate system used in the fuel element

\subsection{Solid Model Development}

A quarter of a fuel element model consists of 15 solid cylindrical pellets, a hollow sheath and an end cap. To simplify the contact problem, fuel element details such as pellet chamfers and dishes are not modeled. The end cap is represented by a solid cylindrical disk where a diameter is the same as the outside diameter of the sheath and an equivalent thickness is used. The end cap is brazed to the sheath. A portion of the simplified model is shown in Figure 2-3.

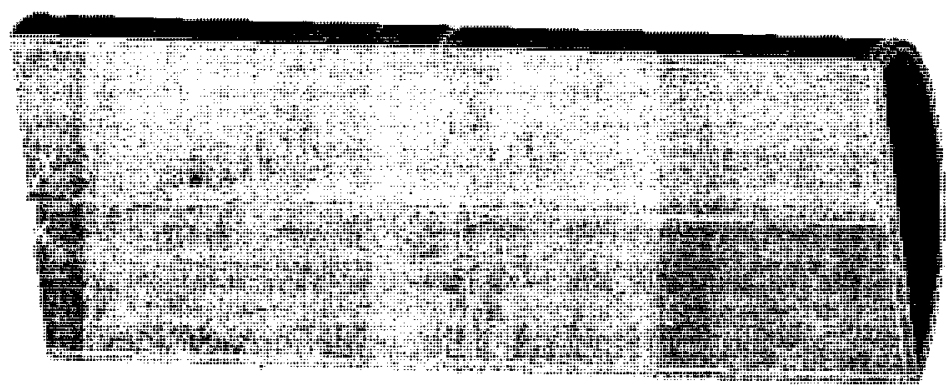

Figure 2-3 A portion of simplified solid components of fuel element 
Five FE models having various combinations of initial radial and initial axial gap sizes are created. The 20-node three-dimensional structural finite element SOLID186, shown in Appendix, is used to mesh all solids in a fuel element - sheath, pellets and end caps. The geometric parameters and material properties in the FE models are given in Tables 2-1 and 2-2, respectively. All of the parameters presented in this thesis are consistent with the reported data at AECL. The diametral clearance may lead to slippage between pellets and sheath when friction is not present, small radial gaps $0.001 \mathrm{~mm}$ and $0.005 \mathrm{~mm}$ are applied so that high pellet-sheath mechanical interaction may still occur.

Table 2-1 Geometric Parameters

\begin{tabular}{|l|c|c|c|c|c|}
\hline \multirow{2}{*}{ Geometric Parameters } & \multicolumn{5}{|c|}{ Models } \\
\cline { 2 - 6 } & $1^{\text {st }}$ & $2^{\text {nd }}$ & $3^{\text {rd }}$ & $4^{\text {th }}$ & $5^{\text {th }}$ \\
\hline End cap thickness (mm) & 2.5 & 2.5 & 2.5 & 2.5 & 2.5 \\
\hline Number of pellets & 15 & 15 & 15 & 15 & 15 \\
\hline Pellet radius (mm) & 6.14 & 6.14 & 6.14 & 6.14 & 6.14 \\
\hline Pellet full length (mm) & 16.4 & 16.4 & 16.4 & 16.4 & 16.4 \\
\hline Pellet-sheath initial radial gap (mm) & 0 & 0 & 0 & 0.001 & 0.005 \\
\hline Pellet-pellet initial axial gap (mm) & 0 & 0.05 & 0.1 & 0 & 0 \\
\hline Sheath inner radius (mm) & 6.14 & 6.14 & 6.14 & 6.141 & 6.145 \\
\hline Sheath thickness (mm) & 0.4 & 0.4 & 0.4 & 0.4 & 0.4 \\
\hline
\end{tabular}


Table 2-2 Material Properties

\begin{tabular}{|l|c|c|}
\hline \multicolumn{1}{|c|}{ Properties } & $\mathrm{UO}_{2}$ & Zircaloy \\
\hline Young's modulus (GPa) & 170 & 84.1 \\
\hline Poisson's ratio & 0.3 & 0.33 \\
\hline Thermal expansion coefficient $\left(K^{-1}\right)$ & $9.25 \times 10^{-6}$ & $1 \times 10^{-5}$ \\
\hline
\end{tabular}

\subsection{Mesh Generation}

In creating FE models, the element size is controlled according to the computer capacity. Figures

2-4 and 2-5 illustrate a portion of the meshed fuel element. A total of 10,585 nodes and 3,007 finite elements are used in the models.

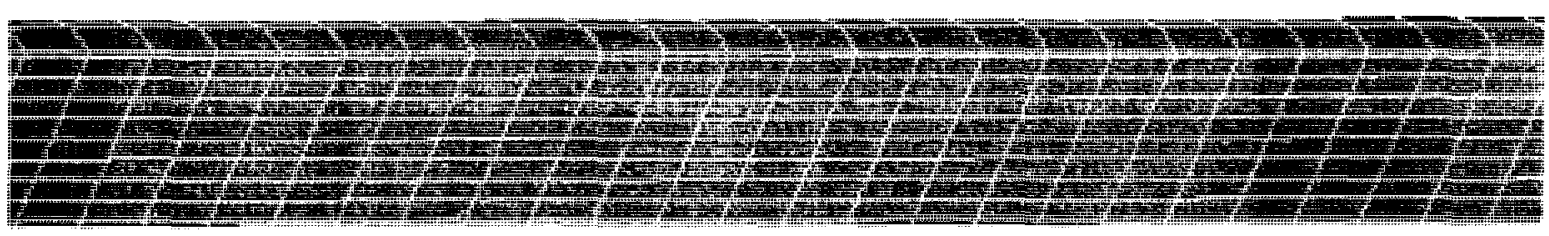

Figure 2-4 Portion of meshed pellets and sheath

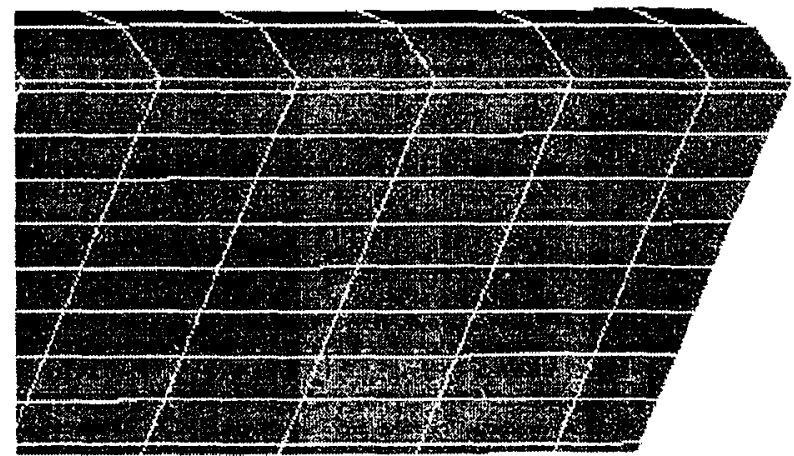

Figure 2-5 Meshed end cap and a portion of meshed pellet and sheath 


\subsection{Solution Techniques}

In ANSYS, the linear algebraic equations generated by the finite element procedure are solved using a direct elimination process or an iterative method. Two direct solvers are available: the Sparse Direct Solver and the Frontal (Wavefront) Solver. The Sparse Direct Solver makes use of the fact that the finite element matrices are sparsely populated. This sparseness allows the system of simultaneous equations to be solved efficiently by minimizing the operation counts. Iterative (preconditioned conjugate gradient (PCG)) solvers include Jacobi Conjugate Gradient (JCG) and Incomplete Cholesksy Conjugated Gradient (ICCG).

A direct elimination process is primarily the use of Gaussian elimination to solve for the unknown vector of variables $\{u\}$ in the following equation:

$$
[K]\{u\}=\{F\}
$$

where $[K]$ is the global stiffness matrix; $\{u\}$ is the global displacement vector; and $\{F\}$ is the global load vector.

The direct elimination process involves decomposition of the matrix $[K]$ into lower triangular matrix $[L]$ and upper triangular matrix $[U]$, that is $[K]=[L][U]$, then forward and back substitutions using $[L]$ and $[U]$ to compute the solution vector $\{u\}$. Equation $(2.1)$ is subjected to contact conditions. 
A typical iterative method involves an initial guess of the solution vector $\{u\}$, and then successive steps of iteration lead to a sequence of vectors such that, in the limit, $\{u\}_{n}=\{u\}$ as $n$ tends to infinity. The calculation of $\{u\}_{n+1}$ involves $[K],\{F\}$ and $\{u\}$ vectors from one or two of the previous iterations. Typically, the solution converges to within a specified tolerance after a finite number of iterations. 


\section{Chapter 3}

\section{MULTIBODY CONTACTS IN A CANDU FUEL ELEMENT}

In this chapter, ANSYS is used to analyze multibody contacts in a CANDU fuel element. The solid model development and mesh generation are the first two steps for the finite element formulation. After the model is meshed, the analysis procedure includes: (i) using surface-to-surface contact elements to create contact pairs; (ii) employing temperature-dependent material properties of the pellets, sheath and end cap assembly; (iii) prescribing temperatures in all solids; and (iv) applying appropriate boundary conditions. To prevent any potential mistakes, the International System of Units (SI) is used in the FE modeling.

\subsection{Analysis Procedure}

Once the model is meshed, the contact pairs are built to simulate interaction between two contacting surfaces. Target and contact surfaces form a contact pair. Constraints and loads are applied directly into the finite element nodes.

The TARGE170 and CONTA174 contact pairs shown in. Appendix are used as the contact elements because (i) they can model curved surfaces; (ii) they are compatible with the high-order solid elements used to mesh individual solids; and (iii) they permit large sliding between two contacting surfaces. In the FE models, all potential contact surfaces are modeled using contact elements TARGE170 and CONTA174. A total of 30 contact pairs are created to monitor radial 
contacts between the pellets and the sheath, as well as axial contacts between the neighboring pellets. During the analysis process, normal contact stiffness factor (FKN) is specified at each load step to ensure the FKN is large enough so that the contact penetration is acceptably small; and allowable penetration tolerance (FTOLN) values can be adjusted, a too small value may cause nonconvergence of the global solution.

Appropriate boundary conditions ensure that all FE model components are properly constrained, and all rigid body motions of components are avoided. Symmetry boundary conditions are applied to all symmetric planes. The end cap is used to restrain the displacement of the fuel element in the radial direction. The central node of the end cap has its radial degree of freedom constrained. For the FE model involving neither initial radial gap nor initial axial gap, no nodes on the pellets are restrained to avoid any singularities during the solution. However, axial contact does not occur in models involving axial gap. As a result, each pellet has a rigid body motion mode in the axial direction. To eliminate the rigid body motion, the axial degrees of freedom of pellet central nodes are constrained.

In this thesis, the temperature and the temperature gradient in the pellets are the only driving forces for fuel element deformations. The temperature distributions applied on the fuel element are given in Table 3-1. 
Table 3-1 Temperature Distributions

\begin{tabular}{|l|c|c|}
\hline \multicolumn{1}{|c|}{ Deformations } & In pellets $(\mathrm{K})$ & In sheath and end cap (K) \\
\hline Uniform Expansion & $T=T_{\text {ref }}+\Delta T_{1}$ & $T=T_{\text {ref }}$ \\
\hline Expansion and Bending & $T=T_{0}+\left(\frac{\Delta T}{2}\right)\left(\frac{r}{r_{p}}\right) \cos \theta$ & $T=T_{\text {ref }}$ \\
\hline
\end{tabular}

where $\Delta T_{1}$ is the temperature difference between the pellet and the sheath. As shown in Figure 3-1, $T_{\text {ref }}$ is the reference temperature; $T_{0}$ is the average volume temperature in the pellets; $\Delta T$ is the temperature gradient across the pellet diameter in the direction of the flux depression. and $r$ and $\theta$ are radial and angular coordinates as shown in Figure 3-2.

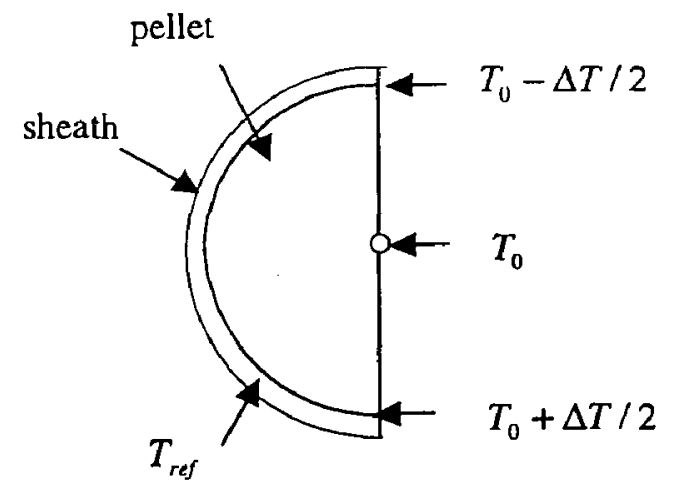

Figure 3-1 Illustration of temperatures in fuel element

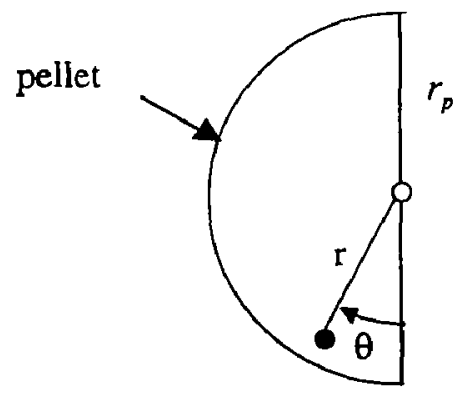

Figure 3-2 Illustration of polar coordinates $r$ and $\theta$ 


\subsection{Validation of FE Models}

Three FE models are first created to validate the feasibility of the structural solid elements and the surface-to-surface contact elements. The FE results obtained from the three models are verified against independent analytical solutions.

\subsubsection{Test of Radial Contact}

Figure 3-3 shows a two-dimensional view of a three-dimensional idealized model. One pellet and its surrounding sheath are involved in this model, hence only the radial contact is concerned. Initial radial gap is set to be zero.

The temperatures are $T_{p}=T_{\text {ref }}+800^{\circ} \mathrm{K}$ in the pellets and $T_{s}=T_{\text {ref }}$ in the sheath. Contact occurs when the pellet experiences uniform thermal expansion. Due to the pellet uniform expansion in the radial direction, the contact pressure is uniform in the circumferential direction.

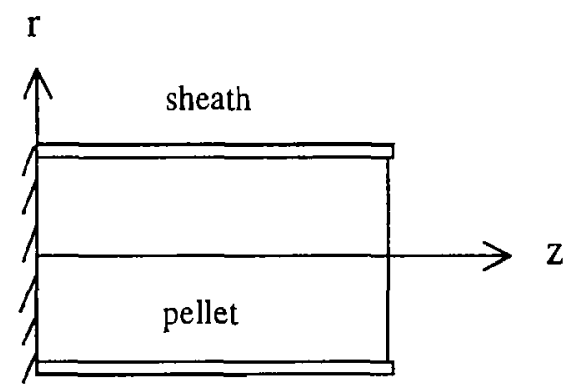

Figure 3-3 Test of radial contact between pellet and sheath

An analytical solution for the radial contact pressure and radial displacement of the sheath with infinite length was derived by $\mathrm{Xu}(2000)$. It is used here to validate the ANSYS models. 
From Figures 3-4 and 3-5, it is seen that radial contact pressure between the pellet and sheath, as well as the radial displacement of the sheath at $r=r_{s, i}$ obtained from ANSYS is in good agreement with the analytical solutions. However, there is some discrepancy in the magnitude between the ANSYS and analytical solutions. This may be attributed to the fact that analytical solution is obtained for an infinitely long cylinder.

As shown in Figure 3-5, thermal expansion in the pellet end regions is larger than that in the pellet midplane regions. This hourglassing phenomenon causes a ridging effect on the sheath, and the design of the chamfer in the pellet is to avoid this unfavorable effect. The same trend as in Figure 3-5 is also found in Figure 3-4 for radial contact pressure.

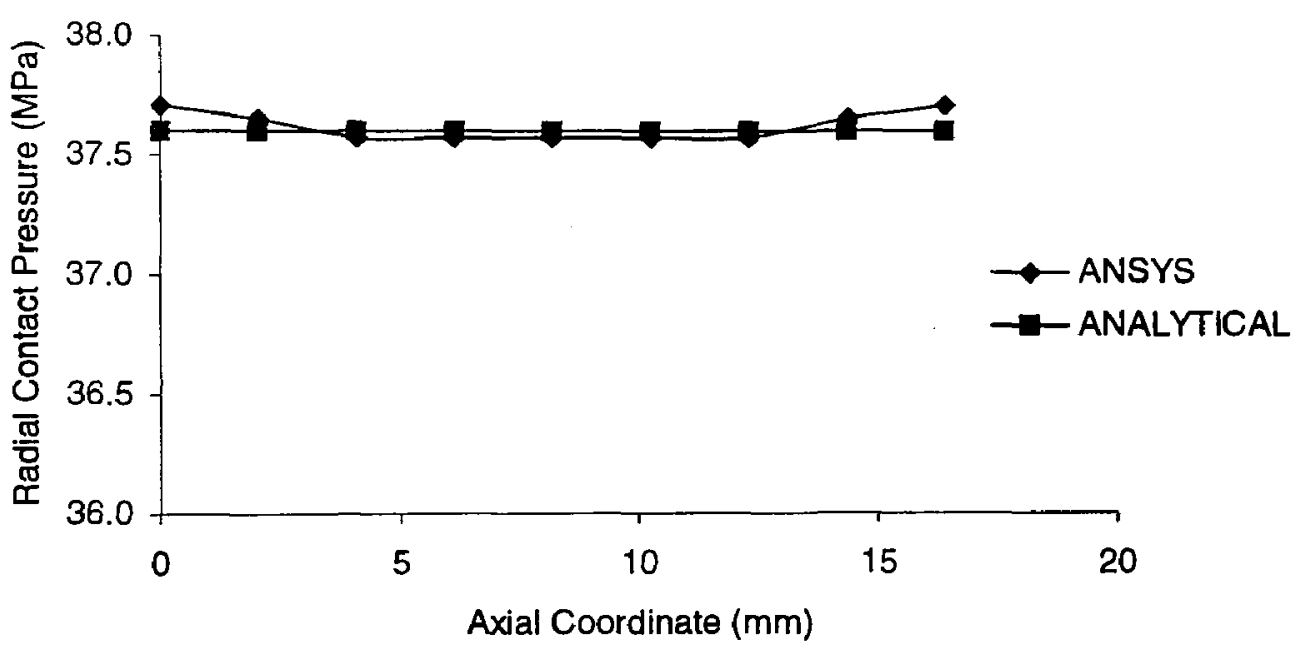

Figure 3-4 Comparison of radial contact pressure 


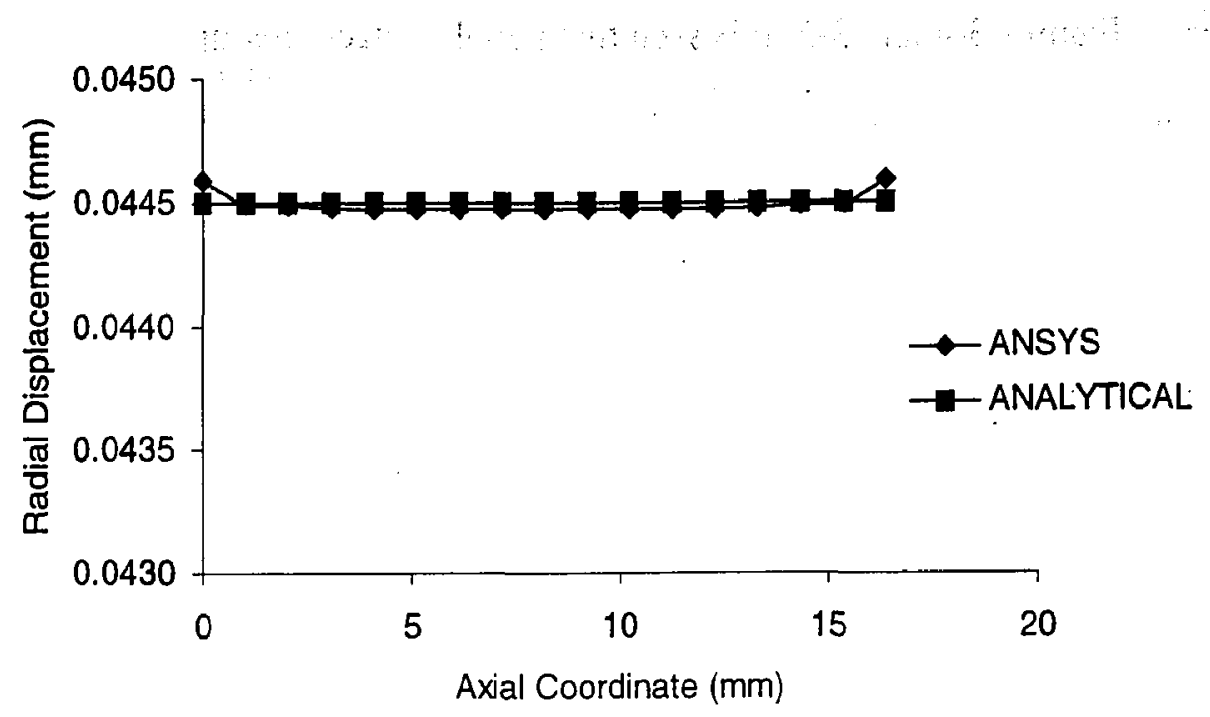

Figure 3-5 Comparison of radial displacement

\subsubsection{Test of Axial Contact}

A two-dimensional view of an idealized FE model is shown in Figure 3-6. In this test case, the initial radial gap and initial axial gap are all set to be zero. The temperature in the pellet is $T_{p}=T_{\text {ref }}+50^{\circ} \mathrm{K}$, and in the sheath is $T_{s}=T_{\text {ref }}$. It is further assumed that i) the middle plane of the second pellet is constrained in the $z$ direction; ii) the radial contact as well as the axial contact between two pellets is neglected; iii) a very rigid end cap, whose material modulus of elasticity $84.1 \times 10^{6} \mathrm{GPa}$ is present. Therefore, in this model, only the axial contact between the second pellet and the end cap is involved. When the second pellet expands in the $\mathrm{z}$ direction, the axial contact occurs. 


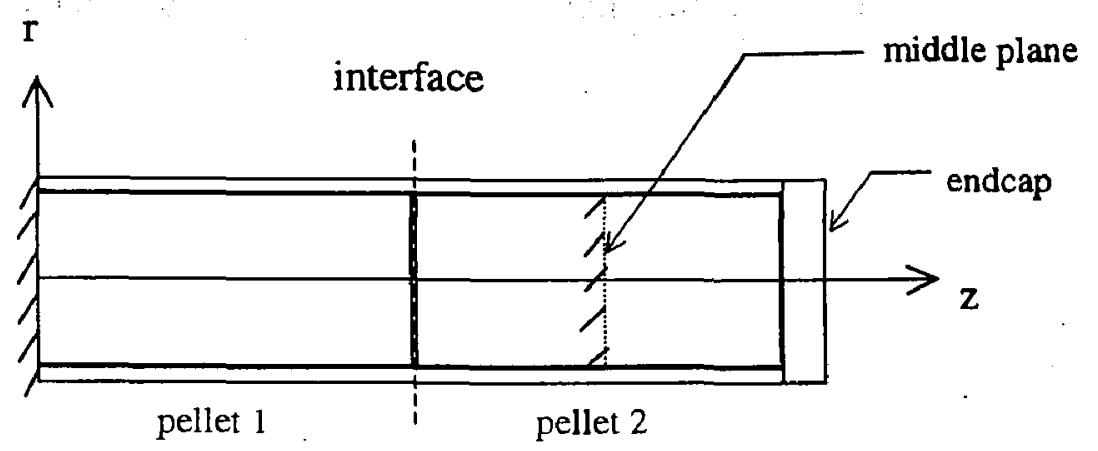

Figure 3-6 Test of axial contact between second pellet and end cap

The axial contact pressure and the stress of the sheath in the $\mathrm{z}$ direction may be obtained from the following three conditions:

i) Force equilibrium in the axial direction:

$$
\sigma_{s} A_{s}=\sigma_{p} A_{p}
$$

where $\sigma_{s}$ is the axial stress in the sheath; $\sigma_{p}$ is the axial stress in the pellet; $A_{s}$ is the sheath cross-sectional area; and $A_{p}$ is the pellet cross-sectional area.

ii) Hooke's law:

$$
\sigma_{s}=E_{s}\left(\varepsilon_{s}-\varepsilon_{s}^{t h}\right)=E_{s} \varepsilon_{s}
$$

where $E_{s}$ is sheath Young's modulus; $\varepsilon_{s}$ is the sheath axial strain due to deformation; and $\varepsilon_{s}^{\text {th }}$ is the sheath axial strain due to thermal load.

$$
\sigma_{p}=E_{p}\left(\varepsilon_{p}-\varepsilon_{p}^{t h}\right)=E_{p}\left(\varepsilon_{p}-\alpha_{p} \Delta T_{1}\right)
$$

where $E_{p}$ is pellet Young's modulus; $\varepsilon_{p}$ is the pellet axial strain due to deformation; $\varepsilon_{p}^{\text {th }}$ is 
the pellet axial strain due to thermal load; $\alpha_{p}$ is pellet thermal expansion coefficient; and $\Delta T_{1}$ is the temperature difference between pellet and sheath.

iii) Geometric relationship:

$$
\varepsilon_{p} \cdot \frac{L_{p}}{2}=\varepsilon_{s} \cdot 2 L_{p}
$$

where $L_{p}$ is the length of each pellet.

As a result, the axial contact pressure is derived as:

$$
p_{z}=\sigma_{p}=\frac{E_{p} \alpha_{p} \Delta T_{1}}{1+\frac{4 A_{p}}{A_{s}} \frac{E_{p}}{E_{s}}}
$$

and the axial stress in the sheath is derived as:

$$
\sigma_{s}=\frac{E_{p} \alpha_{p} \Delta T_{1}}{\frac{A_{s}}{A_{p}}+\frac{4 E_{p}}{E_{s}}}
$$

Table 3-2 presents the comparisons of the results between ANSYS and analytical solution. It is noted that the two sets of results show excellent agreement. The relative error is within $1 \%$. 
Table 3-2 Comparisons of Axial Contact Pressure and Stress

\begin{tabular}{|c|c|c|c|}
\hline Parameters & ANSYS & Analytical & Error (\%) \\
\hline Axial contact pressure (MPa) & 1.2864 & 1.2868 & -0.031 \\
\hline Axial stress (MPa) & 9.5653 & 9.5649 & 0.004 \\
\hline
\end{tabular}

\subsubsection{Test of Contact Pair between Two Pellets}

A three-dimensional two-pellet model shown in Figure 3-7 is created. The initial radial and axial gaps are all zero for this test case. One contact pair is built between two pellets. The thermal load is replaced by a concentrated force $F$, which is applied on the central node of end cap and whose direction is in the negative $z$ direction. The magnitude of $F$ is assumed to be $100 \mathrm{~N}$ to ensure the test results are in static scope.

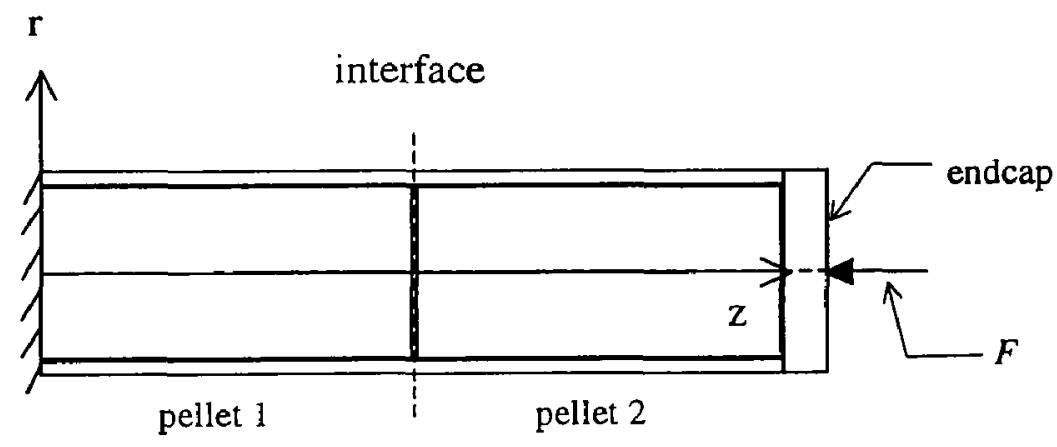

Figure 3-7 Test of contact pair between two pellets

The analytical solution to pressure between two pellets is calculated as $2 F / A_{p}$. The ANSYS result is compared with the analytical solution result in Table 3-3. The difference between the two sets of results is well within $1 \%$. 
Table 3-3 Comparison of Pressure Between Two Pellets

\begin{tabular}{|c|c|c|c|}
\hline Parameter & ANSYS & Analytical & Error (\%) \\
\hline & & & \\
Pressure (MPa) & 1.6905 & 1.6886 & 0.112 \\
\hline
\end{tabular}

The test results for the aforementioned three test cases all agree very well with the analytical solutions. The FE models, in conjunction with the 20-node structural solid finite elements and the surface-to-surface contact pairs, can be used to efficiently and accurately solve the thermomechanical and multibody contact problems in a CANDU fuel element. 


\section{Chapter 4}

\section{THERMAL EXPANSIONS AND BENDING IN FUEL ELEMENT}

In this chapter, simulation results are obtained from one FE model involving neither initial radial gap nor initial axial gap. An analytical solution is also derived using the composite beam theory.

\subsection{Uniform Temperature}

Figures 4-1 through 4-4 present comparisons of the thermal expansions and contact pressure for three different pellet temperatures: $343.15^{\circ} \mathrm{K}, 393.15^{\circ} \mathrm{K}$ and $443.15^{\circ} \mathrm{K}$. The temperature in the sheath is $T_{s}=T_{\text {ref }}$.

Figure 4-1 shows the variations of the radial expansion of the sheath inner surface with the axial coordinate. The radial expansion is uniform in the axial direction. However, in the region near the end cap, the radial expansion is no longer uniform because of the end cap effect. 


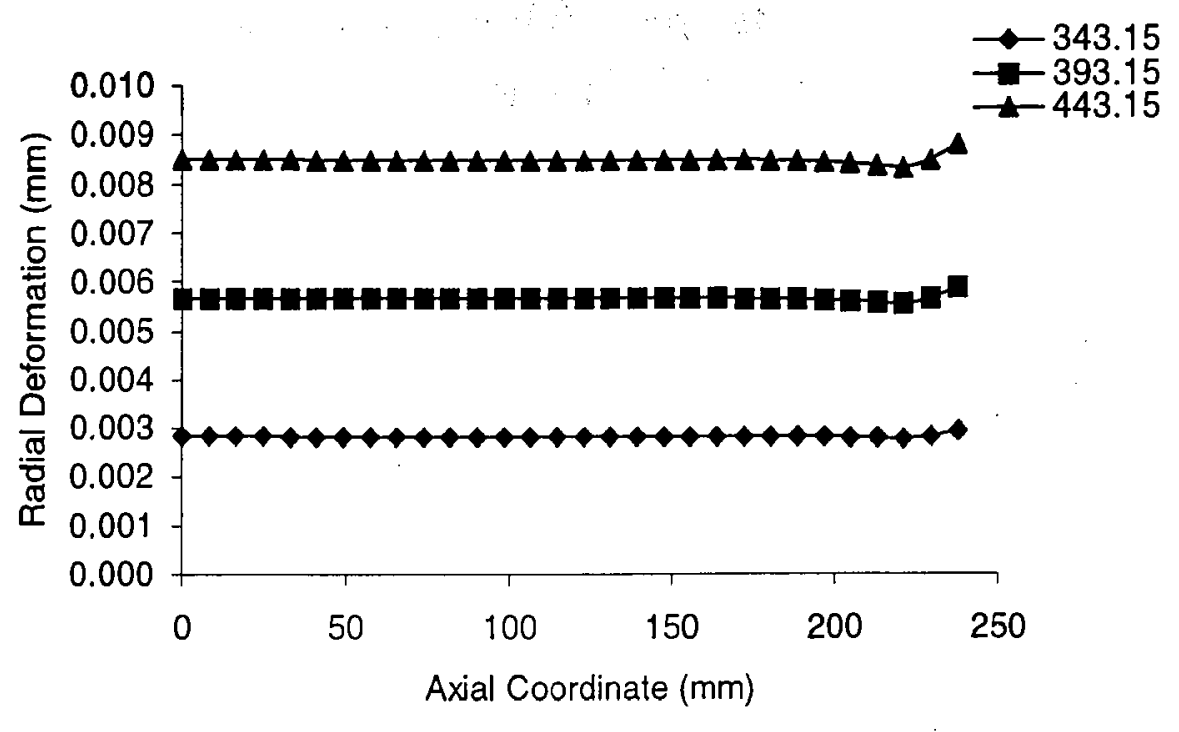

Figure 4-1 Radial displacement in the sheath inner surface

Figure 4-2 shows the variations of the contact pressure between the sheath inner surface and the pellets in the axial direction. The contact pressure shows uniformity in the region away from the end cap. Some variations are observed in the region near the end cap.

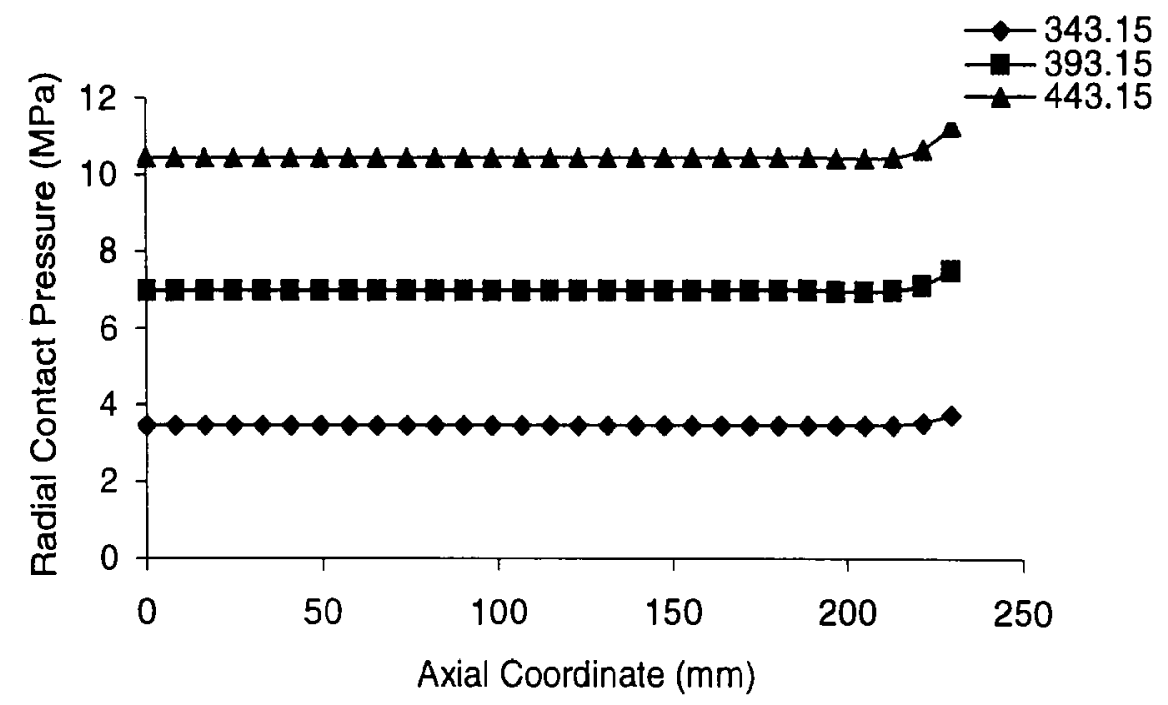

Figure 4-2 Radial contact preșsure between sheath inner surface and pellets 
Figure 4-3 presents the axial expansions of each pellet centerline node at the midplane. The expansion increases linearly with the axial coordinate; the distribution of the axial strain in the longitudinal direction is uniform.

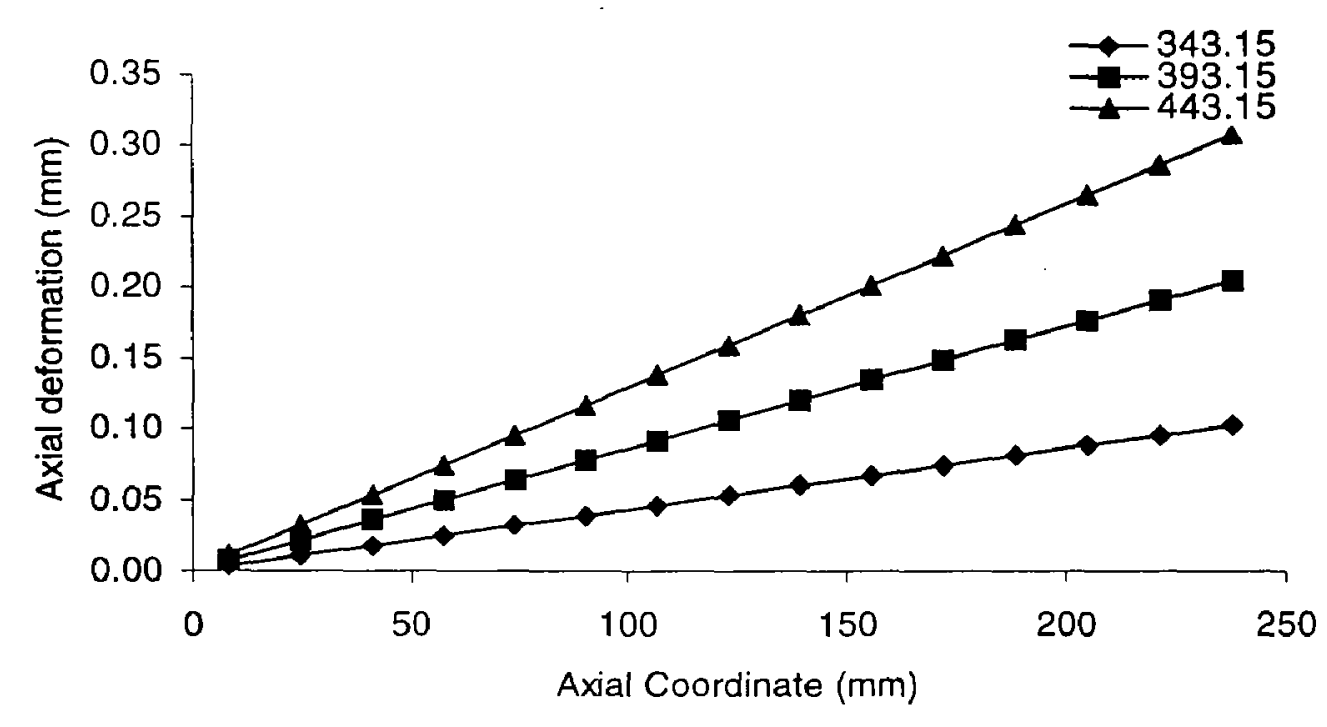

Figure 4-3 Axial expansion of pellet centerline node at the midplane

Figure 4-4 presents the axial contact pressure at every interface. Fourteen sets of pellet-to-pellet contact pairs plus one set of contact pair between the pellet and the end cap are represented by a row of fifteen points. The axial contact pressure between each contact pair is similar in magnitude. However, the deformation of the end cap lessens contact pressure between the pellet and the end cap. 




Figure 4-4 Axial contact pressure for axial contact pairs

Figure 4-5 presents the illustration of top and bottom inner surfaces of the sheath. Figures 4-6 and 4-7 show radial and axial stress distributions at the top of the sheath inner surface for a uniform temperature of $343.15^{\circ} \mathrm{K}$. The temperature in the sheath is $T_{s}=T_{\text {ref }}$. The radial and axial stress distributions are uniform in the areas away from the end cap. This is consistent with the radial displacement and radial contact pressure distributions. Due to uniform expansion of the pellets, at the bottom inner surface of the sheath, the values are identical for the radial and axial stresses, respectively. In the regions near the end cap, some variations appear due to end cap effect.

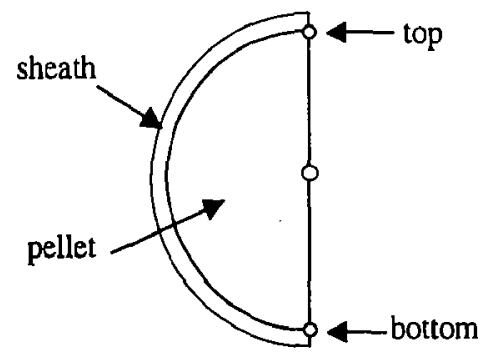

Figure 4-5 Illustration of top and bottom inner surfaces of sheath 


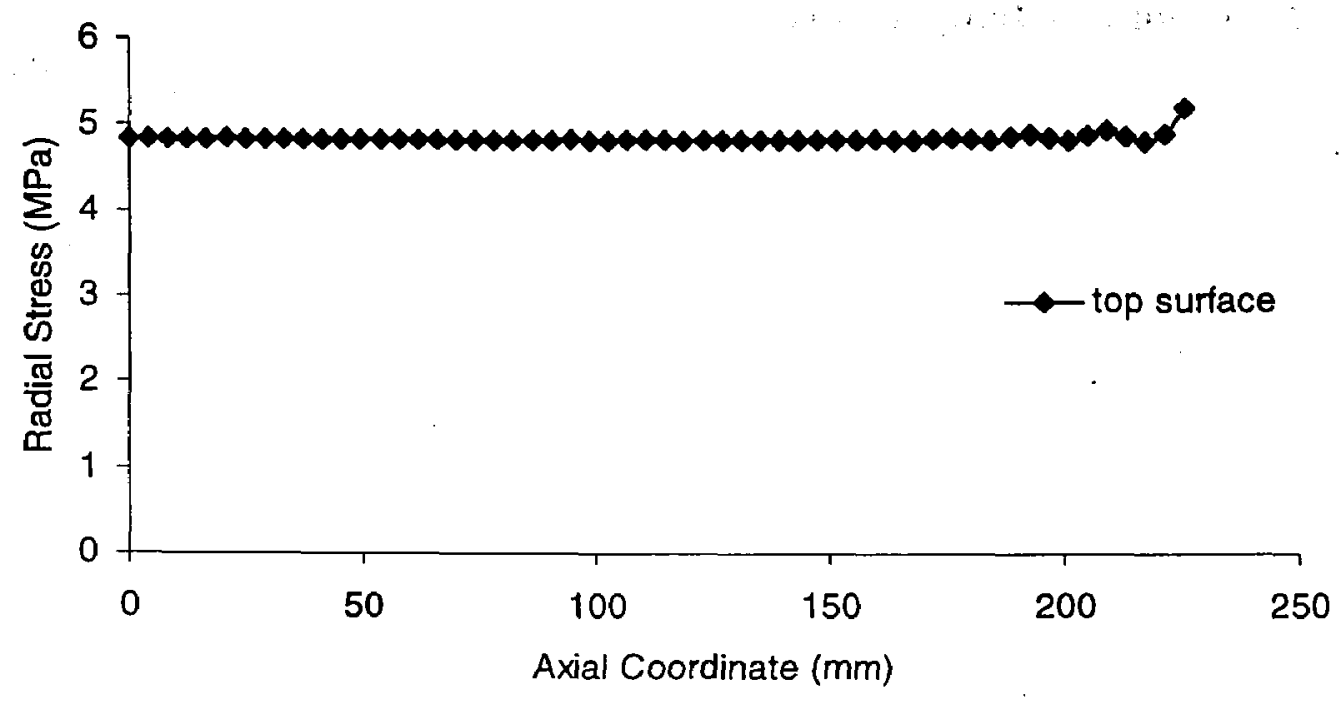

Figure 4-6 Radial stress distribution in top inner surface of the sheath

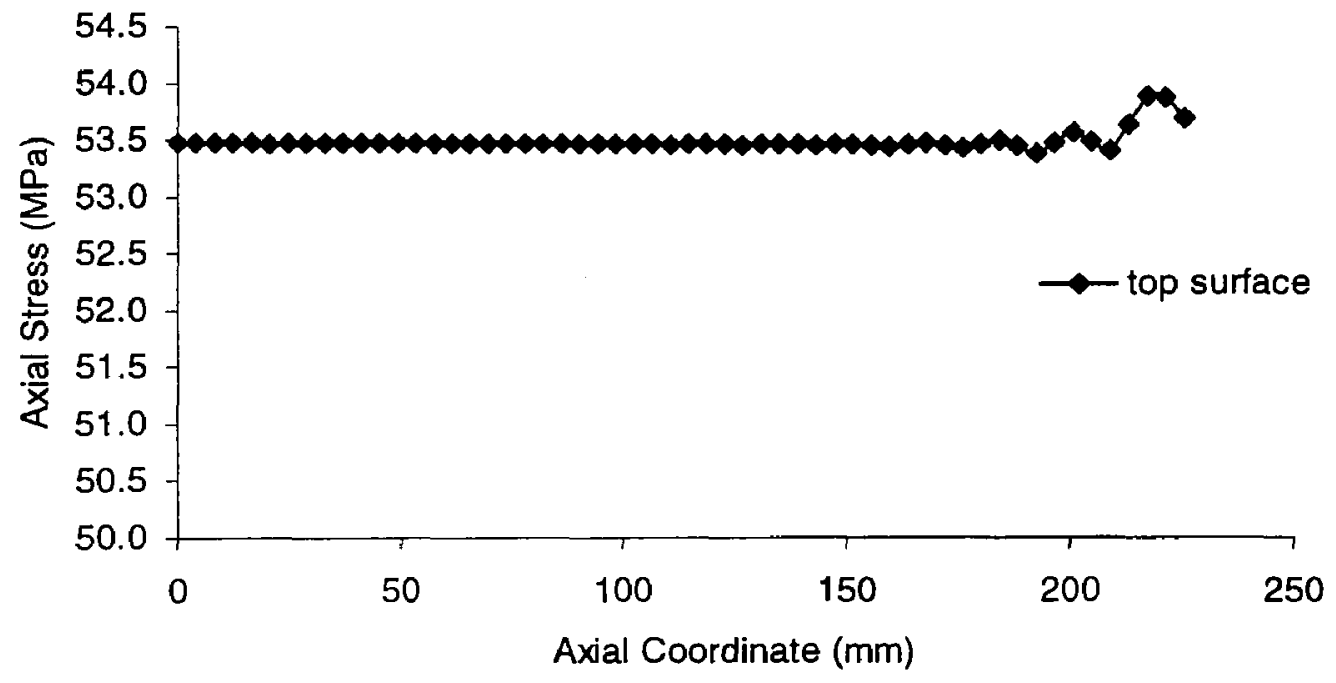

Figure 4-7 Axial stress distribution in top inner surface of the sheath 


\subsection{Non-uniform Temperature}

Figure 4-8 compares thermally induced bending in a fuel element when the pellets experience a temperature gradient $\Delta T$ across the pellet diameter. Figure 4-9 shows the relationship between the maximum bending and the $\Delta T$. Values of $\Delta T$ used in the analyses are $50^{\circ} \mathrm{K}, 100^{\circ} \mathrm{K}$ and $150^{\circ} \mathrm{K}$. The average volume temperature in the pellets is $343.15^{\circ} \mathrm{K}$. The temperature in the sheath is $T_{s}=T_{\text {ref }}$. It is noted from Figure 4-8 that the larger the value of $\Delta T$, the more significant the bending. Thus, the bending of a fuel element is sensitive to the magnitude of $\Delta T$. From Figure 4-9 it is observed that the maximum bending is in linear relationship with the $\Delta T$.

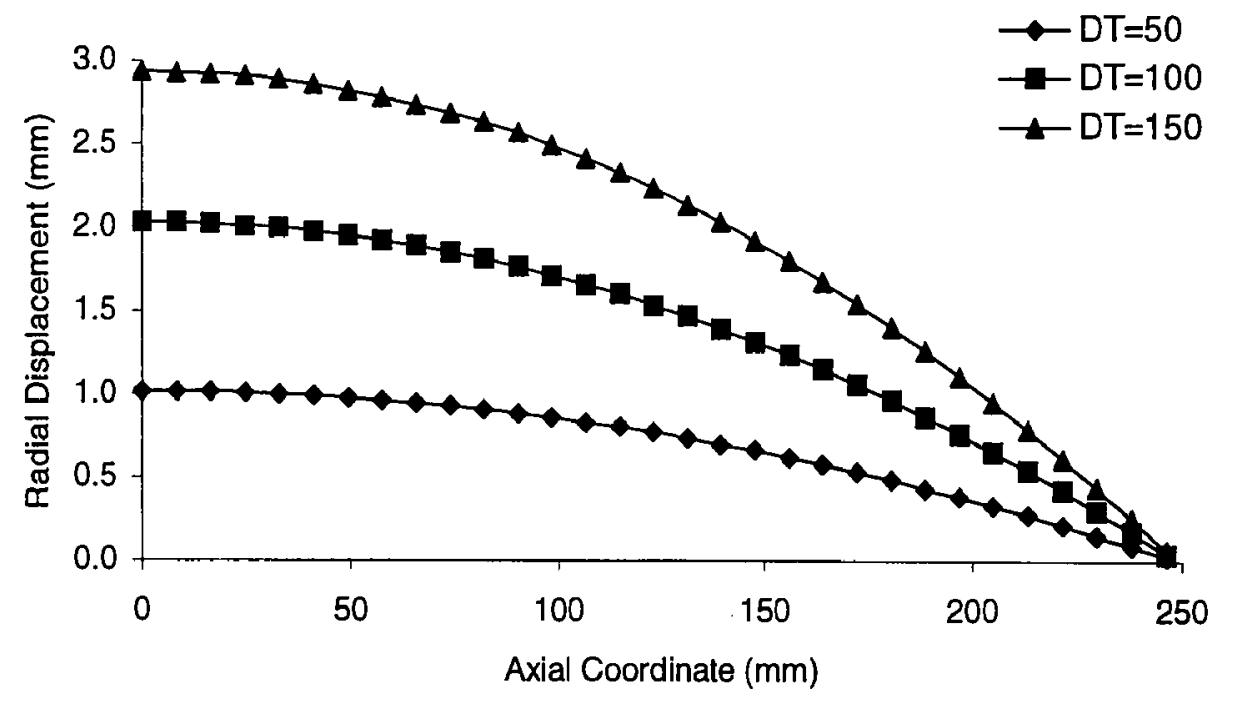

Figure 4-8 Radial displacement in the sheath inner surface 


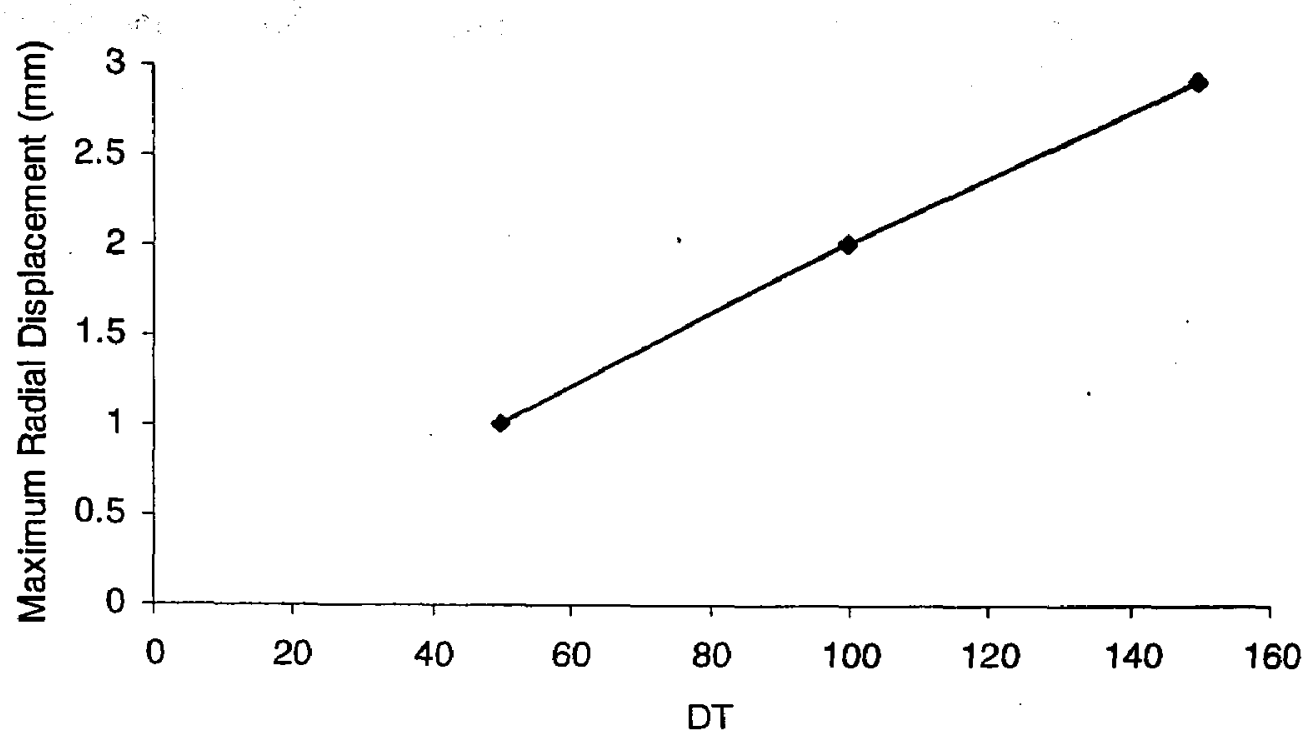

Figure 4-9 The relationship between maximum bending and $\Delta T$

In the case when a fuel element experiences thermal bending, the radial and axial stress distributions at the top and bottom inner surfaces of the sheath are compared in Figures 4-10 and 4-11. These distributions in the sheath reflect the stress variations for the pellets stacked end-toend. In this analysis, $\Delta T=50^{\circ} \mathrm{K}, T_{0}=343.15^{\circ} \mathrm{K}$, and $T_{s}=T_{\text {ref }}$, and the temperature increases linearly along the pellet diameter from top to bottom, so the top is the colder surface, and the bottom is the hotter surface.

It is seen from Figures 4-10 and 4-11 that the radial and axial stresses at the sheath bottom surface are larger than those in the top surface due to downward bending of the fuel element. As shown in Figure 4-10 for radial stresses, some variations are noted for each segment distribution, which verifies that bending instead of uniform expansion occurs. 


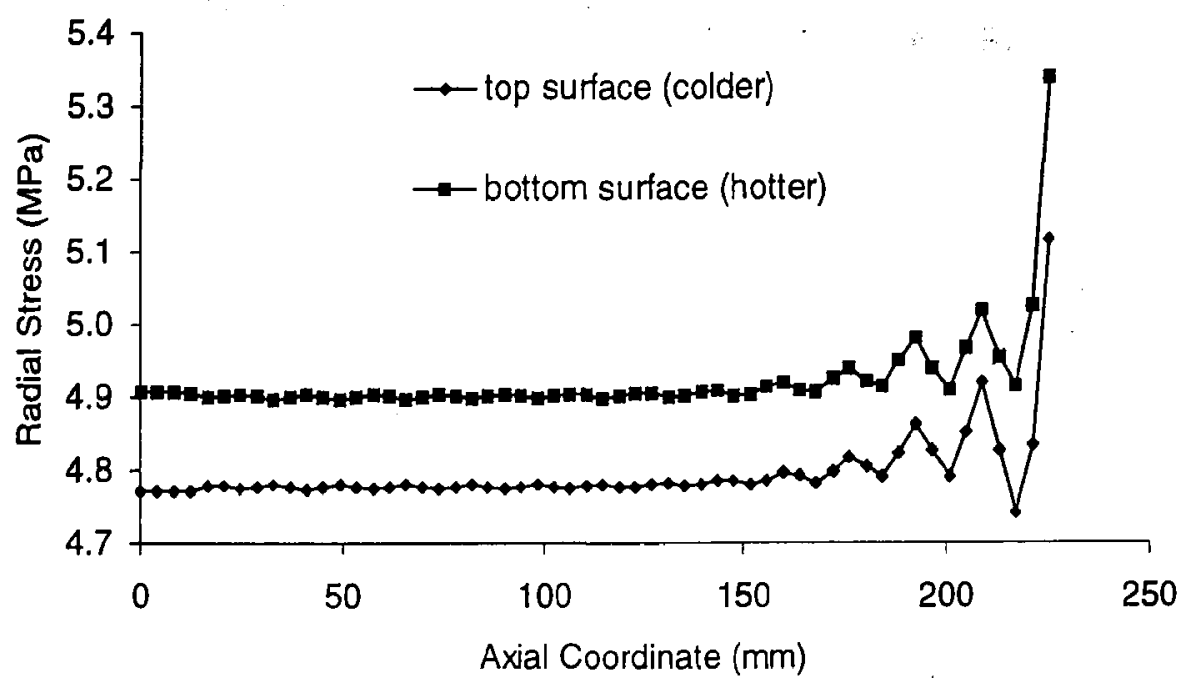

Figure 4-10 Radial stress distribution in top and bottom inner surfaces of sheath



Figure 4-11 Axial stress distribution in top and bottom inner surfaces of sheath 
Once the finite element model is created, it is possible to predict the bending of a fuel element under a variety of thermal loads. As a result, operating condition limits can be established to ensure that the amount of bending is acceptable.

\subsection{Bending of a Composite Beam}

Under certain conditions, a fuel element may be considered as a single straight composite beam for which an analytical solution can be easily obtained. The key assumption is that gaps everywhere must be initially zero and remain zero after the application of thermal loads. Assume initial radial gap and initial axial gap are all zero. Figures 4-12 and 4-13 illustrate a composite beam consisting of two distinct components (Zircaloy sheath and $\mathrm{UO}_{2}$ pellets). The beam is simply supported at two ends to simulate the constraints of a fuel element.

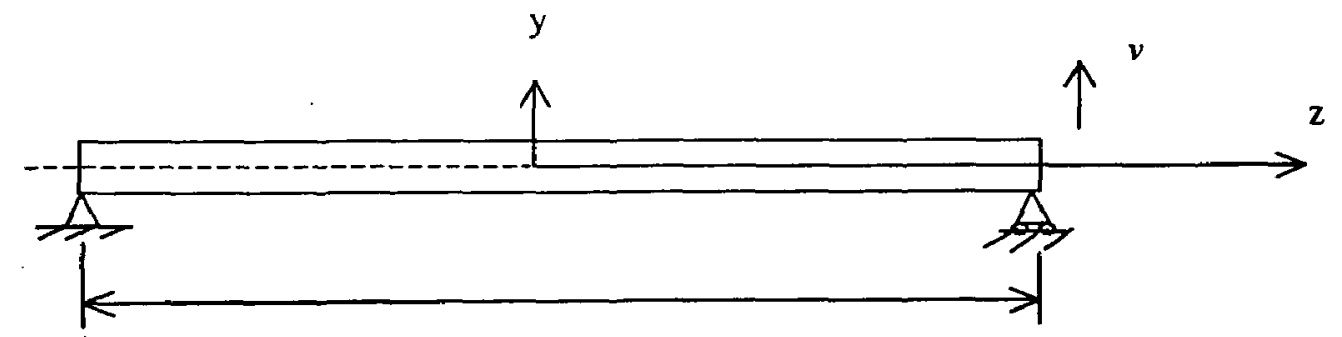

$2 \mathrm{~L}$

Figure 4-12 A simply supported composite beam 


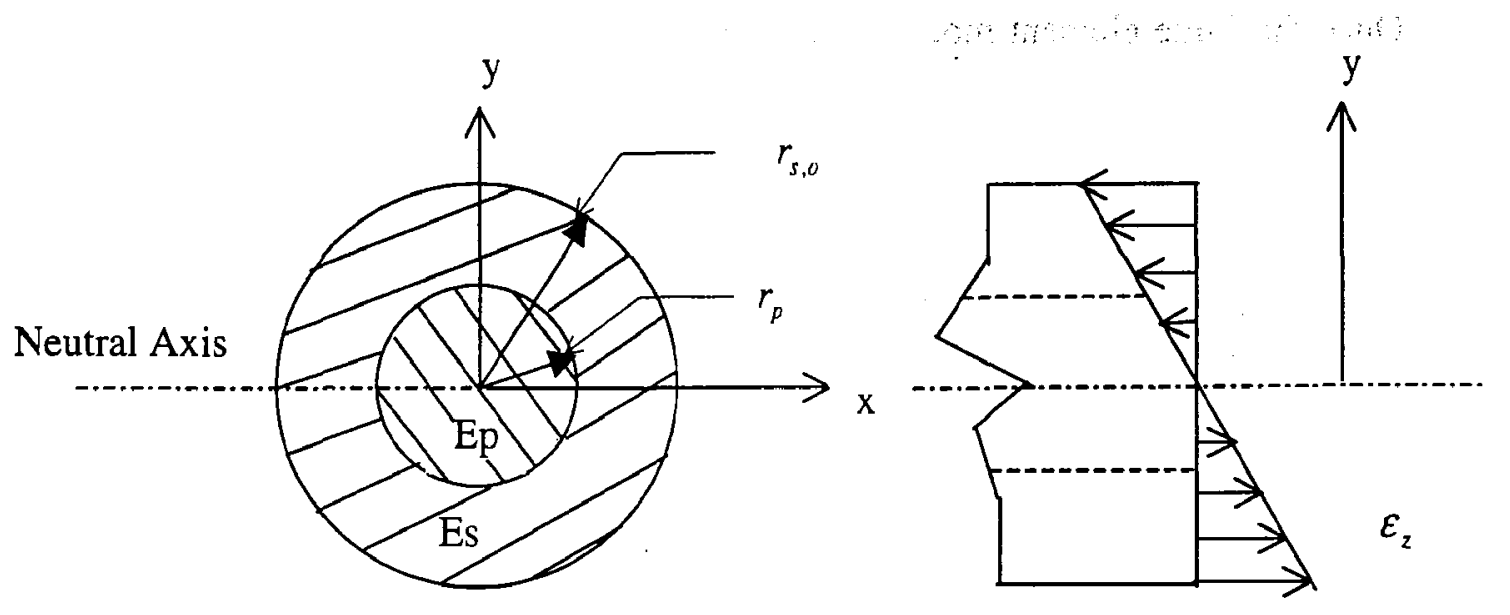

Figure 4-13 Beam cross-section and its axial strain due to bending

According to Boley, the equivalent thermal bending moment for a linear temperature distribution in the pellet, may be written as:

$$
M^{T}=\int_{A_{p}} E_{p} \alpha_{p}\left(T_{0}+\frac{\Delta T}{2 r_{p}} y\right) y d A_{p}=\frac{1}{8} E_{p} \alpha_{p} \pi r_{p}^{3} \Delta T
$$

where $\alpha_{p}$ is the pellet linear thermal expansion coefficient; $r_{p}$ is the radius of the pellet; $E_{p}$ is Young's modulus of the $\mathrm{UO}_{2}$ pellet; $A_{p}$ is the cross-sectional area of the pellet; $T_{0}$ is the average volume temperature in the pellet; $\Delta T$ is the temperature gradient across the pellet diameter.

Applying the bending moment, defined in Eqn. (4.1), to a simply supported beam, the lateral deflection $v$ may be found by solving the following differential equation: 


$$
\frac{d^{2} v}{d z^{2}}=\frac{M^{T}}{E_{p} I_{p}+E_{s} I_{s}}
$$

where $E_{s}$ is Young's modulus of the Zircaloy sheath; $I_{p}$ is the second moment of area of the pellet cross section; $I_{s}$ is the second moment of area of the sheath cross section.

Integrating Eqn. (4.2) and applying boundary conditions, for a simply supported composite beam of length $2 L$ whose inner core subjected to a linear temperature distribution, its lateral deflection may be obtained as:

$$
\nu=\frac{E_{p} \alpha_{p} r_{p}^{3} \Delta T}{4\left[E_{p} r_{p}^{4}+E_{s}\left(r_{s, o}^{4}-r_{p}^{4}\right)\right]}\left(z^{2}-L^{2}\right)
$$

where $r_{s, o}$ is the outer radius of the sheath.

\subsection{Comparison}

The deflections of a fuel element having zero gaps everywhere before and after thermal bending moment are obtained using the ANSYS program for $T_{0}=343.15^{\circ} \mathrm{K}$ and $\Delta T=50^{\circ} \mathrm{K}$. For the same fuel element and the same temperature load, the analytical solution is obtained and compared in Figure 4-14. 




Figure 4-14 Comparison of ANSYS and composite beam theory results

From Figure 4-14, it can be seen that there is excellent agreement between the two sets of results. For this special fuel element model, the fuel element axial length is much greater than the radial diameter, and the fuel element is straight and has constant cross sections, so the fuel element may be treated as a composite beam. Therefore, the analytical solution can be derived easily to validate the ANSYS fuel element model. 


\section{Chapter 5}

\section{CURVATURE TRANSFER FACTOR CORRELATION}

The curvature transfer factor (CTF), defined as the ratio of sheath curvature increase to the pellet curvature, is used to quantify the amount of pellet bending transferred to the sheath. The CTF value depends on many geometric and operational parameters. It varies between zero (no interaction between the pellets and sheath) and a limiting value $(<1)$ when there is full contact everywhere.

In this chapter, the geometric and operational parameters affecting CTF value are identified and ranked according to their impact on CTF. Sensitivity studies on key geometric and operational parameters are conducted, and CTF curves for different operating conditions are presented.

\subsection{Parameters Affecting CTF}

Table 5-1 shows all geometric and operational parameters that affect the CTF. These parameters Tre ranked as high (1), medium (2) or low (3). The parameters ranked as high are key geometric Ind operational parameters, and sensitivity studies on them are conducted in this thesis. 
Table 5-1 Parameters Affecting CTF

\begin{tabular}{|l|c|}
\hline \multicolumn{1}{|c|}{ Parameter Description } & Ranking \\
\hline initial sheath-pellet radial gap & 1 \\
\hline initial pellet-pellet axial gap & 1 \\
\hline temperature gradient across pellet diameter & 1 \\
\hline average pellet volume temperature & 2 \\
\hline average sheath volume temperature & 3 \\
\hline pellet radius & 1 \\
\hline pellet length & 3 \\
\hline sheath thickness & 3 \\
\hline end cap thickness & 3 \\
\hline chamfer height (axial direction) & 3 \\
\hline chamfer width (radial direction) & 3 \\
\hline dish radius & 3 \\
\hline dish depth & 1 \\
\hline average sheath-pellet radial contact pressure & 1 \\
\hline average pellet-pellet axial contact pressure & \\
\hline
\end{tabular}

\subsection{Sensitivity Studies}

\subsubsection{Initial Pellet-Pellet Axial Gap}

Figures 5-3 through 5-5 present comparisons of radial displacement in the hotter inner surface of the sheath, and Figures 5-6 through 5-10 show comparisons of radial stress distribution in both colder and hotter inner surfaces of the sheath for $T_{0}=343.15^{\circ} \mathrm{K}, \Delta T=50^{\circ} \mathrm{K}$, and initial pellet-pellet axial gaps are $0,0.05 \mathrm{~mm}$ and $0.1 \mathrm{~mm}$, respectively. For the FE models involving 
axial gaps, their stress distributions are made up of two figures: one shown in Figure 5-1 contains nodes contacting with central nodes of each pellet, and the other shown in Figure 5-2 includes nodal points having interaction with two end side nodes of each pellet.

midplane

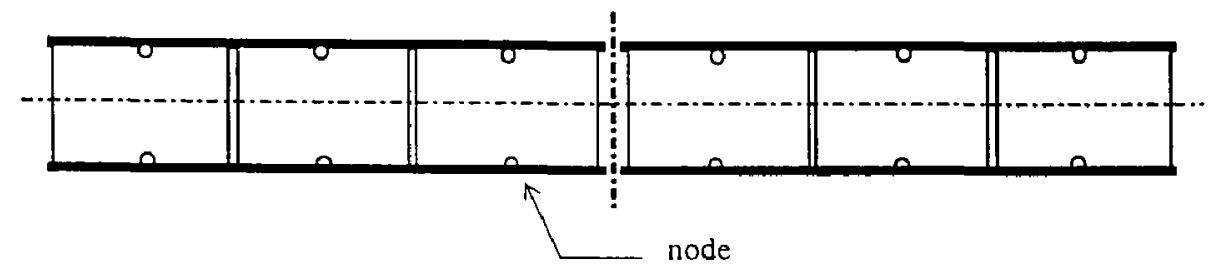

Figure 5-1 Sheath nodes contacting with central nodes of each pellet

midplane

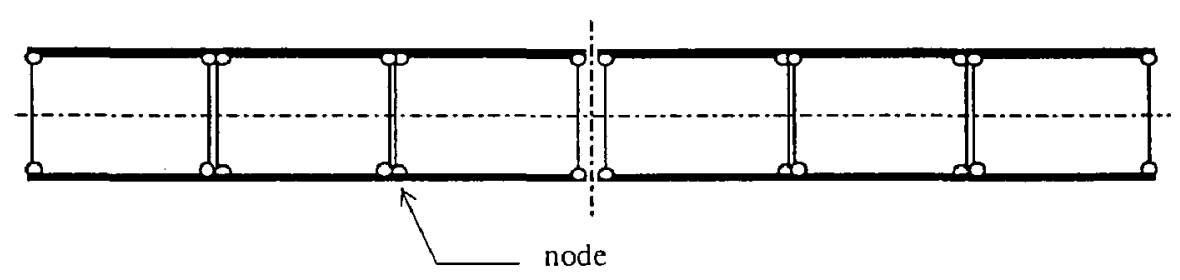

Figure 5-2 Sheath nodes contacting with end side nodes of each pellet

To investigate the effect of axial contact on the CTF, the axial gap is introduced so that it is large enough to avoid any axial contact. For the FE models involving the axial gap, the pellet thermal bending moment can only get transferred to the sheath through pellet-sheath contact. Subsequently, the amount of bending in the fuel element is very small, which causes a smaller radial stress compared with the model without the axial gap. Therefore, the initial pellet-pellet axial gap plays a significant role in the CTF value. 
Results shown in Figures 5-4 and 5-5 indicate that the deflections of a fuel element with axial gaps of $0.05 \mathrm{~mm}$ and $0.1 \mathrm{~mm}$ are almost identical. This indicates that the global bending behavior is not dependent on the axial gap under non-axial contact conditions. Moreover, it is noted that the local bending is captured, and this is because of the zero radial gap between the sheath and pellets and non-zero axial gaps between the neighboring pellets.

Consistent with the radial displacement, the radial stress distributions are almost identical for the finite element models without the axial contact, as shown in Figures 5-7 through 5-10. The stress values in the colder inner surface of the sheath are smaller than those in the hotter inner surface for the central nodes, whereas for the end side nodes, the situation is converse.

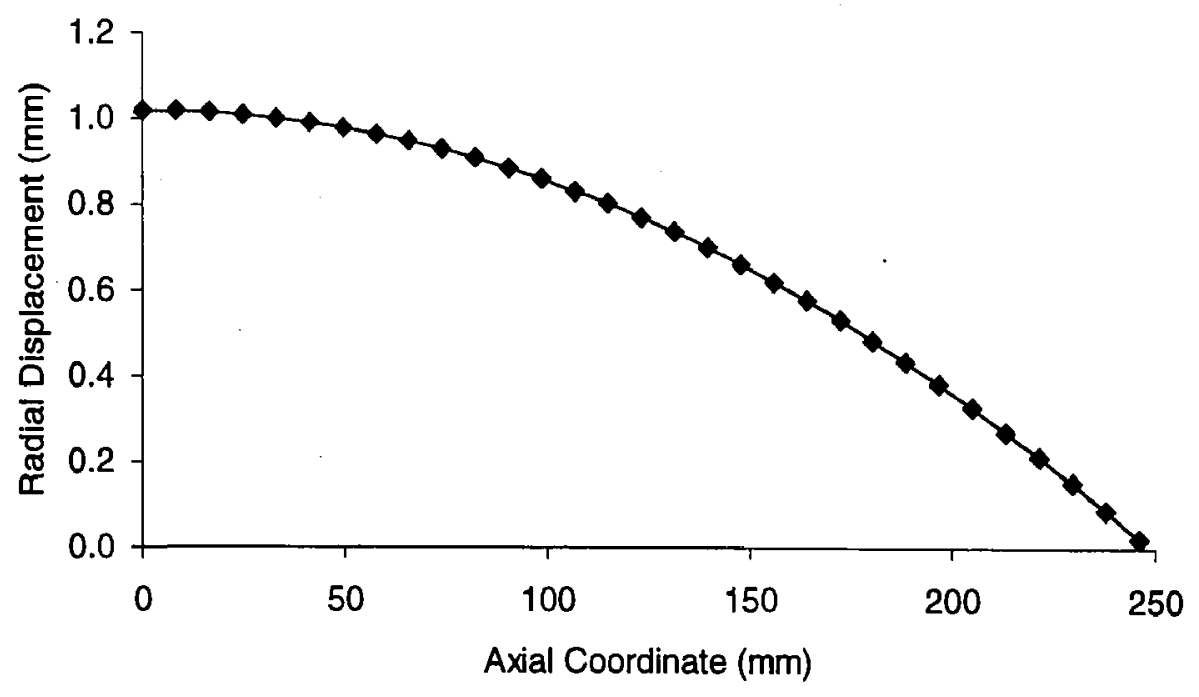

Figure 5-3 Radial displacement for non-axial gap model 


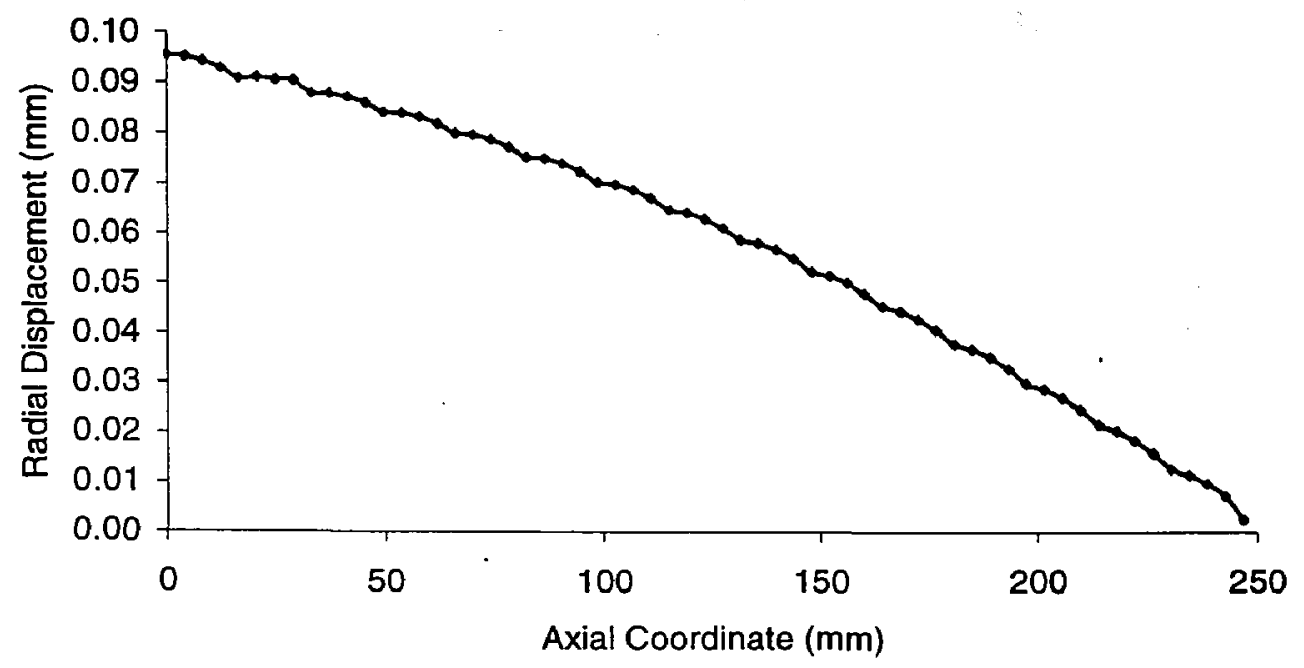

Figure 5-4 Radial displacement for axial gap $0.05 \mathrm{~mm}$ model

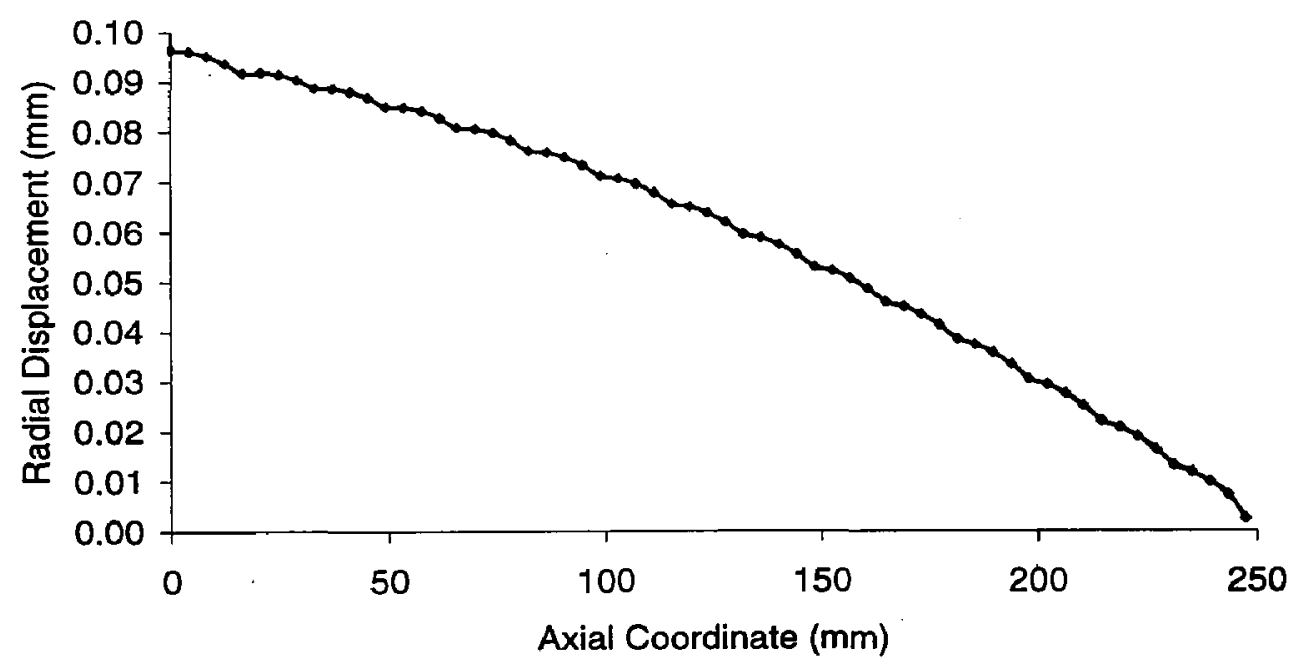

Figure 5-5 Radial displacement for axial gap 0.1 mm model 


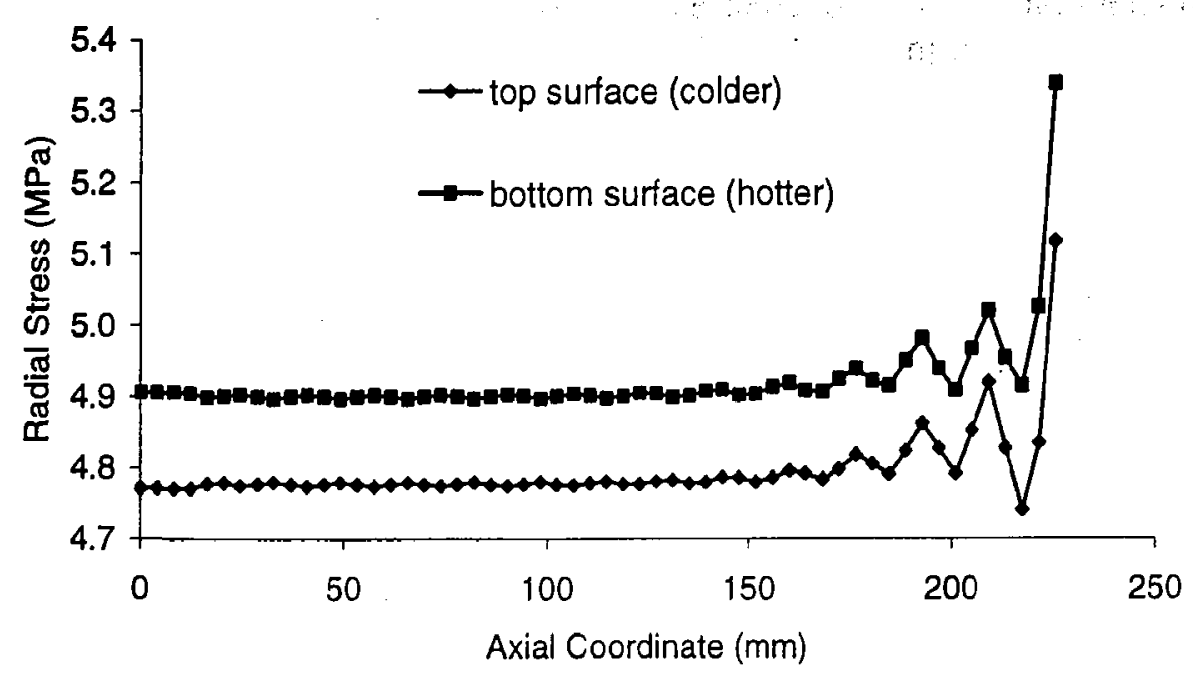

Figure 5-6 Radial stress distribution for non-axial gap model

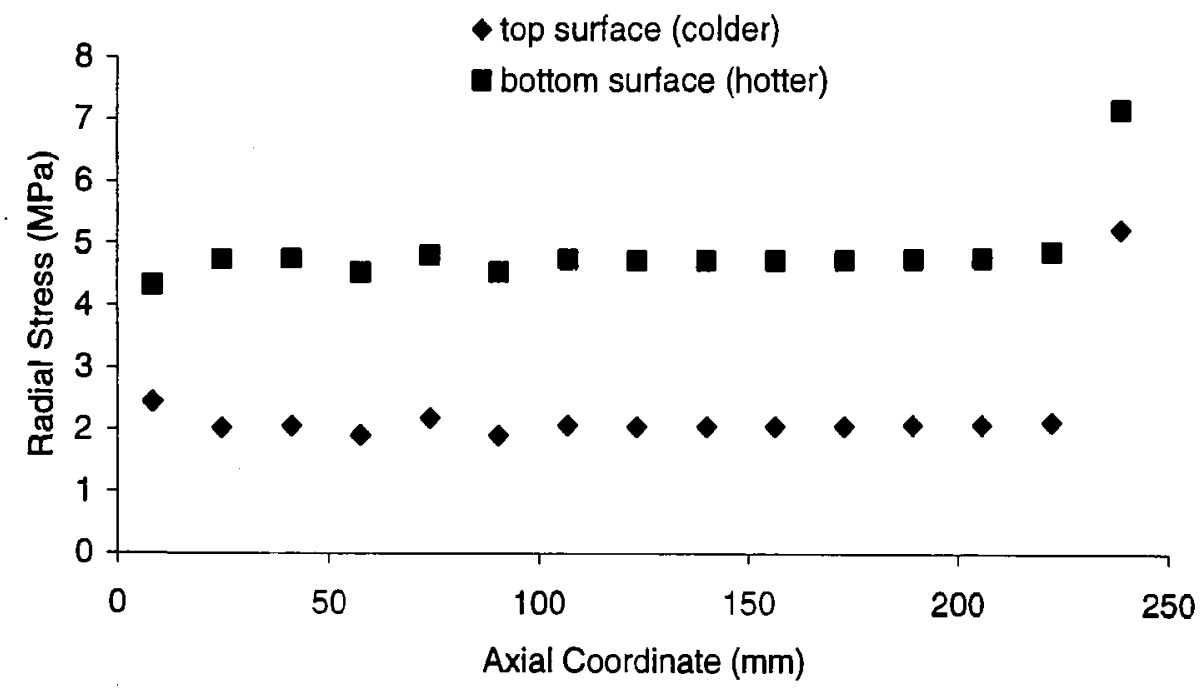

Figure 5-7 Central node radial stress distribution for axial gap 0.05mm model 


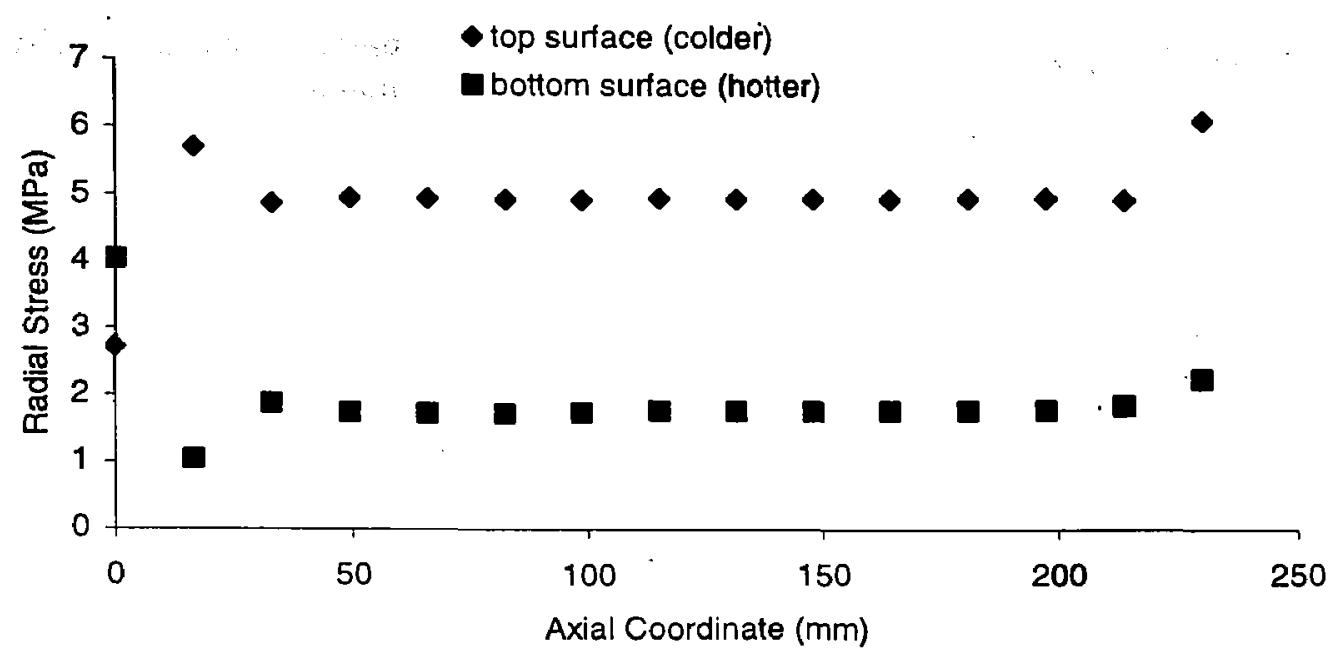

Figure 5-8 End side node radial stress distribution for axial gap $0.05 \mathrm{~mm}$ model

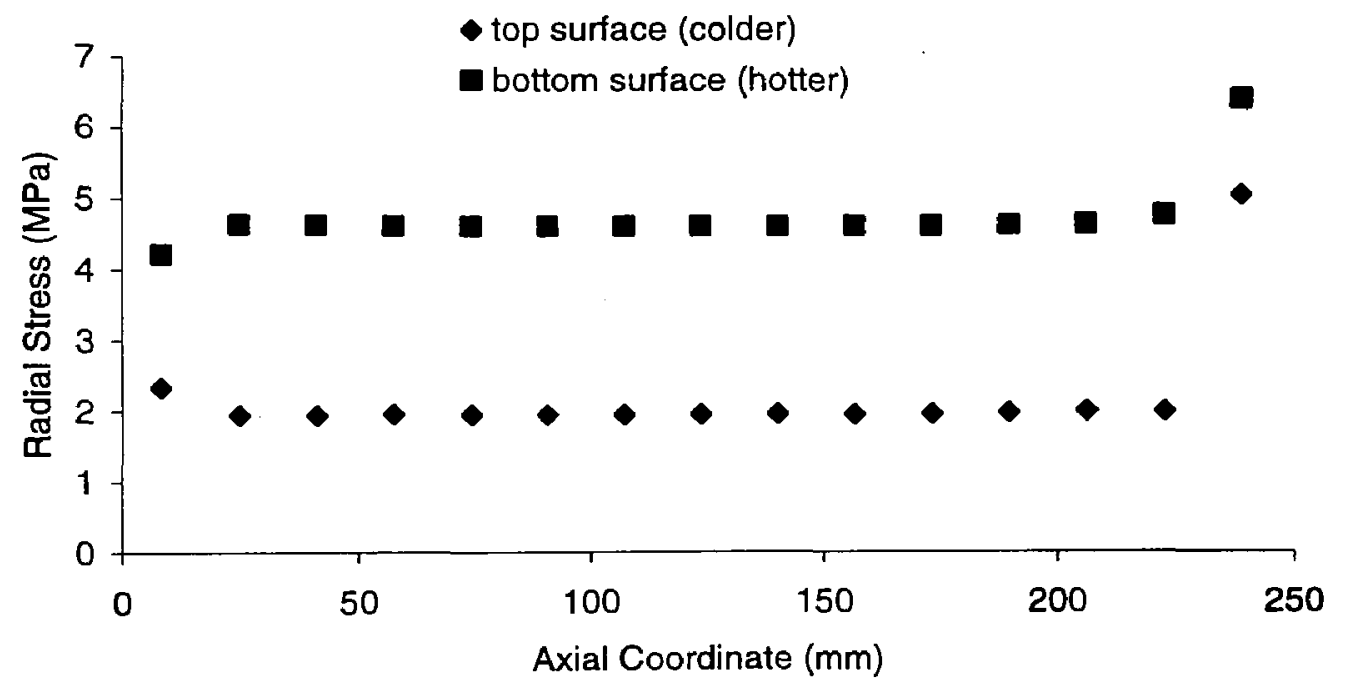

Figure 5-9 Central node radial stress distribution for axial gap $0.1 \mathrm{~mm}$ model 




Figure 5-10 End side node radial stress distribution for axial gap 0.1mm model

\subsubsection{Initial Sheath-Pellet Radial Gap}

Sensitivity studies on initial sheath-pellet radial gap are conducted on two finite element models involving zero initial pellet-pellet axial gaps, and initial sheath-pellet radial gaps are 0 and $0.005 \mathrm{~mm}$, respectively. For both models, $T_{0}$ is $443.15^{\circ} \mathrm{K}$, and $\Delta T$ is $50^{\circ} \mathrm{K}$. Figures $5-11$ and 5-12 show the radial displacement in the hotter inner surface of the sheath, and Figures 5-13 and 5-14 present comparisons of the radial stress distribution in the colder and hotter inner surfaces of the sheath.

The radial displacement decreases with increasing radial gap, as the pellets cannot come into tight contact with the sheath because of the pellet-sheath gap. Due to the small difference in magnitude of the radial gap, the difference in displacement is not significant between Figure 5-11 and Figure 5-12. 
In Figure 5-14, the stress distributions show a decreasing trend. The pellet-sheath mechanical interaction is low when the radial gap is present. As a result, under the assumptions that self-weight and friction are negligible in order to reduce the complexity of the model, the initial radial pellet-sheath gap must be limited to a much smaller value than suggested in the nuclear industry $(0.04 \mathrm{~mm})$. Moreover, the temperature $T_{0}$ should be high enough to ensure strong pellet-sheath contact may occur.

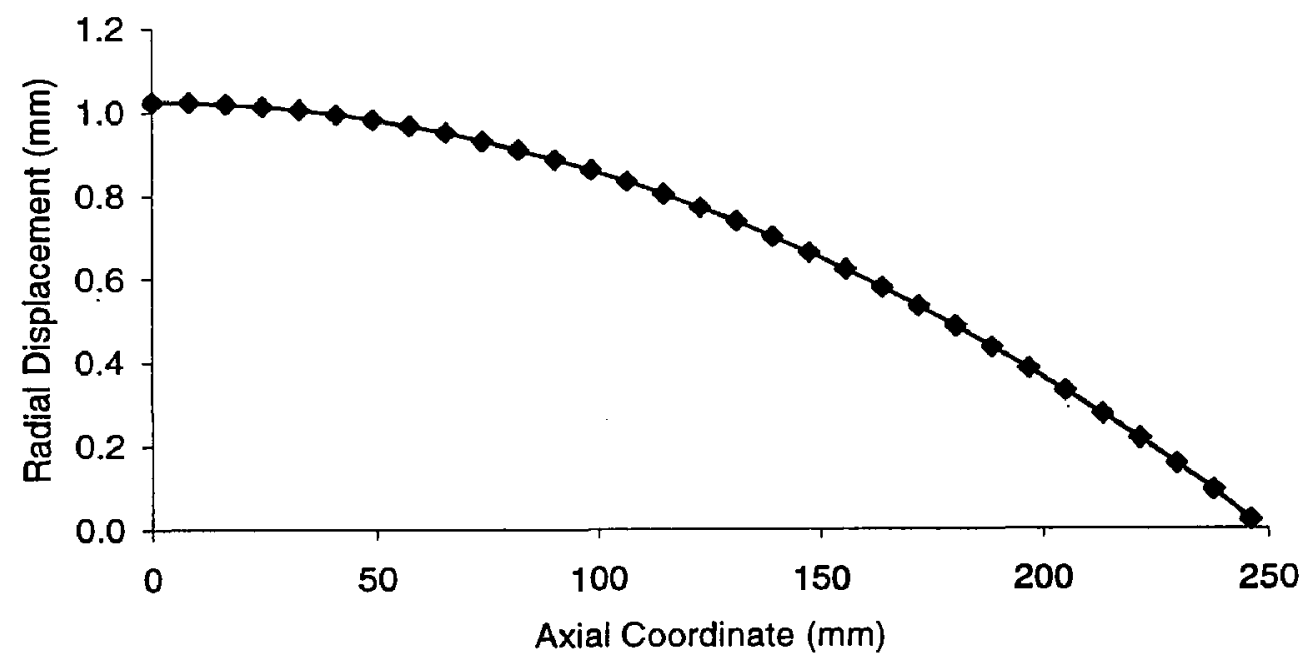

Figure 5-11 Radial displacement for non-radial gap model 


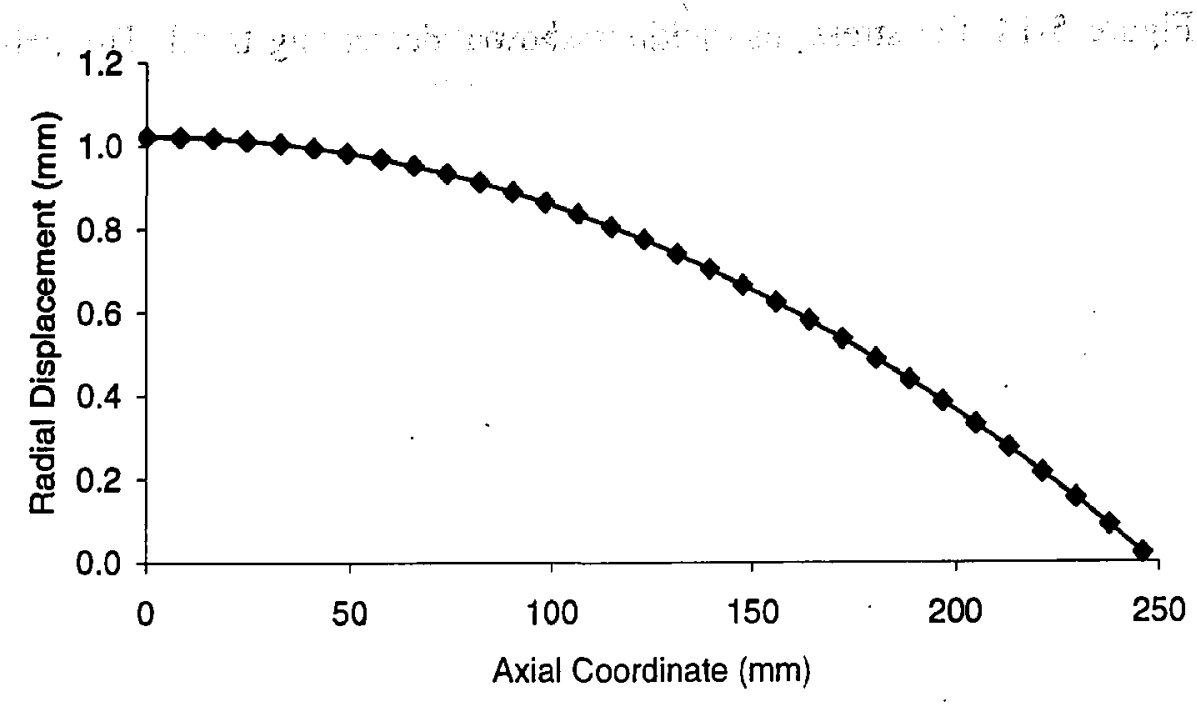

Figure 5-12 Radial displacement for radial gap 0.005mm model

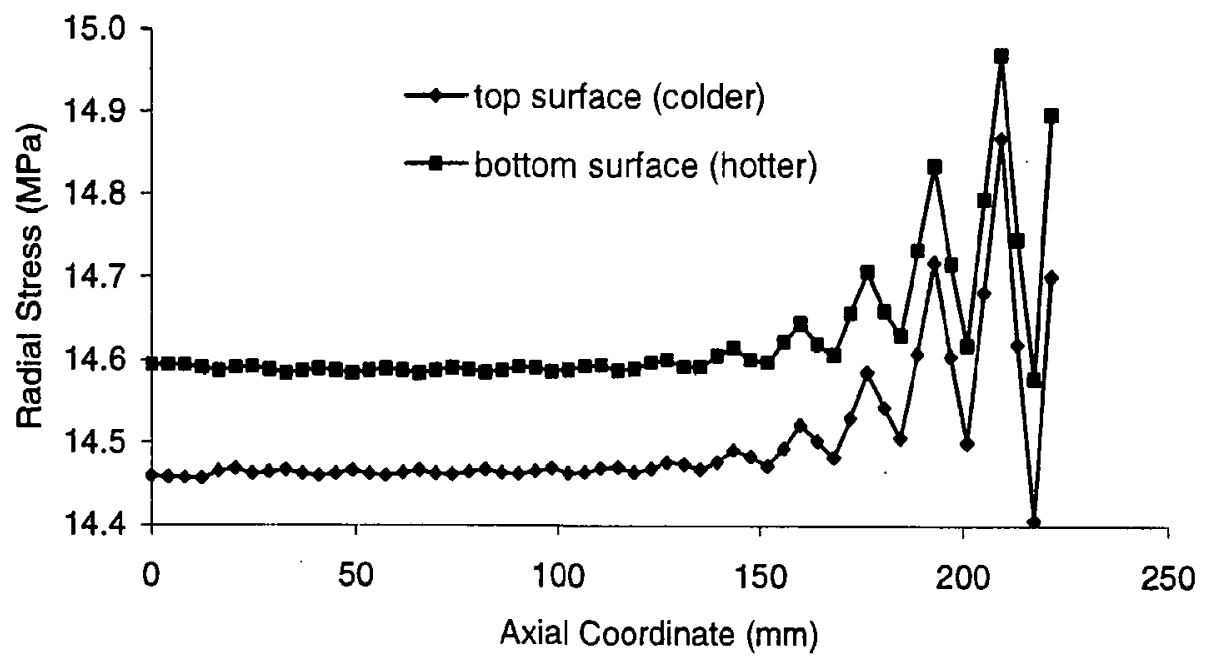

Figure 5-13 Radial stress distribution for non-radial gap model 


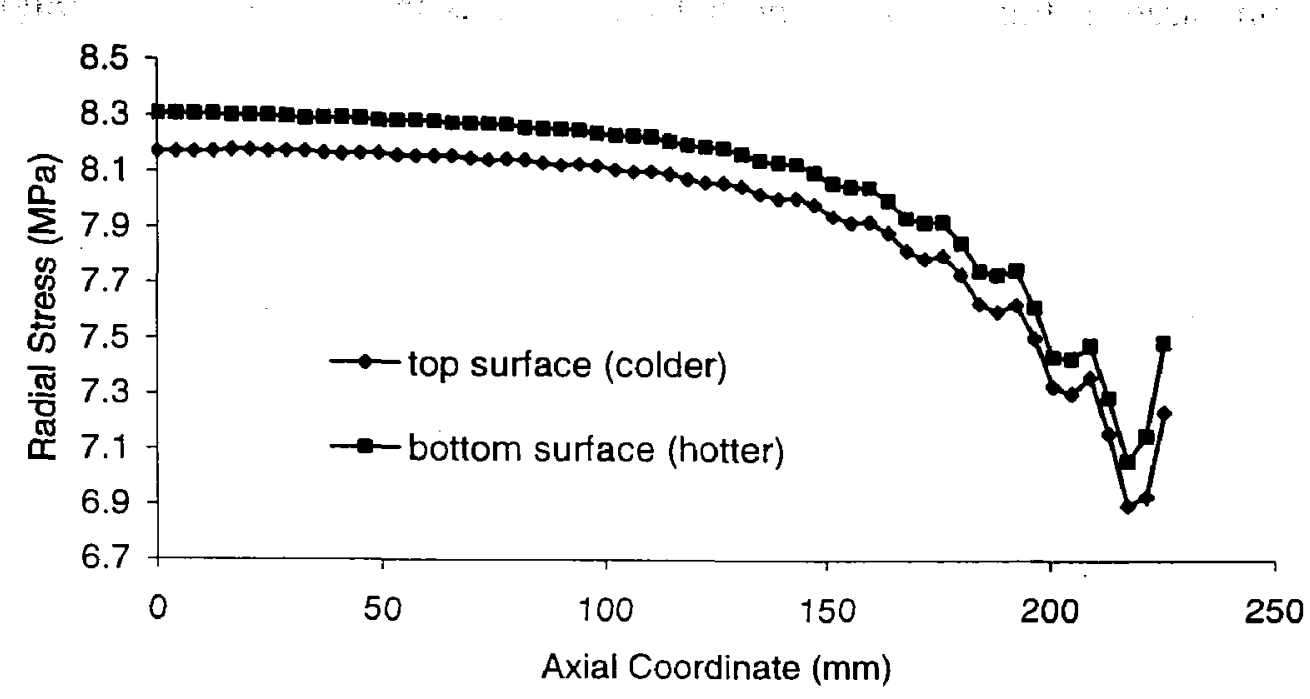

Figure 5-14 Radial stress distribution for radial gap 0.005mm model

\subsubsection{Average Pellet Volume Temperature}

Two finite element models involving average axial gaps 0 and $0.1 \mathrm{~mm}$ are taken as sensitivity study examples. In both of the models, the initial radial gaps are zero. Figures 5-15 through 5-24 show comparisons of deflection and stress distribution when the pellets experience a different average volume temperature $T_{0}$. In this study, the circumferential temperature gradient in the pellets, $\Delta T$, is held constant at $50^{\circ} \mathrm{K}$.

When $T_{0}$ increases from $343.15^{\circ} \mathrm{K}$ to $393.15^{\circ} \mathrm{K}$, as shown in Figures 5-15 and 5-16, and from $393.15^{\circ} \mathrm{K}$ to $493.15^{\circ} \mathrm{K}$, as seen in Figures $5-19$ and $5-20$, it is observed that the deflection increases slightly. This indicates that bending is not very sensitive to $T_{0}$. 
As compared in Figures 5-17 and 5-18, as well as in Figures 5-21 through 5-24, it is noted that the stress for the two individual models rises by a large value with the increase of $T_{0}$. Thus, it indicates that stress is sensitive to $T_{0}$.

Figures 5-17 and 5-18 also show a drastic change in stress in the sheath area close to the end cap.

This is because the initial radial and axial gaps are zero everywhere. Hence, the effect of the end cap on the stress is large.

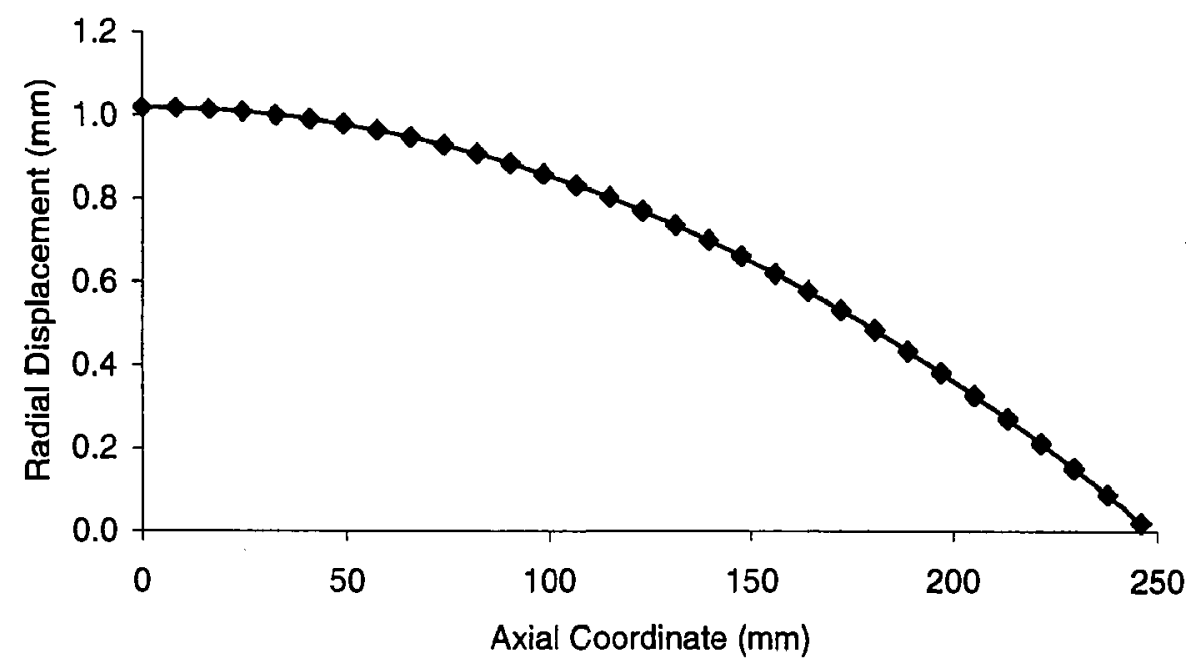

Figure 5-15 Radial Displacement for non-axial gap model $\left(T_{0}=343.15^{\circ} \mathrm{K}\right)$ 


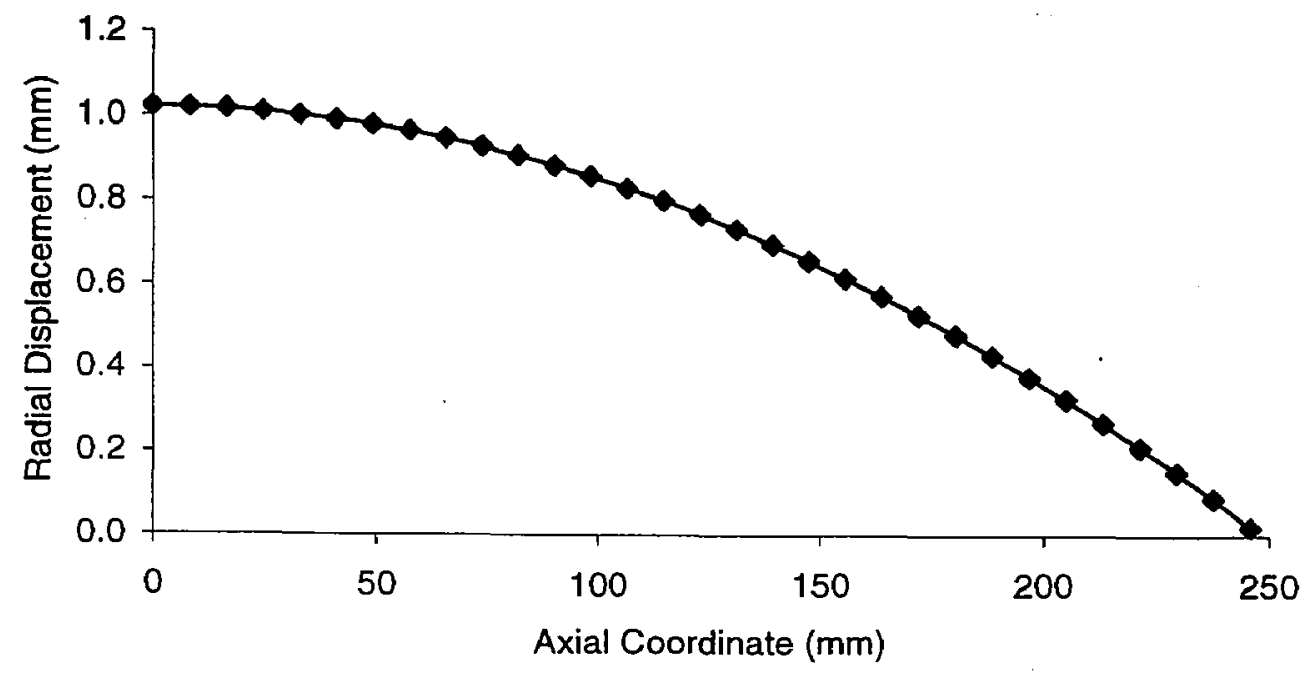

Figure 5-16 Radial displacement for non-axial gap model $\left(T_{0}=393.15^{\circ} \mathrm{K}\right)$

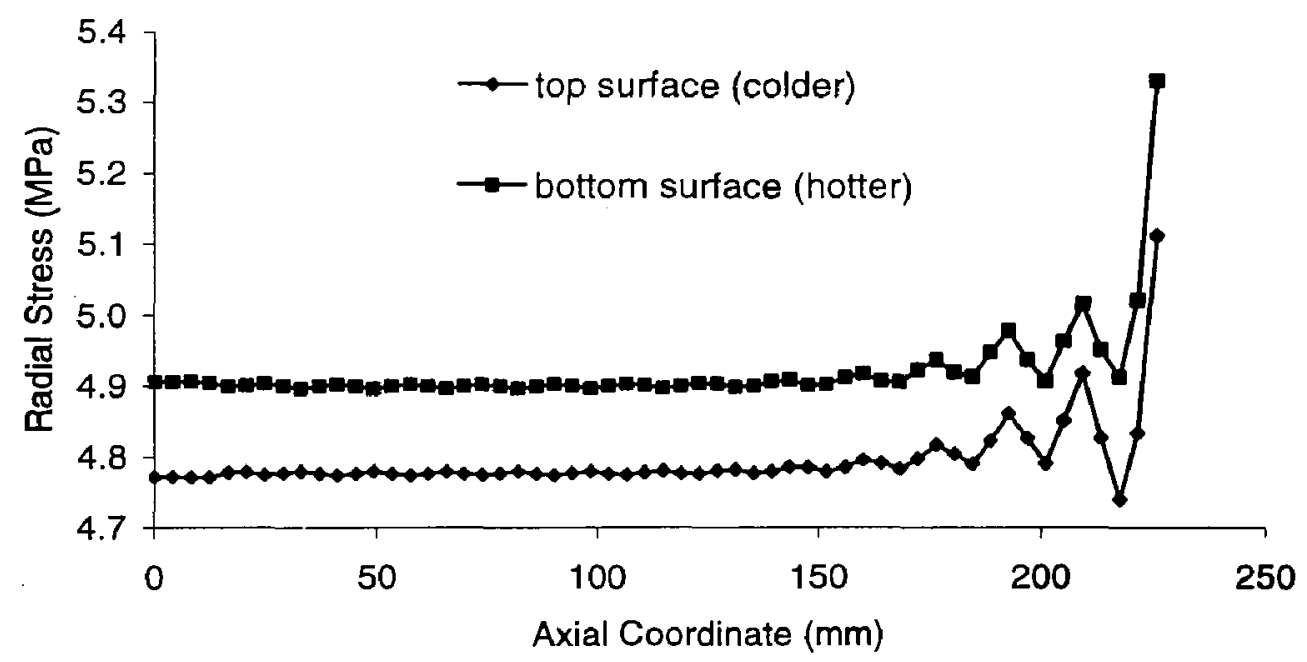

Figure 5-17 Radial stress distribution for non-axial gap model $\left(T_{0}=343.15^{\circ} \mathrm{K}\right)$ 


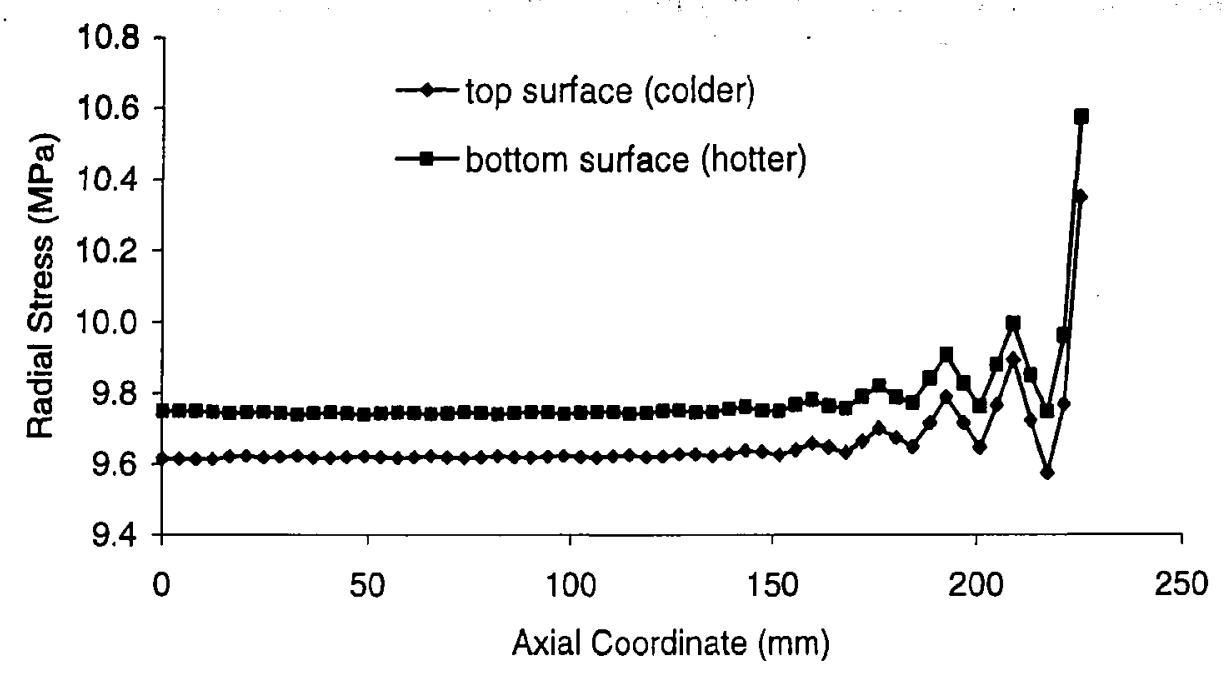

Figure 5-18 Radial stress distribution for non-axial gap model $\left(T_{0}=393.15^{\circ} \mathrm{K}\right)$

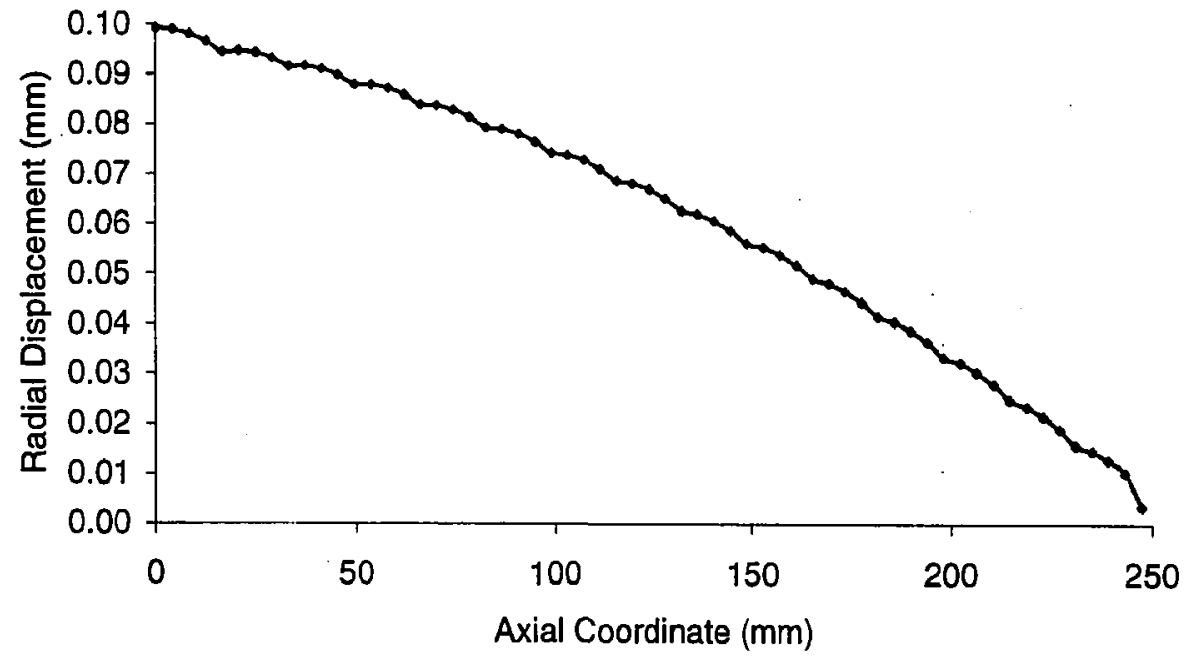

Figure 5-19 Radial displacement for axial gap $0.1 \mathrm{~mm}$ model $\left(T_{0}=393.15^{\circ} \mathrm{K}\right)$ 


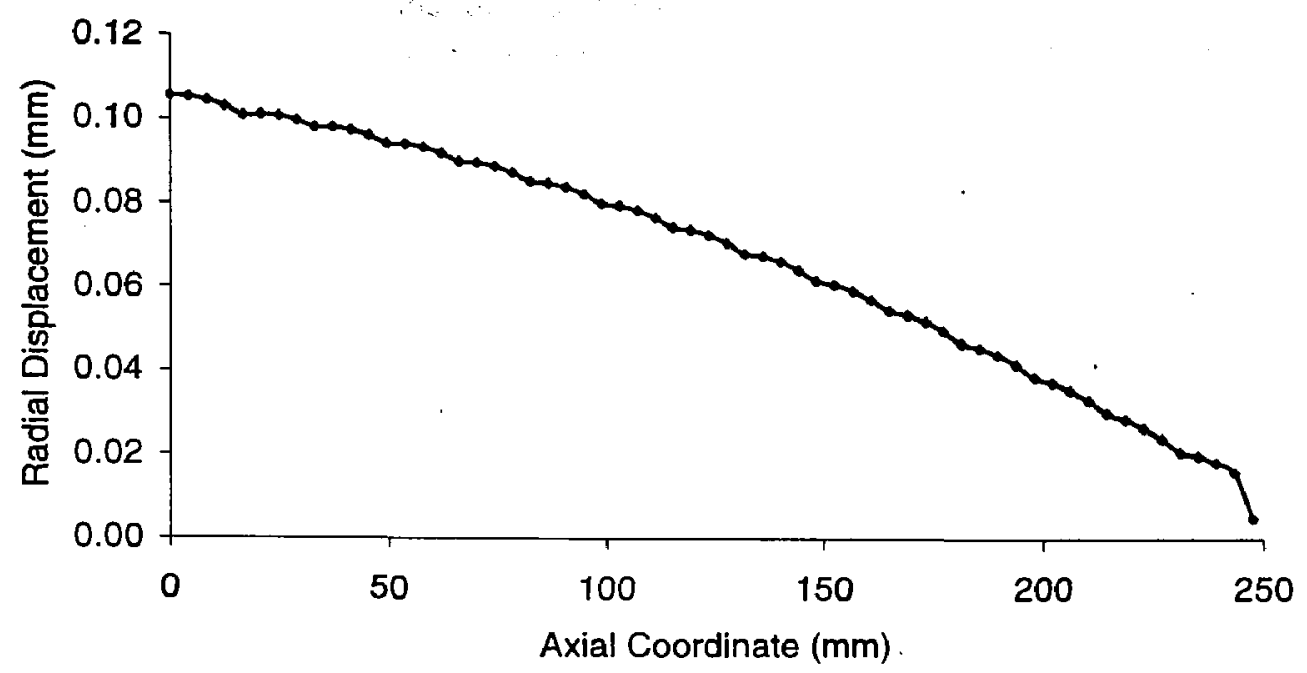

Figure 5-20 Radial displacement for axial gap $0.1 \mathrm{~mm}$ model $\left(T_{0}=493.15^{\circ} \mathrm{K}\right)$

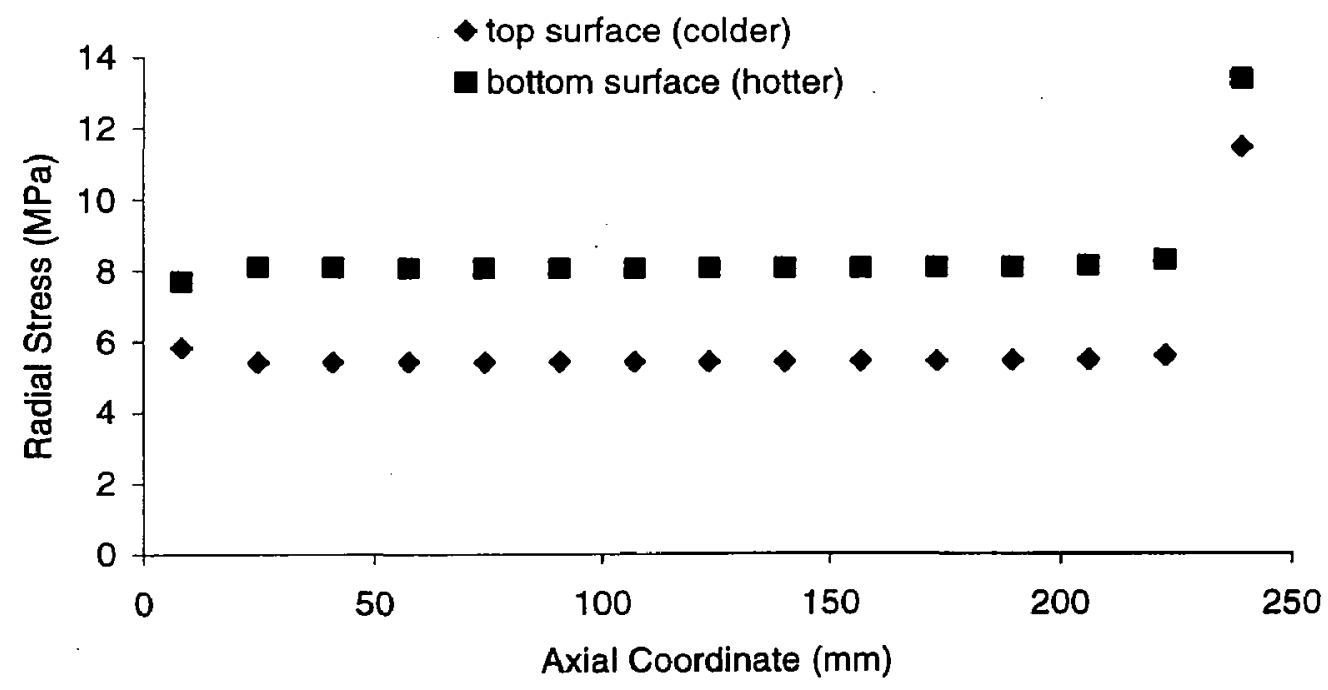

Figure 5-21 Central node radial stress distribution for axial gap $0.1 \mathrm{~mm}$ model

$$
\left(T_{0}=393.15^{\circ} \mathrm{K}\right)
$$




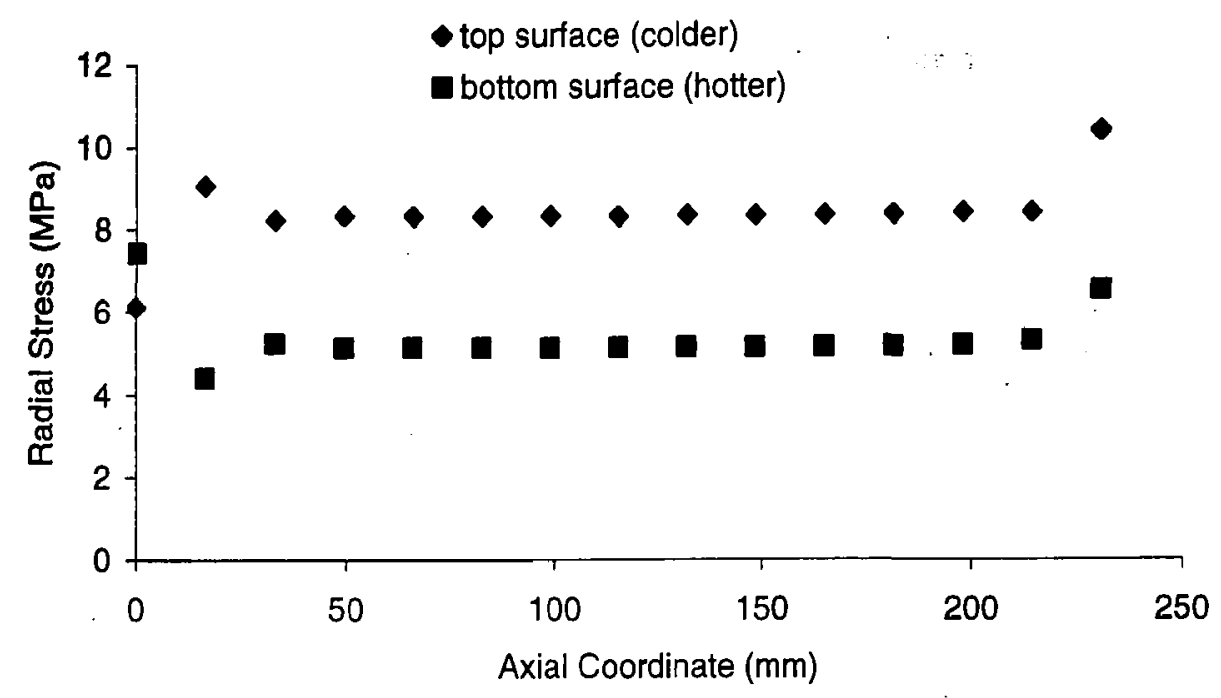

Figure 5-22 End side node radial stress distribution for axial gap 0.1mm model

$$
\left(T_{0}=393.15^{\circ} \mathrm{K}\right)
$$

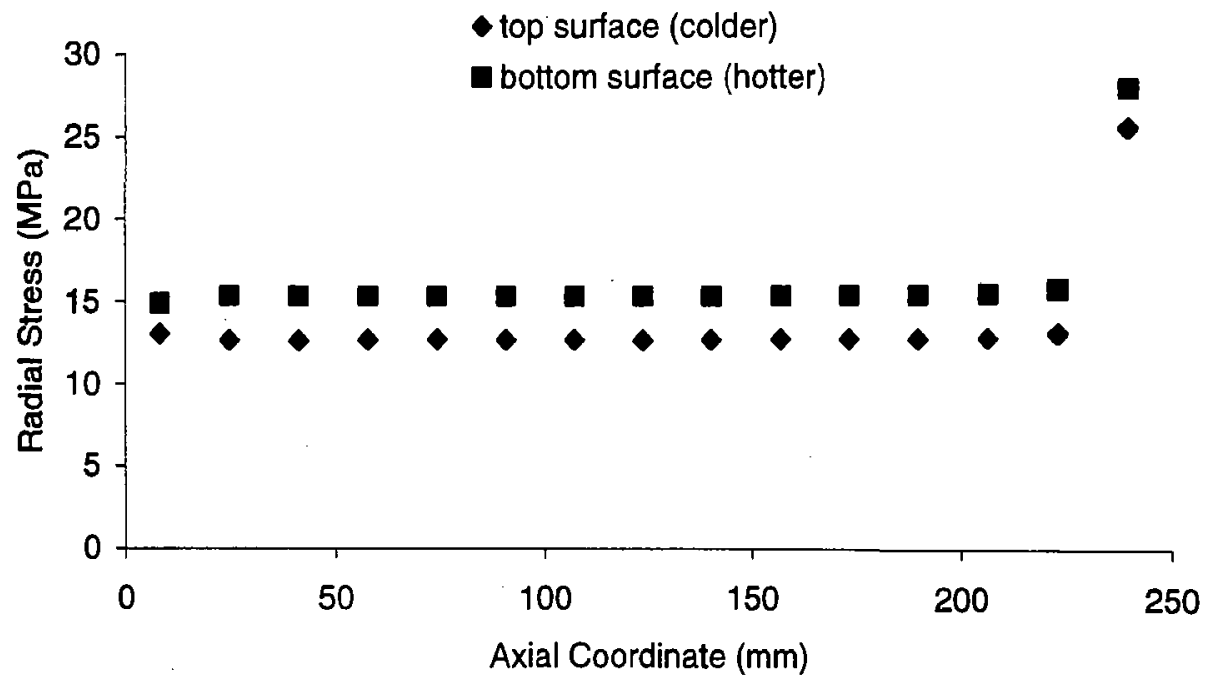

Figure 5-23. Central node radial stress distribution for axial gap $0.1 \mathrm{~mm}$ model

$$
\left(T_{0}=493.15^{\circ} \mathrm{K}\right)
$$




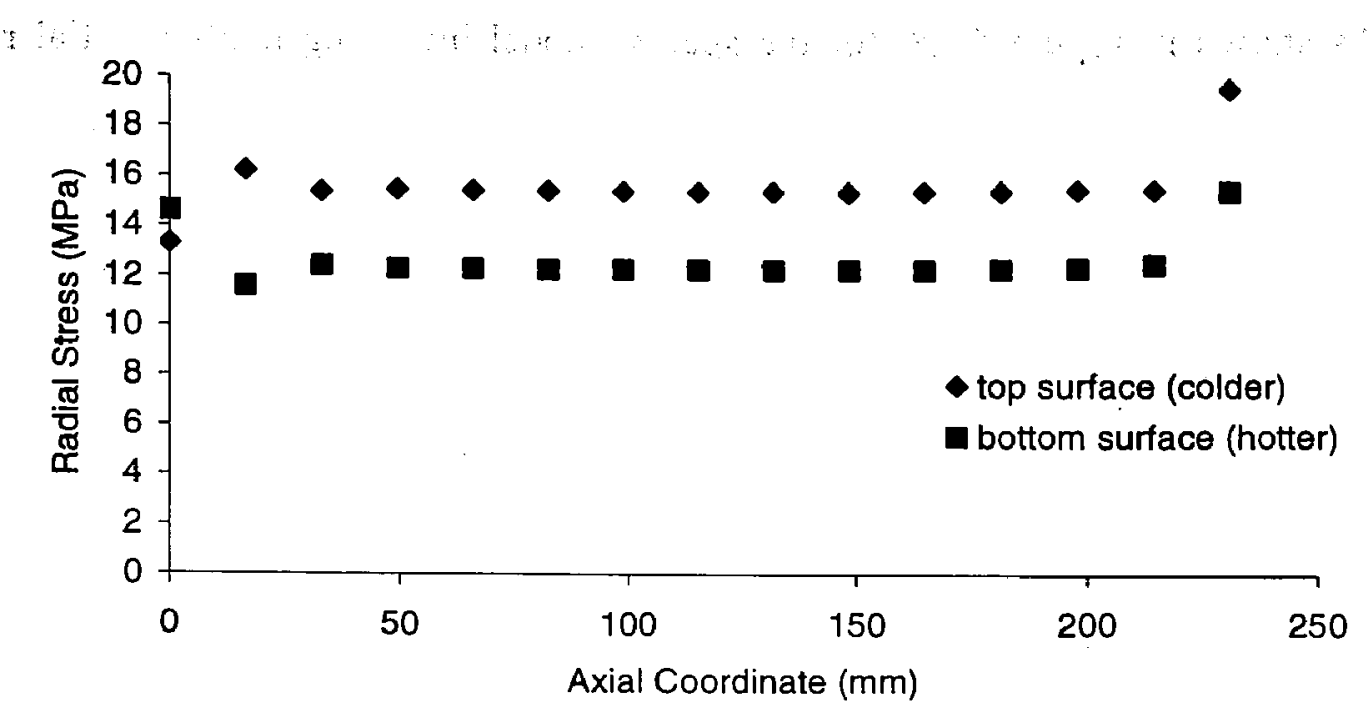

Figure 5-24 End side node radial stress distribution for axial gap $0.1 \mathrm{~mm}$ model

$$
\left(T_{0}=493.15^{\circ} \mathrm{K}\right)
$$

\subsubsection{Temperature Gradient Across Pellet Diameter}

This sensitivity study is conducted on FE models with axial gaps of 0 and $0.1 \mathrm{~mm}$. The radial gaps are zero for both models. Figures 5-25 through 5-28 present comparisons of deflection and radial stress distribution when $T_{0}$ is kept the same at $343.15^{\circ} \mathrm{K}$ and $\Delta T$ varies from $50^{\circ} \mathrm{K}$ to $100^{\circ} \mathrm{K}$. Figures 5-29 to 5-34 show deflection and radial stress distribution comparisons, for which $T_{0}$ is held at $493.15^{\circ} \mathrm{K}$ and $\Delta T$ increases from $50^{\circ} \mathrm{K}$ to $200^{\circ} \mathrm{K}$.

Jbserving results of the two independent models, it can be seen that the deflection increases ignificantly with $\Delta T$ and stress is not sensitive to $\Delta T$. 
As shown in Figure 5-28, for the special model involving neither initial radial nor initial axial gap, when $\Delta T$ is $100^{\circ} \mathrm{K}$, the bending is too much so that the first pellet keeps away from the sheath after deformation, the stress on the sheath is thus low in the segment having interaction with the first pellet. Reasonable initial pellet-sheath radial gap $(0.04 \mathrm{~mm})$ and initial pellet-pellet axial gap $(0.1 \mathrm{~mm})$ are therefore suggested in the nuclear industry to make sure a fuel element can be operated under various temperature conditions.

A sensitivity study on the temperature gradient across the pellet diameter provides the range of $\Delta T$. For the FE model involving the non-axial gap, $\Delta T$ ranges from $50^{\circ} \mathrm{K}$ to $100^{\circ} \mathrm{K}$; for the FE model with the axial gap of $0.1 \mathrm{~mm}, \Delta T$ can reach a maximum of $200^{\circ} \mathrm{K}$.

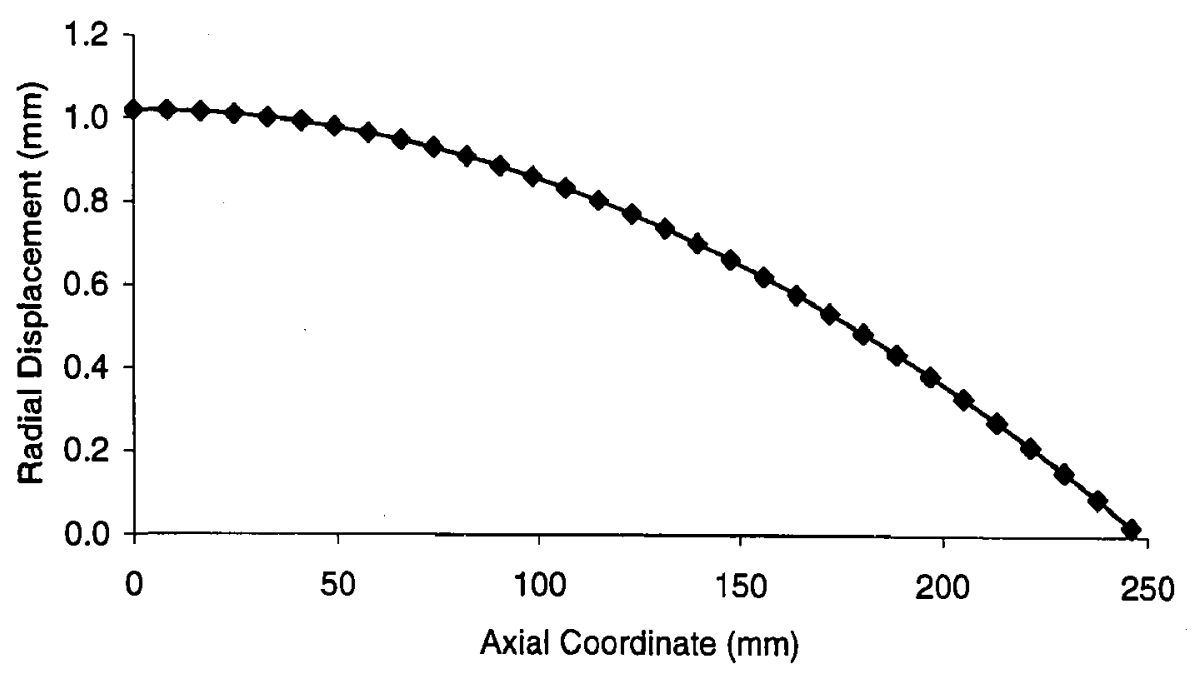

Figure 5-25 Radial displacement for non-axial gap model $\left(\Delta T=50^{\circ} \mathrm{K}\right)$ 




Figure 5-26 Radial displacement for non-axial gap model $\left(\Delta T=100^{\circ} \mathrm{K}\right)$

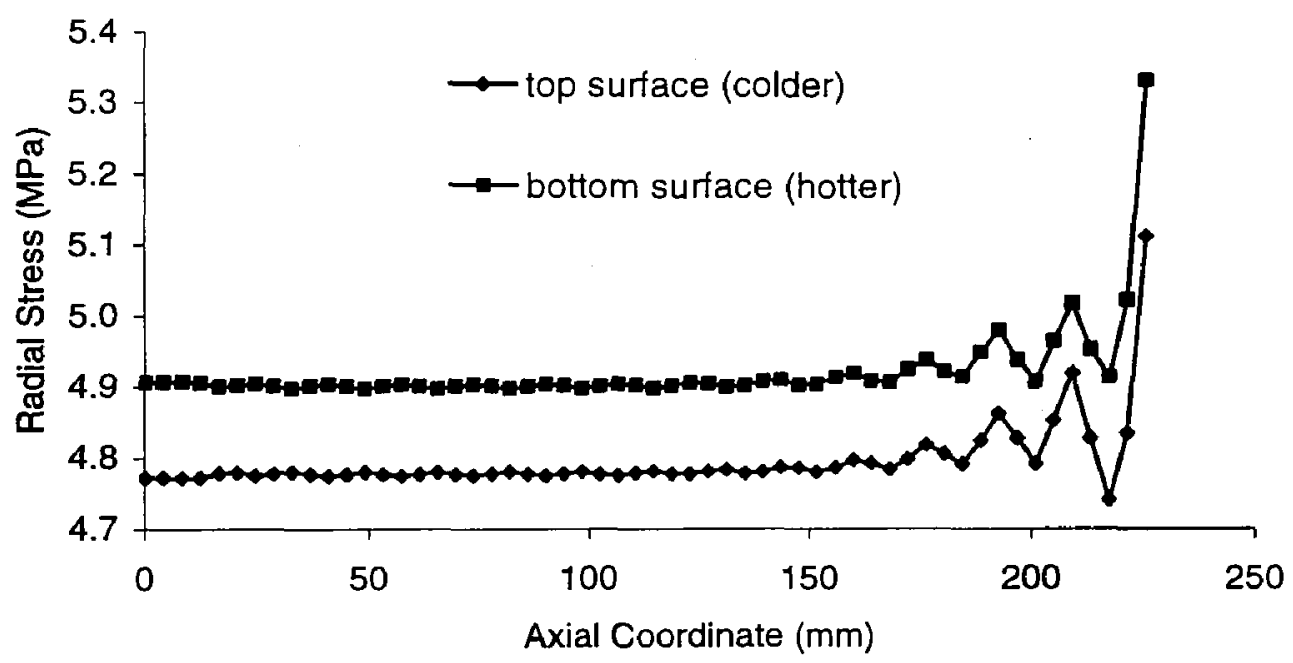

Figure 5-27 Radial stress distribution for non-axial gap model $\left(\Delta T=50^{\circ} \mathrm{K}\right)$ 


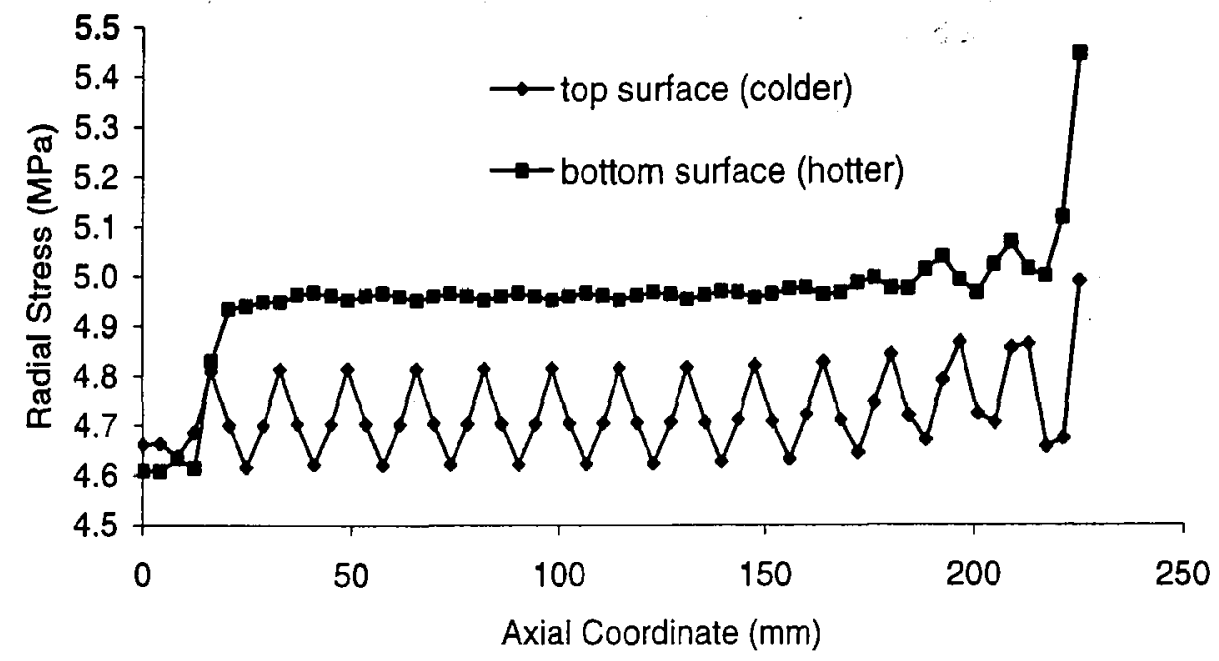

Figure 5-28 Radial stress distribution for non-axial gap model $\left(\Delta T=100^{\circ} \mathrm{K}\right)$

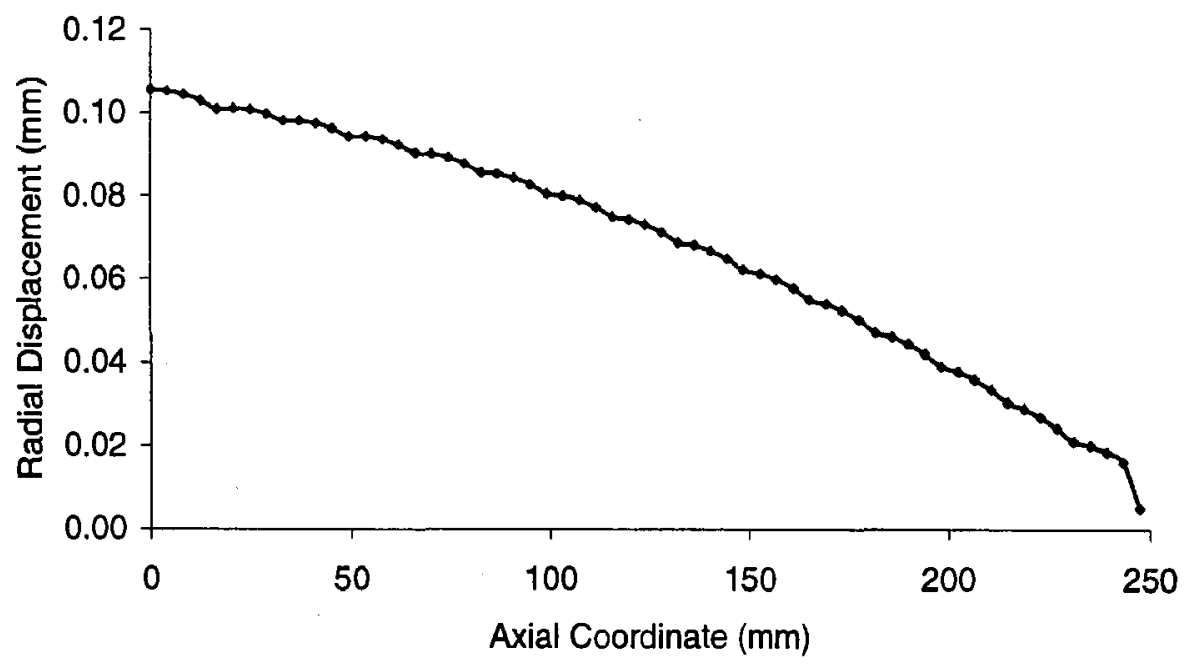

Figure 5-29 Radial displacement for axial gap $0.1 \mathrm{~mm}$ model $\left(\Delta T=50^{\circ} \mathrm{K}\right)$ 


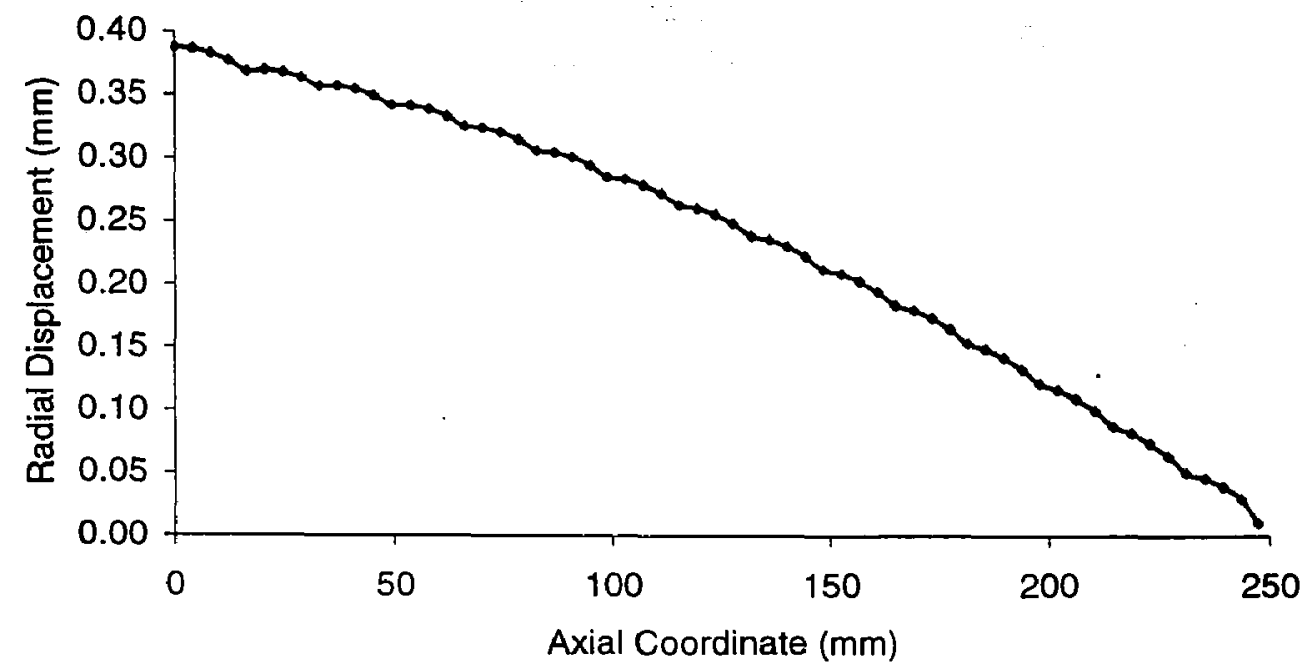

Figure 5-30 Radial displacement for axial gap $0.1 \mathrm{~mm}$ model $\left(\Delta T=200^{\circ} \mathrm{K}\right)$

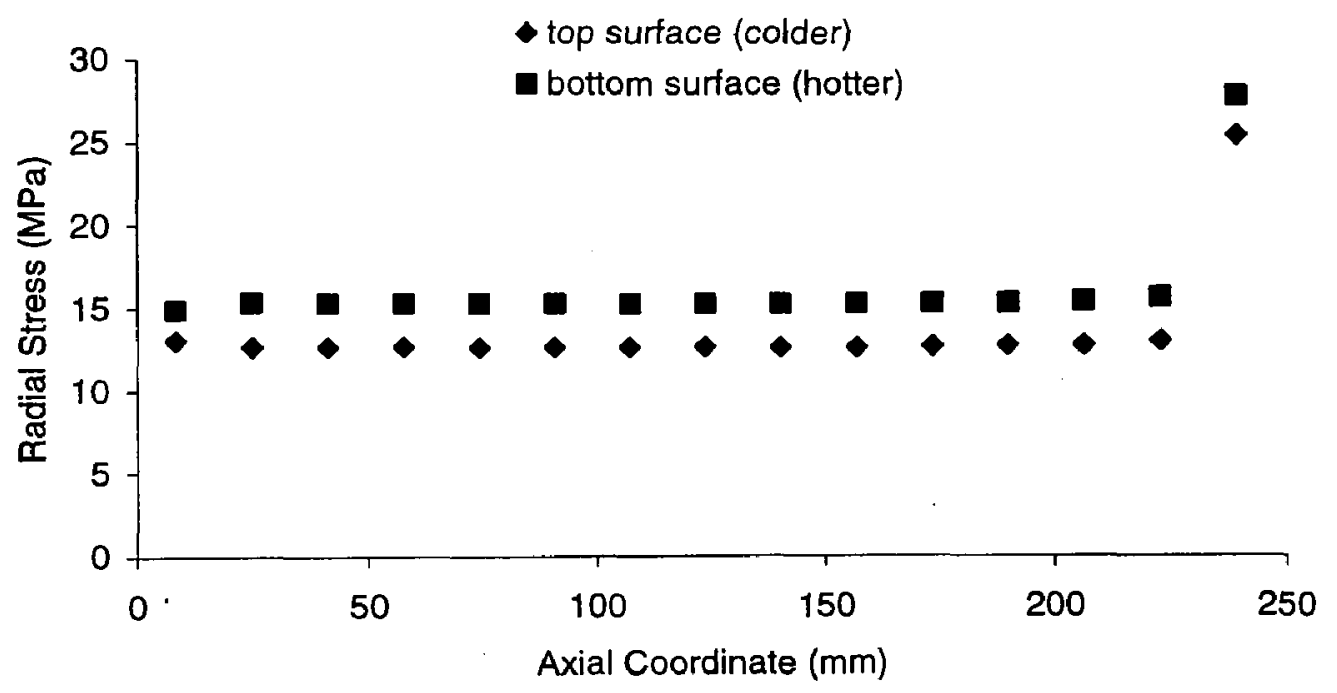

Figure 5-31 Central node radial stress distribution for axial gap 0.1 $\mathrm{mm}$ model

$$
\text { ( } \Delta T=50^{\circ} \mathrm{K} \text { ) }
$$




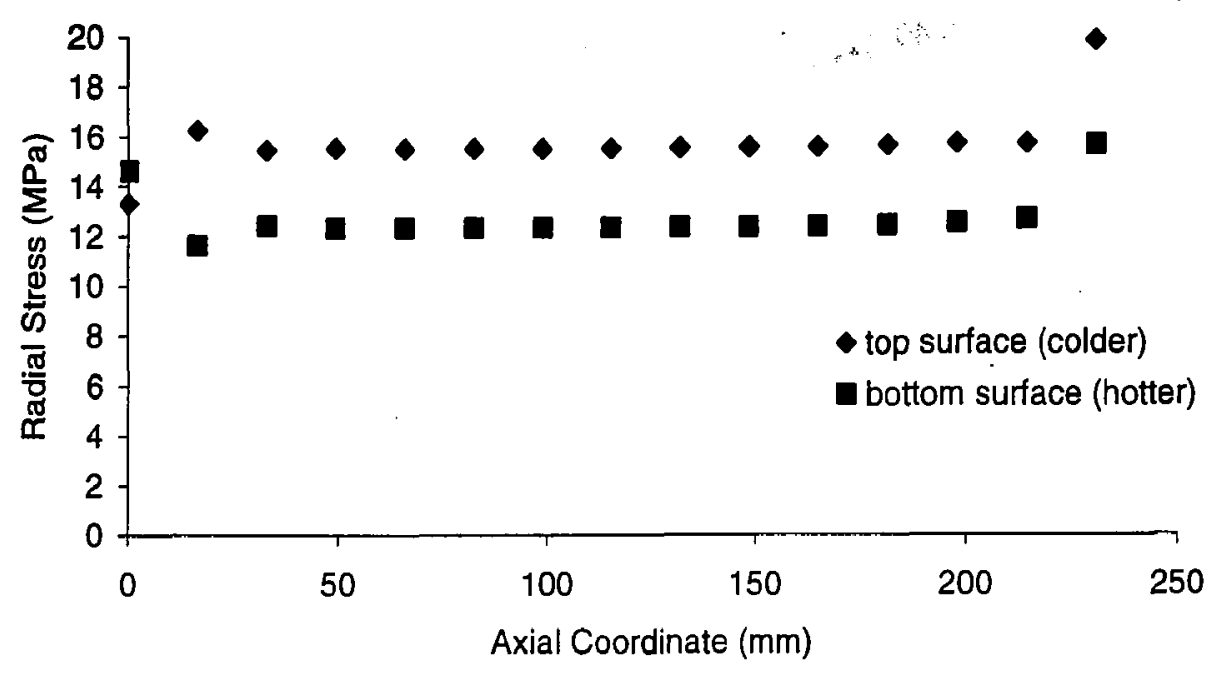

Figure 5-32 End side node radial stress distribution for axial gap 0.1mm model $\left(\Delta T=50^{\circ} \mathrm{K}\right)$

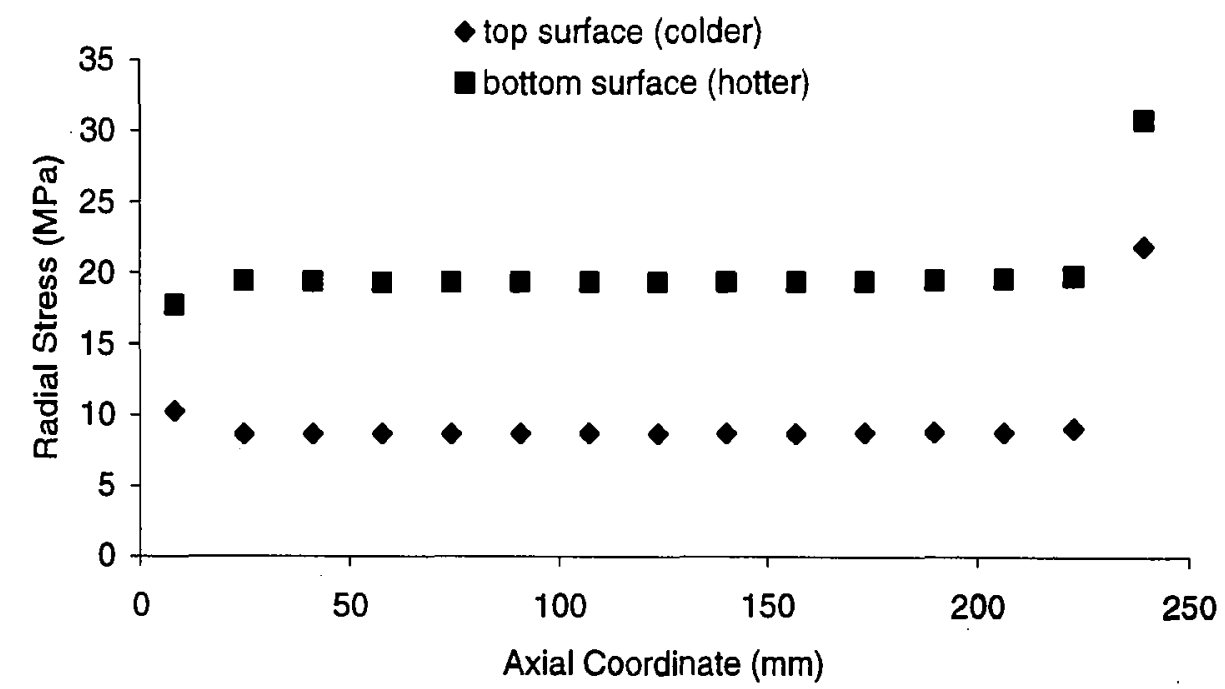

Figure 5-33 Central node radial stress distribution for axial gap 0.1 mm model $\left(\Delta T=200^{\circ} \mathrm{K}\right)$ 


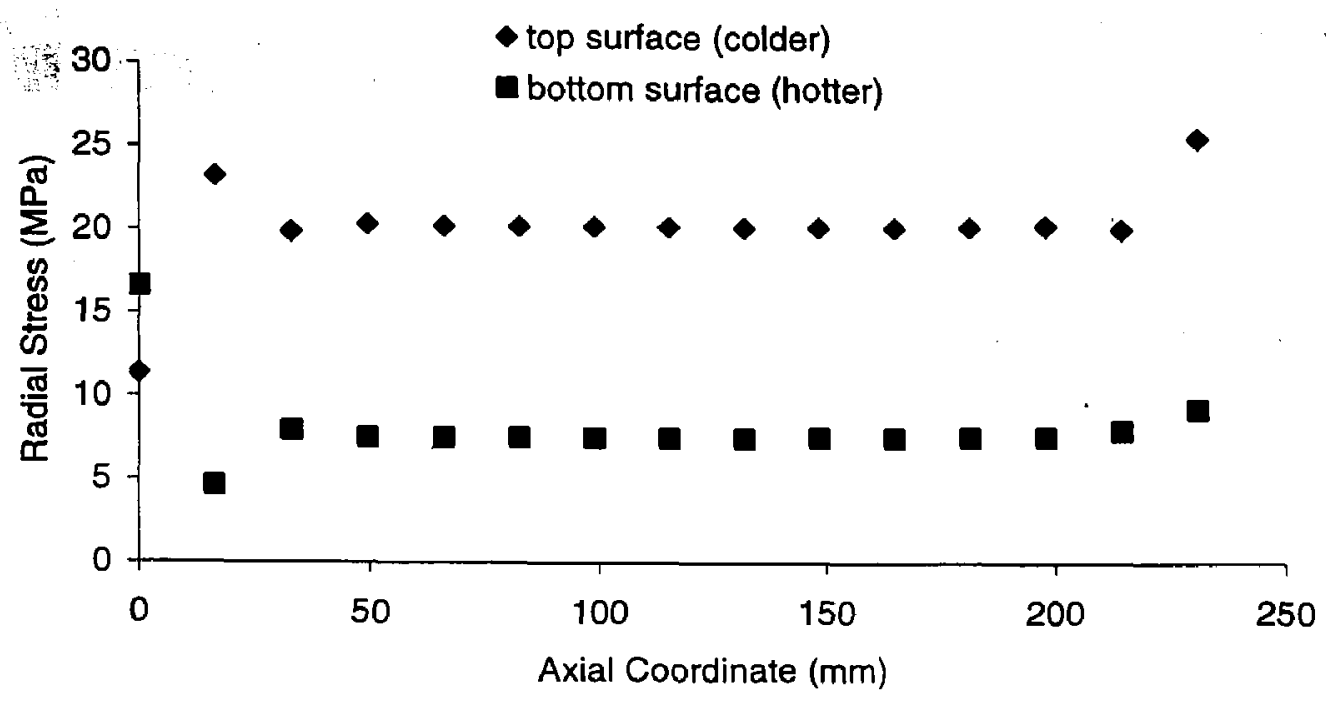

Figure 5-34 End side node radial stress distribution for axial gap 0.1 mm model

$$
\left(\Delta T=200^{\circ} \mathrm{K}\right)
$$

\subsection{Curvature Transfer Factor Curve}

The CTF is defined as the ratio of the sheath curvature to the independent pellet bending curvature. For the single pellet pure bending, it is assumed that there is no transverse shear force along its section. As the pellet bends due to a symmetric thermal load, plane sections remain plane but rotate relative to each other. Figure 5-35 illustrates a finite element mesh for the bending of a single pellet caused by the temperature gradient. Since the pellet cross-section only rotates without warping, the slope of the cross sectional plane is constant, which means that the axial deflection due to bending is linear. The axial strain must also vary linearly with zero value at the neutral axis. 


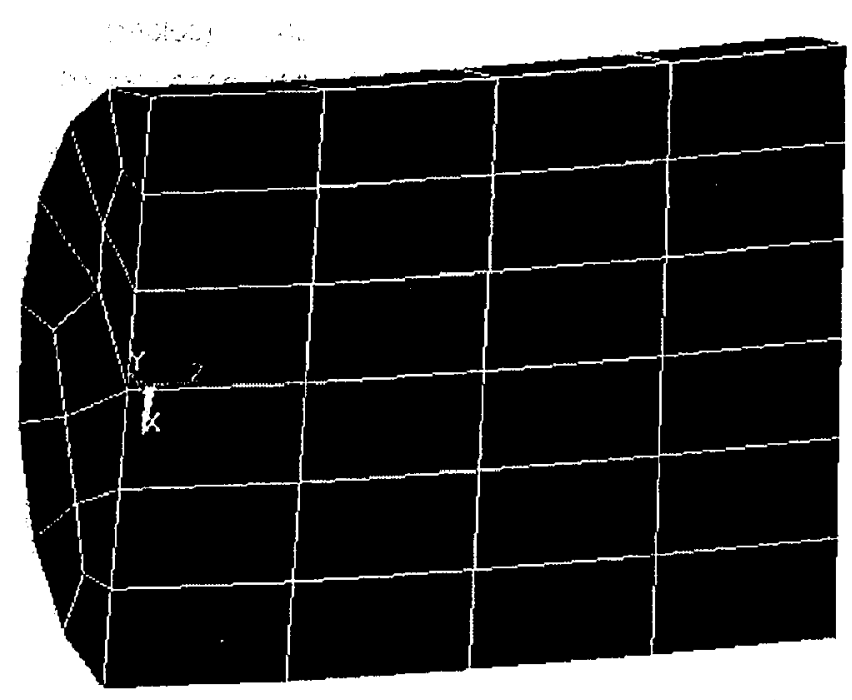

Figure 5-35 Single meshed pellet pure bending

Three sets of CTF curves are obtained and shown in Figures 5-36 through 5-38. The first two sets are conducted on a FE model involving neither initial radial gap nor initial axial gap, so that both radial and axial contacts are included. For the first set, the temperature gradient $\Delta T$ is held constant at $50^{\circ} \mathrm{K}$; and for the second set, the average volume temperature in the pellets $T_{0}$ is a constant of $343.15^{\circ} \mathrm{K}$. As a comparison, the third set is tested on a FE model involving an average axial gap of $0.1 \mathrm{~mm}$, so no axial contact is involved. The temperature gradient $\Delta T$ is held constant at $50^{\circ} \mathrm{K}$ for this model.

Radial contact pressure is dependent on average pellet volume temperature. As shown in Figures 5-36 and 5-38, if the radial contact pressure is small, the pellet bending moment can only transfer a little to the sheath. Therefore, the CTF value is small. Due to the axial contact, the CTF values in Figure 5-36 are larger than those in Figure 5-38. For the FE model with both the radial and 
axial contacts, the CTF values are almost identical with the increasing $\Delta T$, as shown in Figure 5-37.

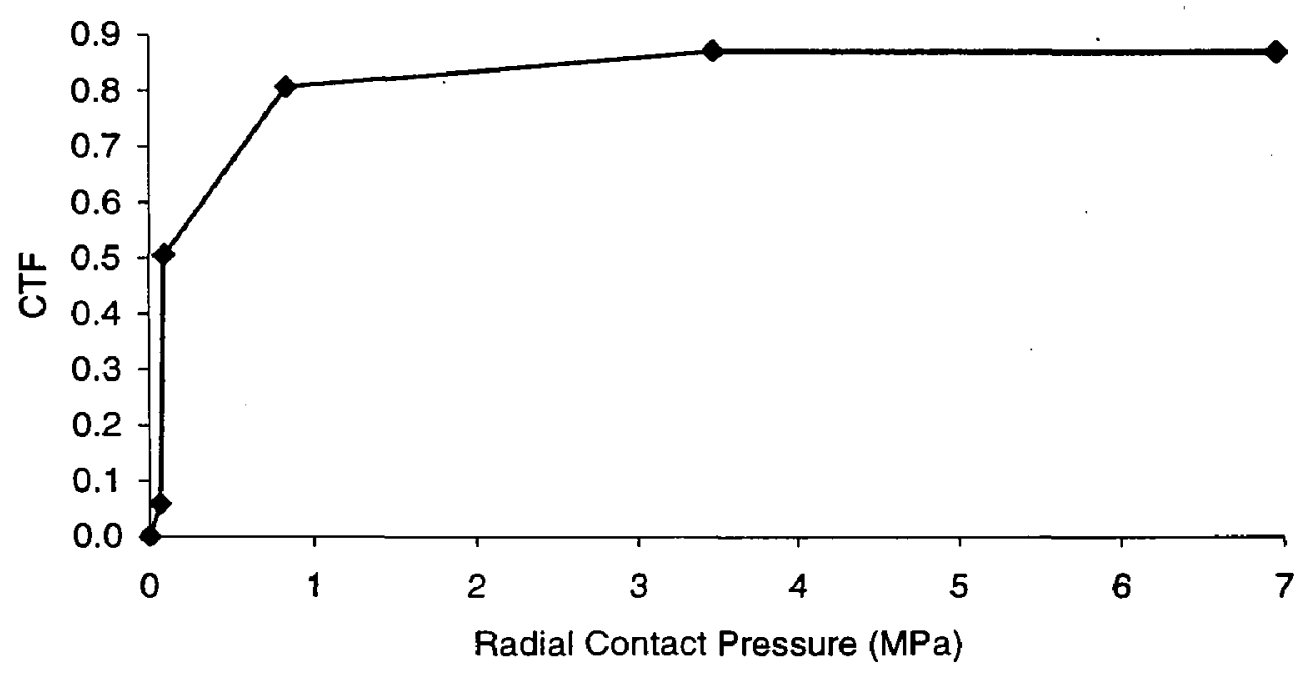

Figure 5-36 CTF curve for FE model involving neither radial nor axial gap

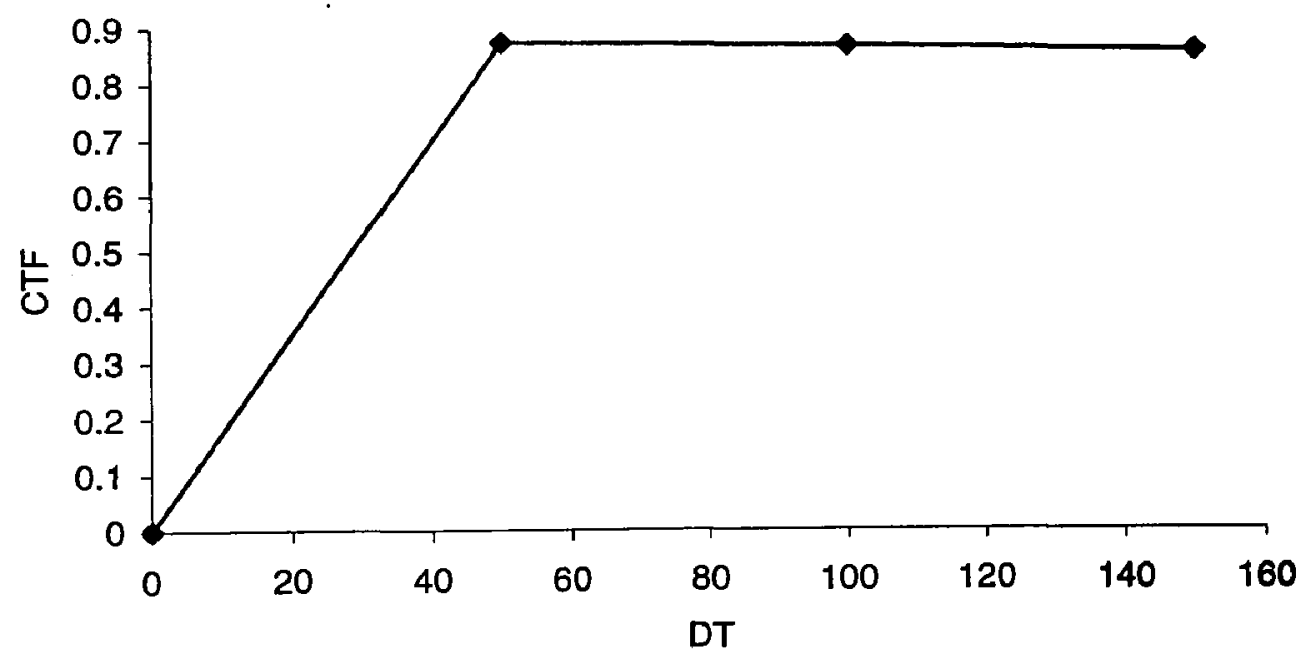

Figure 5-37 CTF values varying with $\Delta T$ for FE model involving neither radial nor axial gap 


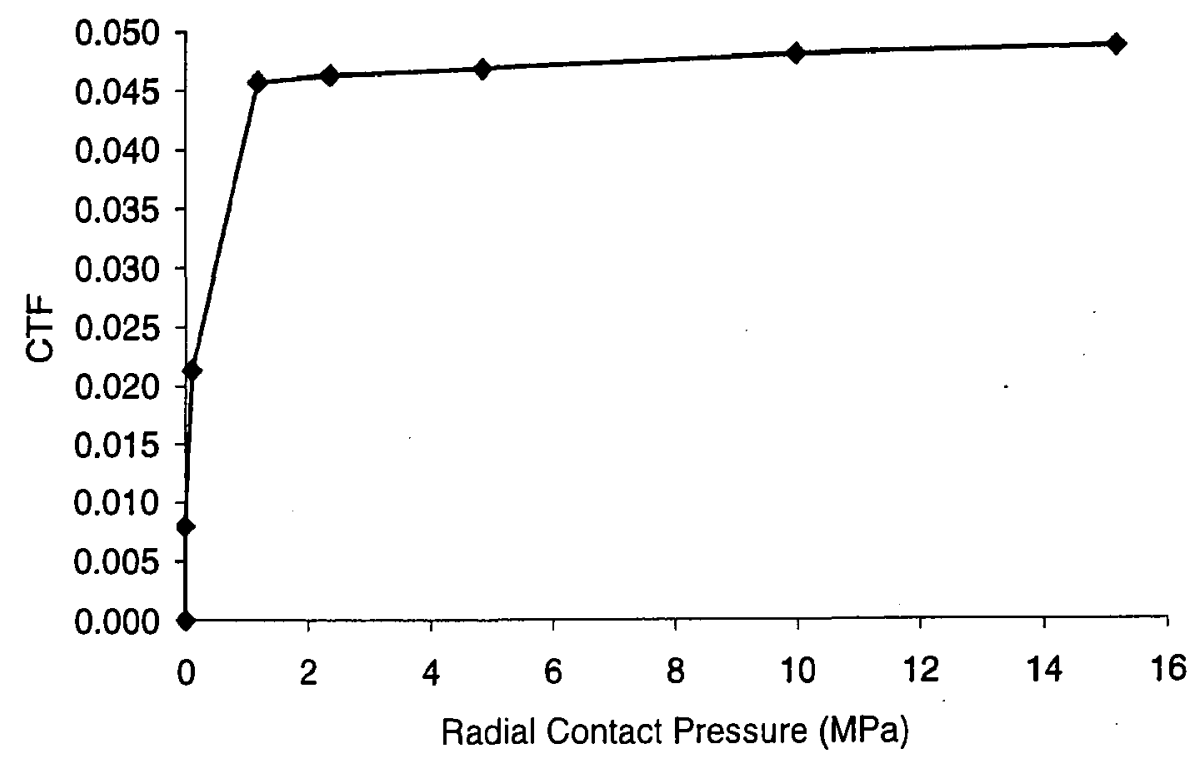

Figure 5-38 CTF curve for FE model involving axial gap $0.1 \mathrm{~mm}$

Bending curves and stress distributions for four fuel element models having various initial radial and axial gap sizes are described in this chapter. As average sheath-pellet radial contact pressure and average pellet-pellet axial contact pressure vary with four key parameters - initial pellet-pellet axial gap, initial sheath-pellet radial gap, average pellet volume temperature, and temperature gradient across pellet diameter, hence the contact pressures are not investigated independently. From the CTF curves, it is noted that under certain contact pressure, the CTF values change significantly with the contact pressures. 


\section{Chapter 6}

\section{THERMAL BENDING ANALYSIS OF A FUEL ELEMENT USING THE TIMOSHENKO BEAM THEORY}

This chapter presents a theoretical development of modeling a fuel element having zero radial gap everywhere. The Timoshenko beam theory is employed in conjunction with a three-node beam element.

\subsection{Theoretical Development}

For a Timoshenko beam, the effects of rotary inertia and shear deformation are taken into account. Consider the element of the beam shown in Figure 6-1. If the effect of shear deformation is disregarded, cross sections normal to the center line remain normal after deformation, the tangent to the deflected center line $O T$ coincides with the normal to the face $B C$. Due to shear deformation, the tangent to the deformed center line $O T$ will not be perpendicular to the face $B C$. The angle $\gamma$ between the tangent to the deformed center line $(O T)$ and the normal to the face $(O N)$ denotes the shear deformation of the element. 


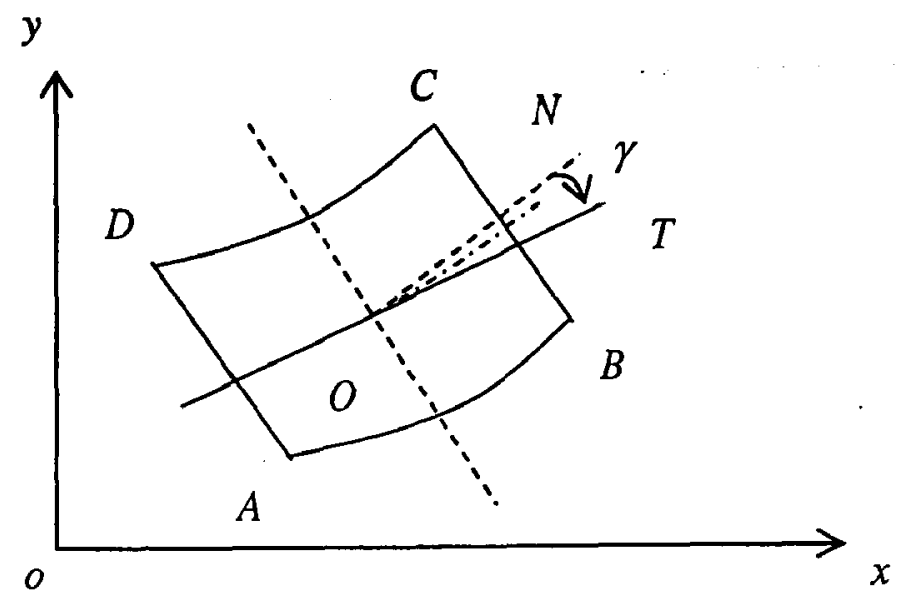

Figure 6-1 Definition of the Timoshenko beam

In dealing with thermally induced bending of a fuel element and the fuel element having one pellet missing at various locations, as shown in Figure 6-2, the finite element method and the Timoshenko beam theory are used. The equivalent thermal bending moment is applied directly to the corresponding beam element nodes. The displacement continuity and force equilibrium conditions across the interface where two different substructures are joined together can be satisfied.



Figure 6-2 A fuel element having one pellet missing

To enhance the accuracy of computed values, a three-node beam element, shown in Figure 6-3, is used. 


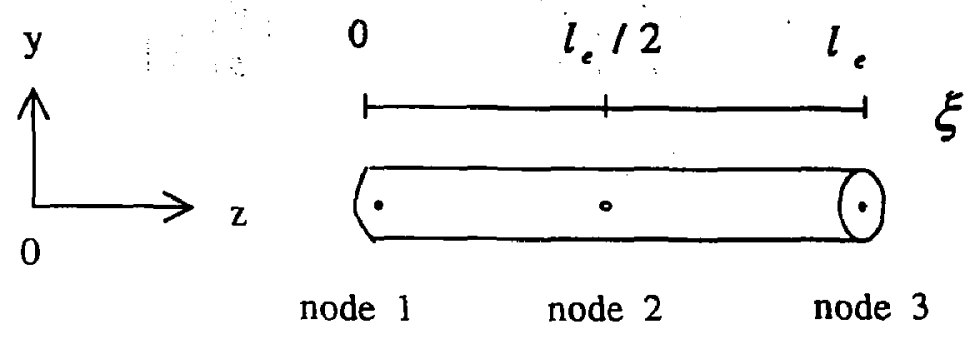

Figure 6-3 A three-node beam element

For the three-node beam element, the lateral displacement and bending angle with respect to the local coordinate are expressed as (Yu (2000)):

$$
\left\{\begin{array}{l}
u_{y} \\
\varphi_{y}
\end{array}\right\}=\left[\begin{array}{cc}
N(\xi) D_{e} & 0 \\
0 & N(\xi) D_{e}
\end{array}\right] q_{e} \quad\left(0 \leq \xi \leq l_{e}\right)
$$

where $\xi$ is the local coordinate; $N(\xi)$ is the shape function matrix; $D_{e}$ is the element geometric matrix; element displacement vector $q_{e}$ is listed as:

$$
q_{e}=\left\{\begin{array}{l}
\bar{u}_{y} \\
\bar{\varphi}_{y}
\end{array}\right\}
$$

where 


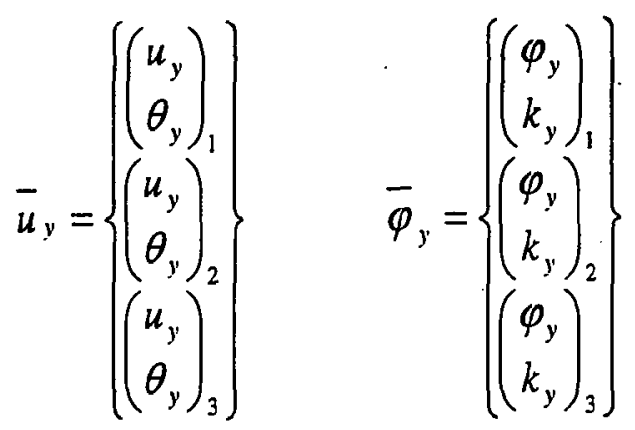

and $\theta_{y}=\frac{\partial u_{y}}{\partial z}, k_{y}=\frac{\partial \varphi_{y}}{\partial z}$.

The element displacement vector $q_{e}$ is rearranged, and is achieved by the transformation matrix

$T_{e}$ as follows:

$$
q_{e}=\left[T_{e}\right]\left\{\begin{array}{l}
q_{e, 1} \\
q_{e, 2} \\
q_{e, 3}
\end{array}\right\}
$$

\section{where}

$$
\left[T_{e}\right]=\left[\begin{array}{llllllllllll}
1 & 0 & 0 & 0 & 0 & 0 & 0 & 0 & 0 & 0 & 0 & 0 \\
0 & 1 & 0 & 0 & 0 & 0 & 0 & 0 & 0 & 0 & 0 & 0 \\
0 & 0 & 0 & 0 & 1 & 0 & 0 & 0 & 0 & 0 & 0 & 0 \\
0 & 0 & 0 & 0 & 0 & 1 & 0 & 0 & 0 & 0 & 0 & 0 \\
0 & 0 & 0 & 0 & 0 & 0 & 0 & 0 & 1 & 0 & 0 & 0 \\
0 & 0 & 0 & 0 & 0 & 0 & 0 & 0 & 0 & 1 & 0 & 0 \\
0 & 0 & 1 & 0 & 0 & 0 & 0 & 0 & 0 & 0 & 0 & 0 \\
0 & 0 & 0 & 1 & 0 & 0 & 0 & 0 & 0 & 0 & 0 & 0 \\
0 & 0 & 0 & 0 & 0 & 0 & 1 & 0 & 0 & 0 & 0 & 0 \\
0 & 0 & 0 & 0 & 0 & 0 & 0 & 1 & 0 & 0 & 0 & 0 \\
0 & 0 & 0 & 0 & 0 & 0 & 0 & 0 & 0 & 0 & 1 & 0 \\
0 & 0 & 0 & 0 & 0 & 0 & 0 & 0 & 0 & 0 & 0 & 1
\end{array}\right]
$$






The element stiffness matrix is calculated as:

$$
\left.k_{e}=\left[T_{e}\right]^{T}\left[\bar{k}_{e}\right] T_{e}\right]
$$

where $\left[\bar{k}_{e}\right]$ is given in $\mathrm{Yu}(2000)$.

Across the interface between two adjacent substructures with different cross-sectional areas, as shown in Figure 6-4, displacement continuity and force equilibrium conditions have to be satisfied according to Yu (2000).



Figure 6-4 Illustration of two adjacent substructures

On the common node $n$, the stiffness matrix for the substructure 1 is divided as: 


$$
\left[\begin{array}{ll}
K_{11}^{1} & K_{12}^{1} \\
K_{21}^{1} & K_{22}^{1}
\end{array}\right]
$$

and for the substructure 2 is divided as:

$$
\left[\begin{array}{ll}
K_{11}^{2} & K_{12}^{2} \\
K_{21}^{2} & K_{22}^{2}
\end{array}\right]
$$

The global stiffness matrix for the two substructures is determined as follows:

$$
[K]=\left[\begin{array}{ccc}
K_{11}^{1} & K_{12}^{1} & 0 \\
K_{21}^{1} & K_{22}^{1}+C^{T} K_{11}^{2} C & C^{T} K_{12}^{2} \\
0 & K_{21}^{2} C & K_{22}^{2}
\end{array}\right]
$$

where

$$
\mathrm{C}=\left[\begin{array}{cccc}
1 & 0 & 0 & 0 \\
0 & \alpha & 1-\alpha & 0 \\
0 & 0 & 1 & 0 \\
0 & 0 & 0 & \beta
\end{array}\right]
$$

and $\alpha=\frac{(G A)_{1}}{(G A)_{2}}, \beta=\frac{(E I)_{1}}{(E I)_{2}}$.

\subsection{Numerical Results}

A typical fuel element contains 30 pellets. When investigating the thermal bending behaviors of a fuel element with one pellet missing at various locations, the bending moment (obtained in 
Chapter 4 for composite beam bending) is applied on each pellet except the place where the pellet is missing and only the sheath is left, because the pellets are used to transmit bending moment. In this analysis, $\Delta T$ is chosen as $50^{\circ} \mathrm{K}$.

The bending deformation is obtained and compared in Figure 6-6. The stars in the figure denote the locations of the missing pellet. It is observed that when there is one pellet missing, the deformation is less than that of a fuel element with no pellet missing; when the location of the missing pellet moves from left to the middle, the bending deformation reduces gradually.



Figure 6-5 Bending moment left when one pellet is missing

The phenomena in Figure 6-6 may be explained as follows. When there is single pellet missing, he bending moments applied on the fuel element are as shown in Figure 6-5, and all of the other sending moments applied on each pellet are crossed out. The bending moment is applied hroughout the axial length of the fuel element except the length where a pellet is not there. As a esult, the bending moment is less, so the whole deformation lessens. What's more, the larger the atio of the two bending segment length (length $2 /$ length 1 ), the larger the final deformation. 


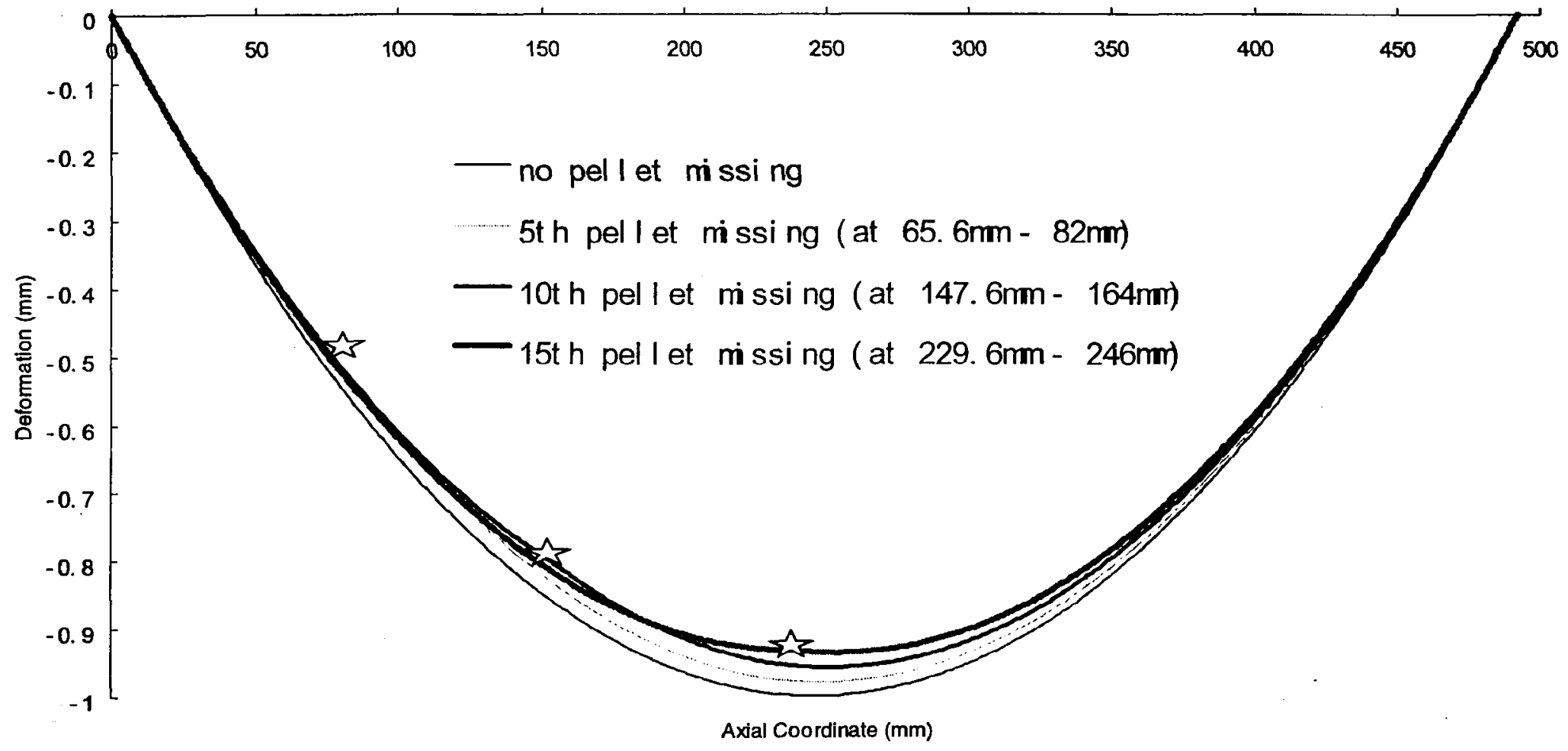

Figure 6-6 Comparison of deformations with pellet missing at various locations 


\section{Chapter 7}

\section{CONCLUSIONS AND FUTURE WORK}

\subsection{Conclusions}

Three-dimensional finite element analyses of CANDU fuel elements are carried out using ANSYS and MATLAB in this thesis. These analyses involve investigations on three-dimensional thermomechanical, large-scale multibody contact and curvature transfer factor problems. Contact pressures, stresses and displacements are determined based on the given temperature profiles applied on fuel element models. Thermal bending behaviors for a fuel element are obtained and compared.

Three idealized FE models involving one or two pellets are first created to validate the radial contact, axial contact and contact pair between two pellets. The models are verified against three independent analytical solutions for pellets subjected to different loads and constraints. The test results demonstrate the feasibility of ANSYS and the modeling techniques.

An analytical solution concerning bending of a composite beam is derived and compared with he ANSYS solution for a fuel element involving neither initial radial gap nor initial axial gap. The key assumption for this case is that gaps everywhere must be initially zero and remain zero after the application of thermal loads. Good agreement between the ANSYS and analytical solutions is observed. 
The CTF values obtained under various operational conditions provide some guidance concerning the amount of bending of pellets due to temperature gradients that is transferred to the sheath through contacts. CTF curves demonstrate the trend of CTF values varying with radial contact pressure. Under certain contact pressure, the CTF values change significantly with the contact pressures. After the radial contact pressure increases to a certain value, the CTF curve becomes smooth.

Series of sensitivity studies on the curvature transfer factor for several key geometric and operational parameters - initial radial gap and initial axial gap, average pellet volume temperature and temperature gradient - show that initial axial gap and circumferential temperature gradient are the major factors affecting bending. Initial pellet-sheath radial gap is small to avoid too much slippage between the pellets and sheath. Bending is not sensitive to the initial radial gap due to its small value, and high pellet-sheath mechanical interaction may still occur. Sensitivity studies also show that ANSYS is applicable to some special situations, converged results are failed to yield in some situations when larger radial gaps are involved or large circumferential temperature gradients are applied on the fuel element model with zero gaps everywhere.

The Timoshenko beam theory, in conjunction with a three-node beam element, is used to analyze thermal deformation of a fuel element with one pellet missing at various locations. The results show that when there is one pellet missing, the deformation is less than that of fuel element with 
no pellet missing. When the location of the missing pellet moves from left to the middle, the bending deformation reduces gradually.

\subsection{Future Work}

Future development of the fuel element model may include the pellet hourglassing phenomenon to model pellet dishes and chamfers, as well as friction between pellets and sheath to investigate larger initial radial gaps. 


\section{REFERENCES}

[1] Xu, S. Z., 2000. Three Dimensional Thermal Stresses and Contact Problems in a CANDU Nuclear Fuel Element, M. E. Sc. Thesis, The University of Western Ontario, Canada.

[2] Zhong, Z. H., 1993. Finite Element Procedures for Contact-Impact Problems, Oxford University Press Inc., New York.

[3] Tayal, M., 1989. "Modeling the Bending/Bowing of Composite Beams Such As Nuclear Fuel: the Bow Code," Nuclear Engineering and Design 116, 149-159.

[4] Suk, H. C., Sim, K. S., Park, J. H., Park, G. S., 1995. "Thermally-Induced Bowing of CANDU Fuel Elements," Proc. of the $4^{\text {th }}$ International Conference on CANDU Fuel, 4B: 52-69, Pembroke, Canada.

[5] ANSYS Inc., ANSYS Theory Reference 6.1, Canonsburg, PA, 2002 April.

[6] Johnson, D. H., Principles of Simulating Contact between Parts Using ANSYS, Penn State-Erie Erie, Pennsylvania, USA.

[7] Walters, L. C., Williams, A. F., 2003. Fuel Bundle Deformation Model, Atomic Energy of Canada Limited (AECL).

[8] Timoshenko, S., Goodier, J. N., 1951. Theory of Elasticity, New York: McGraw-Hill.

[9] Ugural, A. C., Fenster, S. K., 1995. Advanced Strength and Applied Elasticity, Englewood Cliffs, N.J.: Prentice Hall. 
[10] Solecki, R., Conant, R. J., 2003. Advanced Mechanics of Materials, New York: Oxford University Press.

[11] Yu, S. D., Xu, S., 2002. "Modeling of Three-dimensional Steady State Non-linear Heat Transfer in CANDU Nuclear Fuel," Nuclear Engineering and Design 216, 165-181.

[12] Yu, S. D., Xu, S., 1999. "Analysis of Thermomechanical Behaviors of a Fuel Element Using Three Dimensional Isoparametric Finite Elements," Proc. of the $6^{\text {th }}$ International Conference on CANDU Fuel, Niagara Falls, Ont., Canada, 492-503.

[13] Tayal, M., Wong, B. J., Lau, J. H. K., Nicholson, A. M., 1992. Assessing the Mechanical Performance of a Fuel Bundle: BEAM Code Description, Atomic Energy of Canada Limited.

[14] Boley, B. A., and Weiner, J. H., 1960. Theory of Thermal Stresses, Dover Publications, Mineola, NY.

[15] Rao, Singiresu S., 1995. Mechanical Vibration, $3^{\text {rd }}$ edition, Addison-Wesley Publishing Company, Inc.

[16] Yu, S. D., 2000. Free Vibration Analysis of Spinning Stepped Timoshenko Beams with Various Boundary Conditions, Jilin Science and Technology Publishers, Changchun, Jilin, China, ?14-225.

17] Chessa, J., 2002. Programing the Finite Element Method with Matlab, Northwestern Jniversity.

18] Young, W. H., Bang, H., 2000. The Finite Element Method Using MATLAB, CRC Press LLC. 


\section{APPENDIX}

\section{SOLID186 Structural Finite Element}

As shown in Figure 1, SOLID186 is a high-order structural solid element, which permits displacements to vary in complete quadratic polynomials within the element. Each element node has three degrees of freedom: translations in the nodal $x, y$, and $z$ directions. The SOLID186 elements also allow for thermal stress analyses. These capabilities enhance the degree of accuracy and the rate of convergence for computed displacements, stresses and contact pressures.

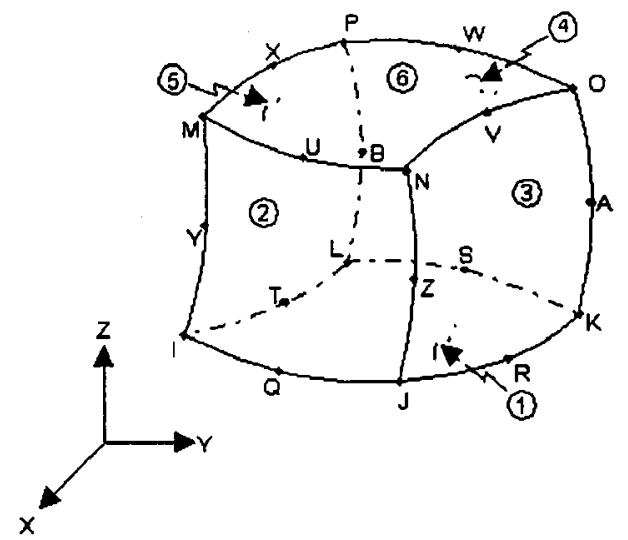

Figure 1 A SOLID186 structural finite element

\section{Surface-to-Surface Contact Pair}

The surface-to-surface contact pair consists of 3D 8-Node surface-to-surface contact element (CONTA174) and target element (TARGE170), as shown in Figure 2. For rigid-flexible contact, the target surface is always the rigid surface, and the contact surface is the deformable surface. 


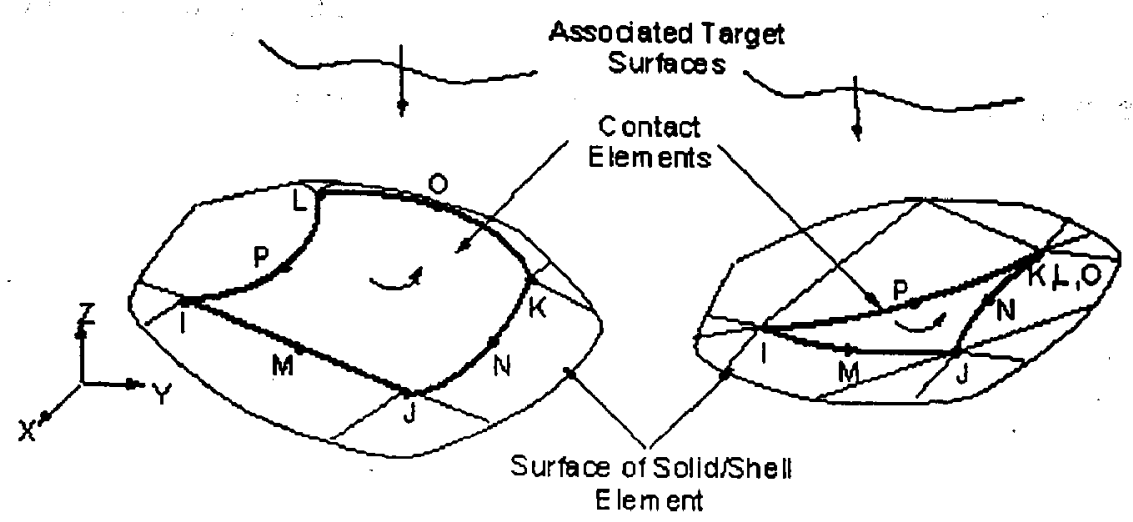

Figure 2 CONTA174 surface-to-surface contact element

CONTA174 is applicable to three-dimensional analyses of coupled thermal and structural contact, and it has the same geometric characteristics as the solid or shell element face with which it is connected. Contact occurs when the element surface penetrates one of the target segment elements TARGE170 on a specified target surface.

Two contact algorithms, the penalty method and the augmented Lagrange method, are available in the ANSYS program. The latter is an iterative method, which takes series of penalty updates to find the exact Lagrange multipliers. To avoid using additional iterations, the direct penalty method is employed in this thesis.

Normal contact stiffness factor (FKN) needs to be specified for each contact pair. The amount of penetration between the two surfaces depends on this stiffness. Higher stiffness values decrease the amount of penetration but can lead to ill-conditioning of the global stiffness matrix and convergence difficulties. Ideally, FKN should be large enough so that the contact penetration is acceptably small. The results are sensitive to the magnitude of FKN when using the direct penalty method. FTOLN is used to calculate allowable penetration, which is a 
factor based on the thickness of the element. FTOLN values can be adjusted; a too small value may cause nonconvergence of the global solution.

Contact detection points, as shown in Figure 3, are located at the Gauss integration points of the contact elements. Use of Gauss integration points provides more accurate results than the Newton-Cotes/Lobatto nodal integration scheme, which uses the nodes themselves as the integration points. The contact elements are constrained against penetrating into the target surfaces at its integration points. However, for target surfaces, they can, in principle, penetrate into the contact surfaces.

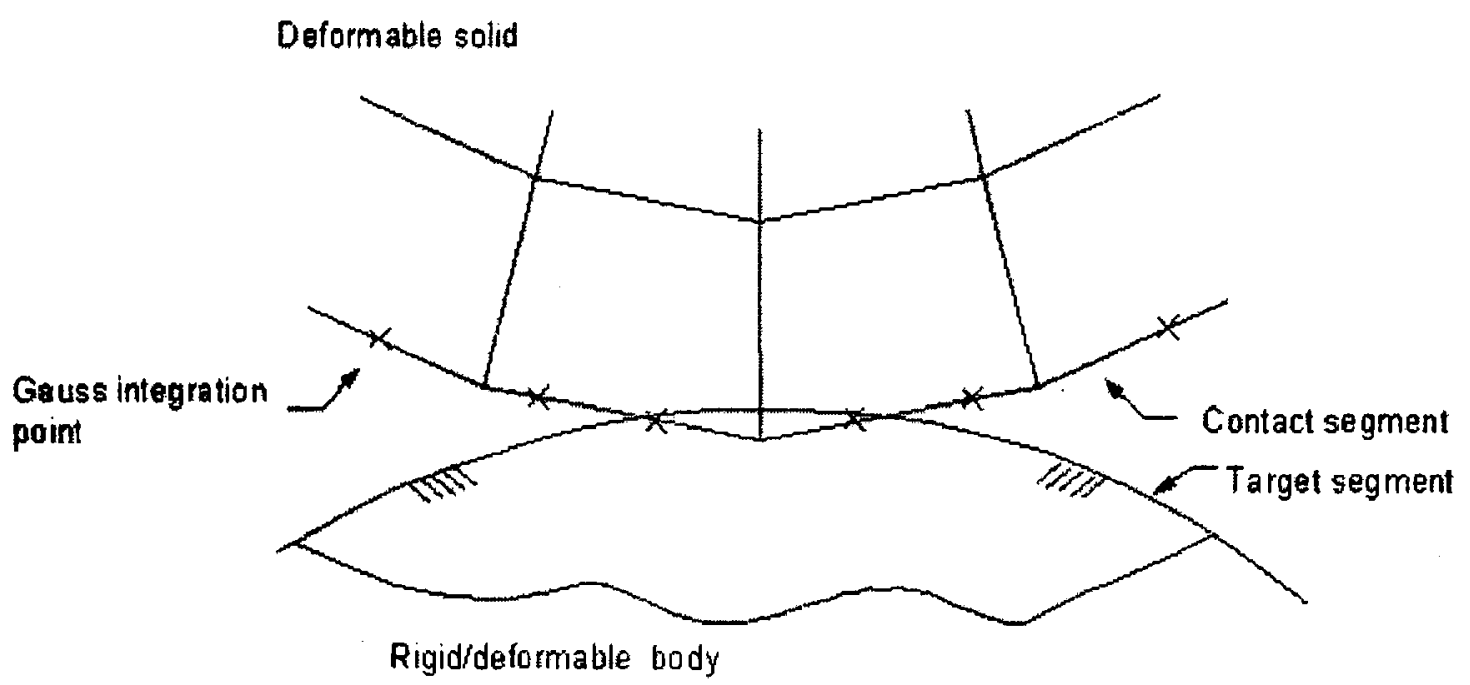

Figure 3 Contact detection points located at Gauss integration points

In static analyses, rigid body displacements often occur when a body is only restrained by contact. Initial contact conditions are adjusted at the beginning of the analyses to ensure that the contact pairs are in contact in the initial geometry. The following techniques can be performed: i) closing the gap; ii) reducing initial penetration; iii) either closing the gap or reducing initial penetration. 